\title{
A STEREO AUDITORY . IMAGE-PERCEPTION AID FOR THE BLIND
}

\author{
Patrick Tantribeau \\ Department of Electrical Engineering \\ McGill University \\ Montreal, Quebec, Canada
}

November 1992

A thesis submitted to the Faculty of Graduate Studies and Research in partial fulfillment of the requirements for the degree of Master of Engineering

(c) Patrick Tantribeau, 1992 


\begin{abstract}
This thesis presents the research to develop a technical aid for the blind to percelve images such as a face or a scenery. The image is scanned and explored interactively by touch through a probe mounted on the index finger of each hand. The pixel intensities of the image are displayed to the user as stereo auditory signals.

For the study, the aid was implemented partly by using a personal computer, a computer graphics tablet, a digital-signal-processing board, and audio equipment In addition, a Time-Multiplexer circuit was built to support inputs from two finger-probes which are made by using two styluses of the graphics tablet. The system softwares were programmed to present the images as stereo auditory display. The aid was evaluated on six blind-frombirth subjects and ten blindfolded sighted subjerts to determine how fast and accurately they could perceive different multu-gray level images, and how their performance change with increased experience. The results showed that. with mcreaser. experience, the same image presented in the second trual can be percelved in a shorter tume than in the first trial. The subjects perceived the binary and the multi-gray level shapes within 2 minutes in average.
\end{abstract}




\section{RESUME}

Cette thèse présente ia recherche qui a pour but de développer unc aide technique pour aider les aveugies à percevoir des manges telles fu'une face humane ou une scène. L'mmage est explorè merachvement en touchant avec un capteur monté sur l'undex de chaque main La luminosite du pixel de l'ımage sont présentées à l'usager sous forme de siguaux auditils en stèréo.

Dans cette étude, l'aide technique est implantèe en utllisant un ordinateur, une tablette de graphiques informatisés, une carte clu traitement de signal numérique, et un équipement de son En plus, un circuil de Muliplexeur-Temps est implanté pour permettre d'avoir les entrées de deux capteurs qui sont fauts a partir de deux stylos de la tabletle graphique Les logiciels du système sont programmes pour présenter le's images sous forme de signaux audiufs en stéréo L'alde a été évaluee sur slx aveugles et sur dix personnes voyantes aver les yeux bandes pour dèterminer la rapidité et la precision avec lessfuelles ils pouvalent percevour les images à nuveaux de gris multiples, et le changement de leur performance avec l'accrobsement de leur expériences Les résullats ont montré que, aver l'accroissement d'expérience, la même image présentere pour la seconde foic. peut être perçue dans un temps inférıeur à celui nécessiatre pour la première: fois. Les sujets percevaient les figures en buane ou a nveanx de gris multiples en un temps inférneur a 2 minutes en moyenne. 


\section{ACKNOWLEDGEMENTS}

I would like to thank my supervisor Dr. H. C. Lee for his patient guidance and advice throughout my Master's degree research and studies. Dr. Lee was also extremely helpful in the preparation of this thesis.

I sincerely thank my fellow graduate students Guo Yan, Wang Xiao for their frutful techmoal advice.

I am grateful to my fellow graduate students Sharock Valaee, Xiao Wang and Micheal Mastme, for proofreading the entire thesis.

I would like to ackowledge my friends who have participated as blindfolded subjects for the evaluation of the and They are Real Choquette, Daniel Genest, Mylene Bernard, Myyoko Tan, Imad Ansari, Anoush Gundjian, Nora Marachelian. Therry Sallon. Nicole Tremblay and Pat Andersen Many thanks are to the senior technicians of the Dept. of Electrical Engneering. in partucular. Mr. John Walkes who kept the computer graphics tablet functioning in this research.

I also would like to thank blind volunteers and to acknowledge the help of Canadian National Institute for the Blind and Montreal Association for the Blind to get the volunteers' participation.

Fmally, I would like to thank and acknowledge the constant love and support I receive from my parents, my sisters, and my fiancee. Without them, neither this thesis nor my education would have been achieved. 


\section{TABLE OF CUNTENTS}

\begin{tabular}{|c|c|c|c|}
\hline Chapter & 1 & Introduction & \\
\hline & 1.1 & Background & 1 \\
\hline & 1.1 .1 & Readıng Aids & 2 \\
\hline & 1.1 .2 & Image Perception Devices & 6 \\
\hline & 1.1 .3 & Cortical Stımulation & 10 \\
\hline & 1.2 & The Motivations of The Research & 10 \\
\hline & 1.3 & The Objectuves & 11 \\
\hline & 1.4 & Thesis Overview & 12 \\
\hline
\end{tabular}

Chapter 2 System Overview

2.1 Conceptual Design 16

2.1.1 Image Acquisition 16

2.1.2 Image Mapping and Scanning 17

2.1.3 Auditory Presentation 18

2.2 System Implementation 19

2.21 Computer Graphucs Tablet 19

2.2.2 Time-Muluplexer Circuit Board 23

2.2.3 Personal Computer PC-AT (80286) 2.3

2.2.4 TMS320C25 DSP Chimera Board 24

Chapter 3 Data Acquisition

3.1 Design Consideratıons 25

3.1.1 Data Transmission 25 
3.2 The Time-Multiplexer Circult Design 28

33 The Circult Implementation 30

3.3.1 Time-Multuplexer Process Implementation 30

3.32 The Flag Implementation 34

$\begin{array}{lll}3.4 & \text { Results } & 39\end{array}$

3.5 Technical Remarks 42

\section{Chapter 4 Design and Implementation of System Software}

4.1 The Software Design 45

4.1.1 System Software Overview 47

$\begin{array}{lll}\text { 4.1.2 Software Descriptions } & 47\end{array}$

4.2 The Software Implementations 49

4.2.1 Main Operation Control Program 50

4.2.1.1 Intialization of The Chimera Board Environment 50

4.2.1.2 Executing The Program in Chımera Board 52

4.2.1.3 Intialization of The Serial Communication Port 53

4.2.14 Loading The Digitized Image 53

4.2.2 Main Tasks 55

4.2.2.1 Reading The Coordinates From The Serial Port 56

4.2.2.2 Mapping The Coordinates Into Image Cells 60

4.2.2.3 Assembling The Data Word 61

4.2.2.4 Sending. Data To TMS320C25 DSP Chımera Board 61

4.23 End of Operation 62

\section{Chapter 5 Generation of Audio Stimuli}

5.1 Essentual Features of The Chmera and AD16 Boards 67

5.1.1 The TMS320C25 Processor 68

$\begin{array}{lll}5.1 .2 & \text { The Memory (RAM) } & 69\end{array}$

5.13 The AD16 Analog Daughter Board 69

$\begin{array}{lll}5.1 .4 & \text { Data Interchange Register } & 70\end{array}$

$\begin{array}{lll}5.2 & \text { Host-Chımera Board Communication } & 71\end{array}$

5.3 Programming The Daughter Board 71 
5.4 The Software Design and Organization 73

5.4.1 Audio Stimuli Outputting Method 73

$\begin{array}{lll}5.4 .2 & \text { Stereo Output } & 74\end{array}$

$\begin{array}{lll}\text { 5.4.3 The Program Structure } & 75\end{array}$

5.4.3.1 The Sound Operation Control 76

5.4.3.2 Initialization of The Mother and Daughter Boards 78

$\begin{array}{lll}\text { 5.4.3.3 Outputting Sounds } & 79\end{array}$

\section{Chapter 6 Evaluation and Discussion}

$\begin{array}{lll}6.1 & \text { Methods } & 84\end{array}$

6.2 Computer Generation of Test Images $\quad 88$

$\begin{array}{lll}6.3 & \text { Initial Training } & 89\end{array}$

6.3.1 Images Used 89

$\begin{array}{lll}\text { 6.3.2 Results } & 90\end{array}$

6.4 Testing of Subjects 95

6.4.1 Test Images $\quad 95$

6.4.2 Test Results 96

$\begin{array}{lll}6.5 & \text { Discussion } & 107\end{array}$

Chapter 7 Conclusion

$\begin{array}{lll}7.1 & \text { Summary } & 110\end{array}$

$\begin{array}{lll}7.2 & \text { Directions for Future Research } & 112\end{array}$

References

Appendix A The Bınary Data Format 118

$\begin{array}{llll}\text { Appendix } & \text { B The Time-Multiplexer Circuit Schematic } & 120\end{array}$

$\begin{array}{llll}\text { Appendix } & \text { C } & \text { The Programming of the PAL16RP6 } & 124\end{array}$ 
$\begin{array}{llll}\text { Appendix } & \text { D } & \text { The Evaluation Data of Binary Images } & 127\end{array}$

Appendix E The Evaluation Data of 3- and 4-Gray-Level Images 131 


\section{LIST OF FIGURES}

2-1 The three main operations of the image-parception atd 16

2-2 The system implementation of the mage-perception aci for our studies

2-3 The equipment used in the expermental study 21

2-4 The speciaily designed finger probes used in the experumental study 21

2-5 The Bit Pad One with square grids for spatial orientation 22

3-1 The sampling time of the left and the right probes 26

3-2 The timung diagram of the control signal of the Bit Pad One 27

3-3 The systum implementation oi the magse-perception and for our studies

3-4 The waveforms of RPO signal (a) RPO when 2 probes are on the lablet (b) RPO when only one probe is on the tablet

3-5 The Time-Multuplexer circuit for two finger-probes

3-6 The block diagram of circuit that mplements flagl and nag2

3-7 The waveforms of signal dff in three cases

(1) When 2 probes are on the BPO. (2) when only the RIGHT probe is on. (3) when only the LEFT probe is on

3-8 The timing diagram of the signals generated by the PAL for Caise $1 \quad 37$

3-9 The tuming diagram when (wo probes are on the BPO surface

3-10 The timng diagram when only the RIGH'T probe is on the BPO 40

3-11 The tmmng diagram when only the LEFT probe is on the BPO 41

4-1 The system implementation of the image-perception aid for our studies 
4-2 Structure of the Main function in VAS.C

4-3 The hierarchy of the subroutines

4-4 The flowchart of the function Main in VAS.C

4-5 The flowchart of subroutine INITC25() 52

4-6 The flowchart of subroutine ASYINITY ) 54

4-7 The flowchart of subroutine Load_Image() 55

4-8 The flowchart of subroutine LireCoordBPO() 57

4-9 The flowchart of subroutine ASYINCH() 59

5-1 The system implementation of the image-perception aid for our studies

5-2 The communication of the Chimera Motherboard with the host computer and the external devices

5-3 The communication of AD 16 Daughterboard with the host and TMS320C25 Processor

5-4 Audio stımuli data transfer

5-5 The two output signals with 40 points of data. (a) Smaller $\Delta T$ gives. for instance, tone frequency $=500 \mathrm{~Hz}$. (b) $2 \times \Delta \mathrm{T}$ gives tone frequency $=250 \mathrm{~Hz}$

5-6 The flowchart of the main program in tspl.asm $\quad 77$

5-7 The flowchart of the initialzation subroutine Inut $\quad 79$

5-8 The flowchart of the outputting subroutine Output 81

6-1 The binary images used for the training perıod 91

6-2 The tume required by the blindfolded sighted subjects to perceive a particular binary image in the first trial (thick bar) and the second tnal (thin bar). (-) shows the average time

6-3 The time required by the blind-from-birth subjects to perceive a particular binary image in the first trial (thick bar) and the second trial (thin bar). (-) shows the average time 
6-4 The average time required by the group of blindfolded sighted subjects compared with the average time required by the group of blind-from-birth subjects to perceive the binary images at the second presentation

6-5 The 3-gray-level images used for the testing 97

6-6 The 4-gray-level Images used for the testing 98

6-7 The time required by the blindfolded sighted subjects to perceive a particular 3-gray-level image in the first trial (thick bar) and the second trial (thin bar). (-) shows the average time

6-8 The time required by the blind-from-birth subjects to perceive a particular 3-gray-level image in the first trial (thick bar) and the second trial (thin bar). (-) shows the average time

6-9 The time required by the blindfolded sighted subjects to perceive a particular 4-gray-level image in the first trial (thlck bar) and the second trial (thin bar). (-) shows the average time

6-10 The time required by the blind-from-birth subjects to perceive a particular 4-gray-level image in the first tnal (thick bar) and the second trial (thin bar). (-) shows the average time

6-11 The average time required for the blind-from-birth and the blindfolded sighted subjects to perceive the 3-gray-level images presented in the second trial

6-12 The average time required for the blind-from-birth and the blindfolded sighted subjects to perceive the 4-gray-level images presented in the second tral

6-13 The time required by the blind-from-birth (thin bar) and the blindfolded (thick bar) sighted subjects to percelve a particular complex 4-gray-level image presented only once. (-) shows the average time 


\section{LIST OF TABLES}

3-1 Summary of the three distinct conditions

6-1 Time (in seconds) required for the ten blindfolded sighted subjects to perceive seven different images during training

6-2 Time (in seconds) required for the six blind-from-birth subjects to perceive seven different images during training

6-3 Time (in seconds) required for the ten blindfolded sighted subjects to perceive the 3- and 4-gray-level images

6-4 Time (in seconds) required for the six blind-from-birth subjects to perceive the 3-and 4-gray-level images

6-5 Time (in seconds) required for the blind-from-birth and blindfolded sighted subjects to perceive the 4-gray-level images presented only once 


\section{Chapter 1}

\section{INTRODUCTION}

\subsection{Background}

Many technical aids have been developed to help the blind pers ins to perceive the surrounding environment. These devices and systems have been designed to provide visual information to the blind by using an alternative sensory modality. Most of them use the senve of touch and/or hearing but recently, there are experimental studies which stimulate directly the visual cortex with electrodes. Most of the technical aids for the blind focus on some small aspect of the visual world. There are aids for reading printed materials, for mobility, for vocational use, and others. 
This thesis is concerned with the development and evaluation of a technical atd for the blind people to perceive images such as a human face or a scene. Aids for the blind can be classified into categories according to their purposes and sensory presentation. Amorig the tactile and auditory types, reading aids and image perception systems are the most relevant to this research.

\subsubsection{Reading Aids}

The oldest and most popular tactile reading aid for the blind is Braille [1]. This aid is used by the visually impaired to read written text. It consists of symbols that are embossed on paper. Each symbol is formed into a braille cell. which is a 6 -dot matrix. Thus, it is possible to present 63 symbols plus one blank space in each cell by selecting which dots of the matrix to be embossed.

Before printed materials can be read by the blind, they must be converted to branlle. Some computer-based systems have been developed to translate text in standard ASCII code to contracted braille [2]. One of these systems, called Duxbury, is a software system that can be run on a number of different computer platforms. The computer output is sent to a braille embosser that forms the raised dot code on single sheets or fanfold braille paper. Thus, any typist can transcribe printed materials to bralle. 
Another recent developinent is reverse translation of braille. The Australian Braille'n'Prnt [3] attaches to a standard embosser called Perkins Brailler, and produces parallel-output ASCII text suitable for printing on an Inexpensive computer printer. This allows the Perkins Brailler to print and produce braille simultaneously. Consequently, the blind and the sighted persons can communicate with each other through writing

Swedish and Japanese manufacturers have introduced an innovative paper, which is impregnated with heat-sensitive plastic bubbles that expand upon heating to raise the page surface enough to detect through touth $|3|$. The black printed dots absorb more heat than the surrounding white paper. accordingly they are raised above the surface, and form a readable bralle As a result, this technique can also be applied to produce tactle graphics as well.

To avoid the need to use paper, a system, called portable bralle reader (PBR), that uses refreshable braille cells [1], was recently developed. The refreshable braille cell is a matrix of holes in the form of standard bralle cell through which small pins protrude to form a braille character. This character can then be read by the blind in the same way as a paper braille One example of PBR is the Versabraille 11$]$ It consists of a 20-cell refreshable braille cell array controlled by a computer. The output information is in blocks of completed words that fit within the 20-rell display. 
Other tactile reading aids, known as the Optacon and the IBM Braille Mouse, have been developed for the blind person to scan written material and to read from a computer screen. The Optacon (OPtical to TActile CONversion) is a direct-translation reading instrument widely used by the blind to convert standard print into a vibrating tactile form. The Optacon consists of a small solid-state portable camera and a $6 \times 24$ tactile array stimulator $[4,5]$ One hand moves the camera across a line of print to optically detect the printed characters. The index finger on the other hand detects the processed optical signal from the tactile array. Camera scanning of an alphabet simultaneously reproduces the same alphabet on the tactile array. Images on the tactle array are produced by miniature vibrating rods. In this manner, the user feels through his finger a moving image of whatever the camera senses. Thus, alphabets or other symbols of printed material can be percelved using these moving tactile images. However, the low reading rates and the difficulty in learning to use the device are generally the limitations of Optacon 16] Initial reading rates with 10 to 60 hours of trainng are about 6 words per minute. Furthermore, great motivation and practice are required to obtain good reading speed and comprehension.

A braille mouse was developed by IBM Laboratories. A refreshable braille cell was bult as part of the mouse [7]. Thus, by moving the mouse, a blind person can scan different characters displayed on the computer screen. While a character is scanned, its braille representation becomes available on the refreshable braille display. 
Besides the tactile reading alds, there are auditory reading aids. The most common aids use either recorded natural speech or synthesized speech. The simplest way is to record books and documents onto audio cassettes for listening by the blind person. A more automated way is to utilize a Character Recognution device [8], which outputs spoken characters while a nage of printed text is scanned More recently. the Kurrwedll Readung Machine was developed [9], to output whole words instead of characters Irom the scanned text. The users can adjust both the speed and the tone of the speech from the machine.

Recently, the SKERF-Pad was developed to enable the blind user to read the contents of a computer screen $[10,11,12]$. The screen is represented by a low-cost touch-pad. As the user presses on the touch-pad, a speech synthesizer enunciates the contents of the screen. There are three additional modes: letters/words, tones and coordinates. In the letters/words mode, letters or whole words can be output by the speech synthesizer In the tone mode, a different tone is designed to each character type, such as upper and lower cases, punctuations, numbers, or spaces Instead of reading a character, the user can read the locations of colununs and rows in coordinate mode. For this design, an overlay is used on the touch-pad in order lo gunde the user's fingers along a aised horizontal lines correspondung to lunes of the text on the screen. More attributes have been added to thr pad such as the voice quality (pitch, loudness, etc.) to indicate underlined or blinking screen characters [13]. 
Another screen reader, called the Screen Reader/PM, was developed and commercialized by IBM [14]. With it, blind persons can get access to the PS/2 and a Graphical User Interface (GUI), as well as to a host of programs running under $\mathrm{OS} / 2$. The Screen Reader/PM works with other voice synthesizers connected through a serial communication port. A small keyboard about the size of a numeric keypad plugs into the mouse port on any PS/2 computer and lets the user control all aspects of the Screen Reader (SRD) such as reading lines, characters, and words, as well as comraands for reading entire windows. As the arrow keys are moved, the synthesizer verbalizes each highlighted menu selection.

\subsubsection{Image Perception Devices}

Early research using tactile stimulation to allow a blind person to percelve an image was performed at the Smith Kettlewell Institute of Visual Sciences $[15,16,17]$. A prototype aid, called Tactile Vision Substitution System (TVSS), consists of an image sensor, a digital scanning circuit, and a matrix of four hundred mechanical stimulators. The image sensor was a camera tube. The stmulators were placed in the backrest of a dental chair. When the camera was focussed on an object, the camera would press a silhouette of the object into the back of the subject.

By combining the results of various perceptual experiments with tactile stimulation $[18,5]$ and the TVSS, Bach-y-Rita proposed an improved TVSS, which breaks an image into smaller sections [19]. Each section is 
presented to the user through a tactile array. The information is gathered by scanning the object, and receiving a relatively small portion of the image at any moment through a low resolution tactile stimulator matrix Such an aid was later designed and tested [20] A 126x64 image from a digital camera is divided into $6 \times 24$ blocks using an IBM personal computer. The computer then sequentially sends these blocks to a vibrotactile device which, in this case, is a $6 \times 24$ vibratory fingertip stimulation matrix on an Optacon reading device. A new block can be presented every 4.35 ms. The user can control certain factors such as horizontal and vertical block overlap, or delay constants between blocks.

Friken-Gibson et al [21] have developed a similar system, which allows the user to control the part of the image to be presented through the tactile array. When the computer mouse is moved on an image, the $8 \times 8$ portion of the image centered at the mouse stimulates the subject The stimulation matrux consists of 64 solenoid stmmulators. They are mounted on $5 \mathrm{~mm}$ centers and form a raised two-dimensional display With the aid of an IBM PC, a visual image can be translated into a contour map of raised pins similar to refreshable braille described earlier. There are four possible heights of the pins representing the discrete levels of image intensity.

The American Foundation for the Blind has reported an electromechanical device that allows the blind user to perceive a graphlc display [22]. It was built with a tactile array of 16000 tactile pins By raising or lowering pins, a 2 dimensional display such as graphs or figures can be formed. The researchers of The Amencan Veterans Administration have 
developed a similar system, which allows the blind user access to a computer screen [23]. This latter system provides both written and graphic information. In the system, the tactile display is presented by an array of plastic pins. In addition, it provides the incorporation of speech output, magnifications of a particular region of interest, and a refreshing mechanism to quickly update the tactile page.

N. Ohnishi et al. 124 l have designed a device that allows the blind to have access to images using both tactile and auditory displays. This device has been tested with electronic circuit diagrams. It provides coarse information about the circuit layout through a tactile array and names the circuit components such as a resistor by using a speech synthesizer. Preliminary testing with nine subjects and an $8 \times 8$ tactile array was carried out and deemed successful. Recently, Ohnishi et al [25] have designed a map database system that allows the blind to perceive their environment in order to move independently using tactile and verbal information. As the user scans the tactule display (matrix $8 \times 8$ pins), he or she will conceptually obtain global information such as road connections.

Recently. S.K. Guha and S. Anand [26] have worked on an inexpensive system to allow a teacher to communicate line diagrams and text directly to the blind students in a classroom through a computer display. A single computer placed on the teacher's desk is connected to the monitors on the students' desks. The information sent by the teacher is displayed or tive students' monitors, and it can be obtained by using an optical sensor controlled by an electronic circuit, and vibrotactile output. 
There are two versions of the sensor. One type of sensor allows the blind student to trace a line diagram on the monitor and obtain a hard copy output on a plastic sheet. If the student only traces the diagram without hard copying, the overall diagram can be enhanced and perceived by sticking small pieces of modeling clay on the monitor where the illuminated points are sensed. The second type of sensor allows the blind student to read, from the monitor, the braille code which is converted from text entered on a computer keyboard.

Lately, H.C. Lee and S. Goodfellow [27] have proposed an interactive and economical system based on auditory display of the images This technical aid is intended to help blind persons perceive images such as a scene, a human face, or any other 2-dimensional information The image of an object to be perceived is digitized and stored in computer memory, and then the pixels of the processed image are mapped one-to-one onto the "cells" of a computer graphics tablet. When the hlind user scans a "cell" on the tablet by touching it, the intensity of the correspondming pixel is displayed as auditory signals. By interactively exploring the pixels through touch on the computer graphics tablet, the blind user can visualize the image by associating the sound heard with the pixel intensities for the area explored The aid was tested on two blindfolded sighted subjects using simple geometrical binary (i.e., 2 gray levels) images. The evaluation results have indicated that the subjects correctly perceived the images in less than 2 minutes. 


\subsubsection{Cortical Stimulation}

Researchers in the field of neurophyslology, such as Brindley $[28,29]$, have shown that when parts of the visual cortex are electrically stimulated, subjects perceive spots of light called phosphenes. By simultaneously stimulating different points on the cortex, subjects are able to perceive simple shapes.

The design of cortical stimulation devices is reviewed by P.E.K Donaldson [30]. A typical device consists of two parts: extracranial and intracranial. The extracranial part is expanded between the scalp and the skull. It contains the radio receivers that receive signals from outside the body. The intracranial part is expanded over the brain surface. It contains the stimulating electrodes in a molded silicone cap. These two parts are connected by a cable through the skull. Thus, when a receiver detects a transmitter's signal, the corresponding stimulator electrically stimulates a point on the brain, and elicits a phosphene in the visual field. The implantation of such a device with a resolution of $10 \times 18$ is reported in [31].

\subsection{The Motivations of The Research}

Most of the technical aids for the blind to perceive images, as discussed previously, are still too expensive or bulky to be provided for each blind individual. Some aids do not provide interaction and flexibility to the user. Therefore, an alternative aid is necessary. Such an aid must be 
economical, portable, interactive and flexible. It would allow the blind to perceive diagrams in printed materials, photographs, or Images.

As described earlier, H.C. Lee et al. [27] proposed an interactive. economical system based on auditory display of the Images The technical aid was designed to help blind persons perceive images such as a scene, a human face, or any other 2-dimensional information. This aid was tested on two blindfolded subjects with binary images. The results seem encouraging and promising because the blindfolded subjects can perceive the binary images in less than 2 minutes on an average. The limiting factors in this ald are the constraint of using a single finger probe which slowed down significantly the perception speed, and binary inages which lumt the representation of the contents within an image. In addition, testung on only two blindfolded sighted subjects limits the accuracy of the results. Thus, improvements are necessary for this aid and its evaluation methods

\subsection{The Objectives}

The objectives of this research are to improve the image perception aid described above and to perform a thorough study of the effectivene'ss of this improved aid. The Image Perception aid can be improveci in two areas First, two finger probes are to be implemented in order to speeri up the image perception rate. Second, multi-gray level images are to be used to determine the effectiveness of this aid. Additionally, more subjerts (torth sighted and the blind-from-burth subjects) are to be used to evaluate the 
effectiveness of this improved technical aid. The evaluation will focus on the speed and the accuracy of a subject to perceive different images and the change in the time required for perception due to increased experience.

\subsection{Thesis Overview}

In this thesis, a stereo auditory image-perception aid for the blind that provides an auditory display is described. When the blind user scans an inıage with finger probes on both left and right hand, the tones representing the gray levels of the points in the image (where the probes are located) can be heard. By carefully scanning the image and listening for four different corresponding tones in stereo, subjects can identify the multi-gray level image contents.

In Chapter 2, an overview of the conceptual design of the imageperception aid is presented. A brief description of how an image can be perceived through touch and auditory display is provided. Then, the proposed design of the stereo auditory image-perception aid is described.

In Chapter 3, the data acquisition process, and the design and Implementation of a Time-Multiplexer circuit board are presented. Some technical and design considerations such as choice of components and data transmission rate are described. 
Chapters 4 and 5 describe essentially the design and implementation of system softwares to present the images as stereo auditory display. In Chapter 4. we propose an algorithm to read the data from the computer graphics tablet, map them onto an image cell, and send a data word to digital-signal-processor (DSP) board for outputting sound. In Chapter 5, we propose another algorithm for the DSP board to generate and output tones simultaneously to two digital-to-analog converters.

In Chapters 6, our proposed image-perception aid is evaluated and discussed. For testing the system, a computer program was written in order to create and store multi-gray level images composed of simple geometric shapes such as triangles, squares, and circles. The aid was tested on six volunteer blind-from-birth subjects and ten volunteer blindfolded sighted subjects. The blindfolded sighted volunteers were needed to evaluate the aid, since the blind volunteers were not always available. The tests were carried out for a period of approximately 5 to 6 hours per blind-from-birth subject. and approximately 7 to 8 hours per blindfolded sighted subject The results were uthlized to address the following questions:

- How fast and accurately could the subjects perceive different images, and how does their performance change with increased experience?

Finally, Chapter 7 reviews the main results of the thesis and considers possible future orientations of the project. This chapter is followed by a set of five appendices, where detalled information of this research is gathered for convenient reference. The appendices are mainly concerned with the designed circuit schematics, and the evaluation data of each 
subject. To avoid inrluding too much detailed information in this thesis, items such as program listings are given in the User's Manual (t.e., Imageperception Aid User's Manual [36]) of the stereo auditory image-perception aid. 
Chapter 2

\section{SYSTEM OVERVIEW}

This chapter presents an overview of the image-perception aid. It gives the reader a notion of how the aid works. In the proposed design, essential aspects about the aid are provided in order to give an overview of the system implementation in our studies. 


\section{1 Conceptual Design}

Fig. 2-1 shows the three main operations in the image-perception aid: Image acquisition, image mapping and scanning, and auditory presentation.

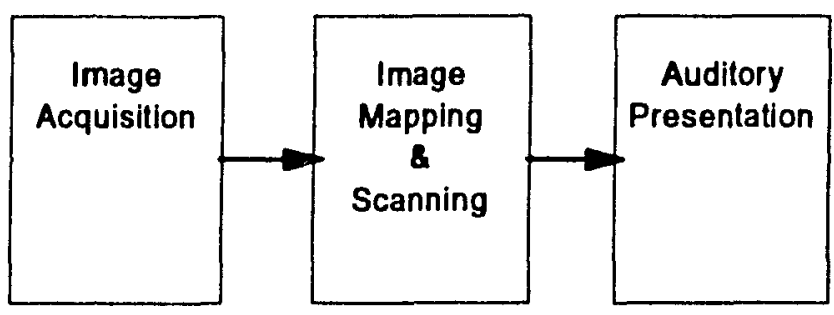

Fig. 2-1 The three main operations of the image-perception aid.

\subsubsection{Image Acquisition}

The main goal of the aid is to allow the blind person to perceive pictorial information such as a human face or scenery. The face or the scenery can be acquired through a video camera as an image. This image is digitized and then stored in the computer memory. In our studies, the proposed aid is not running in real-time. Thus, the image is stored in the computer memory for the convenience of later use.

After digitizing, the acquired image is converted into a gray-level image. Four gray levels are used in our studies in order to make the identification of the gray levels easier during the image perception, so that the evaluation of the aid can be focused mainly on the shape recognition. 


\subsubsection{Image Mapping and Scanning}

The X-Y coordinates of the image in computer memory are mapped to the coordinates of a computer graphics tablet. The tablet required for this study needs lower resolution than most of the avallable tablets. Thus, the coordinate pair output by the tablet has to be divided by a scale factor, which lowers the original resolution. In this manner, the pixels of the processed image can be mapped one-to-one onto the cells of the computer graphics tablet. When a cell on the tablet is activated by a touch of the user with a probe, the gray level of the corresponding pixel will be presented as auditory output signal.

The stored image can be scanned by using two finger probes on the computer graphics tablet. The two finger probes are mounted under the index finger of each hand. The tablet senses the location of the two probes as they pass over the tablet surface, and it outputs the $X-Y$ coordinate pair and the flag signals (identifyng the probes) to the computer. These coordinates indicate the area of the image scanned by the user.

The use of scanning has been reported to be beneficial in other aids. Moricca and Slocum [32] have shown that reading rates with the Optacon increase when the data is scanned from top to bottom, and left to right. White [33] has reported more accurate results when subjects were able to scan a scene with a camera during the experiments with the Tactile Vusion 
Substitution System (TVSS). These results have led to the design of a tactile system with sequential scanning [20]. Frisken-Gibson et al. [21] have implemented a system similar in sume respects to the cne proposed in this thesis In their system, when a subject scans an image with a computer mouse, tactile stimulation was felt on the hand. One improved feature of our system proposed in this research is the use of two finger probes that allow more precise movement than a computer mouse.

The use of scanning also has a perceptual basis. Blind subjects are generally well trained in exploring objects and determining shapes or other features with their hands. Hence, allowing blind subjects to scan an image with finger probes can take advantage of this ability.

\subsubsection{Auditory Presentation}

The gray levels of the image can be represented by characteristic sounds. For our study tones are generated using different frequencies according to the gray levels. The different frequencies have been selected to represent the different gray levels instead of different loudness of a particular frequency This is due to the fact that loudness can not differentiate the signals from the two channels. When the probes simultaneously touch 2 cells. the gray levels of these cells are represented as one loudness which is the sum of the two gray levels. In this case, the subject could not distngunsh the audio stimuli from either channel. On the other hand, with different frequencies representung different gray levels, the 
two auditory signals are distinguishable. If the gray levels of the 2 cells are the same, the signals will have the same frequency, but the combined loudness will be greater.

The left speaker outputs the tones representing the pixels scanned by the left probe while the right speaker outputs the ones representing the pixels scanned by the right probe.

\subsection{System Implementation}

The image-perception aid was implemented as shown in Fig. 2-2. It consists of a computer graphics tablet with two specially designed probes, a control circuit for simultaneously acquiring signals from the probes, a personal computer, and an auditory signal generator board incorporating two Digital-to-Analog (D/A) interfaces, stereo audio amplifier and loud speakers. Fig. 2-3 shows a photograph of the system.

\subsubsection{Computer Graphics Tablet}

The computer graphics tablet available in our laboratory is called the Bit Pad One (BPO) manufactured by Summagraphics Inc It was used in the work of H.C. Lee and S. Goodfellow [27]. This tablet can be connected to a control circuit (described later), which allows the user to scan with two specially designed finger probes in order to speed up image scanning and 
perception. The probe was built by using the magnetic coll from a Bit Pad One stylus. It was cemented with epoxy to a curved piece of metal that fits comfortably under a subject's index finger as shown in Fig. 2-4.



Fig. 2-2 The system implementation of the image-perception and for our studies. 


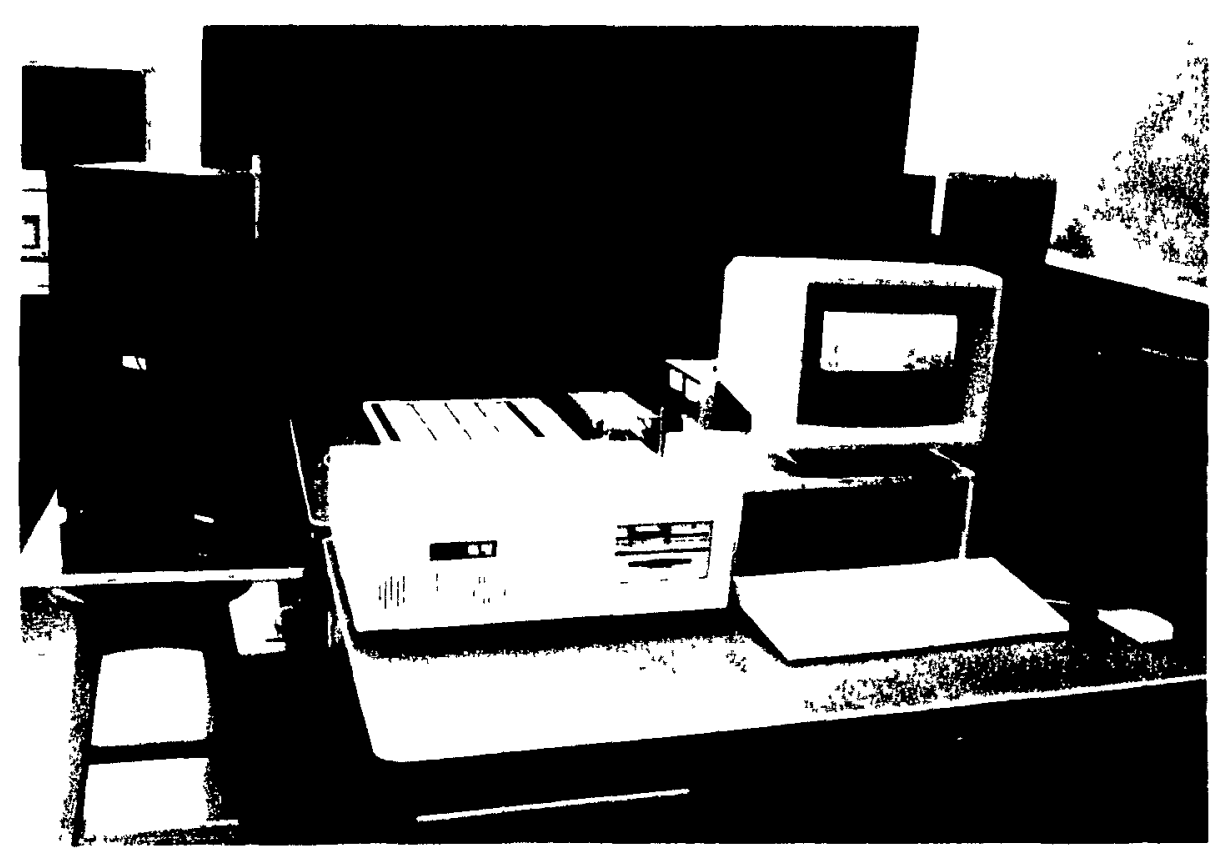

Fig. 2-3 The equipment used in the experimental study

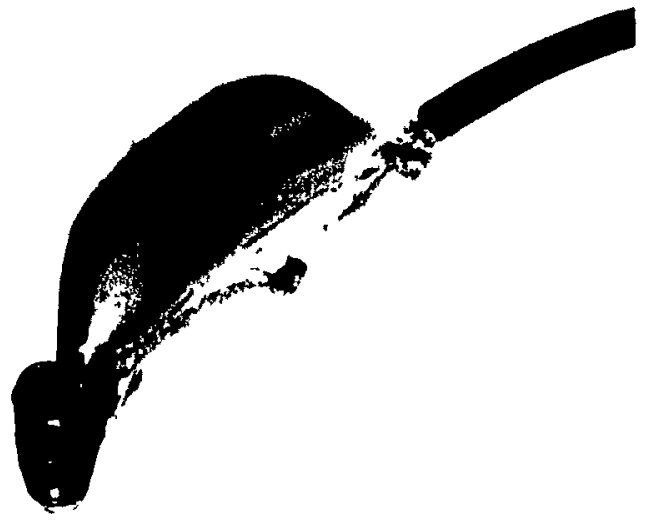

Fig. 2-4 The specially designed finger probes used in the experimental study 


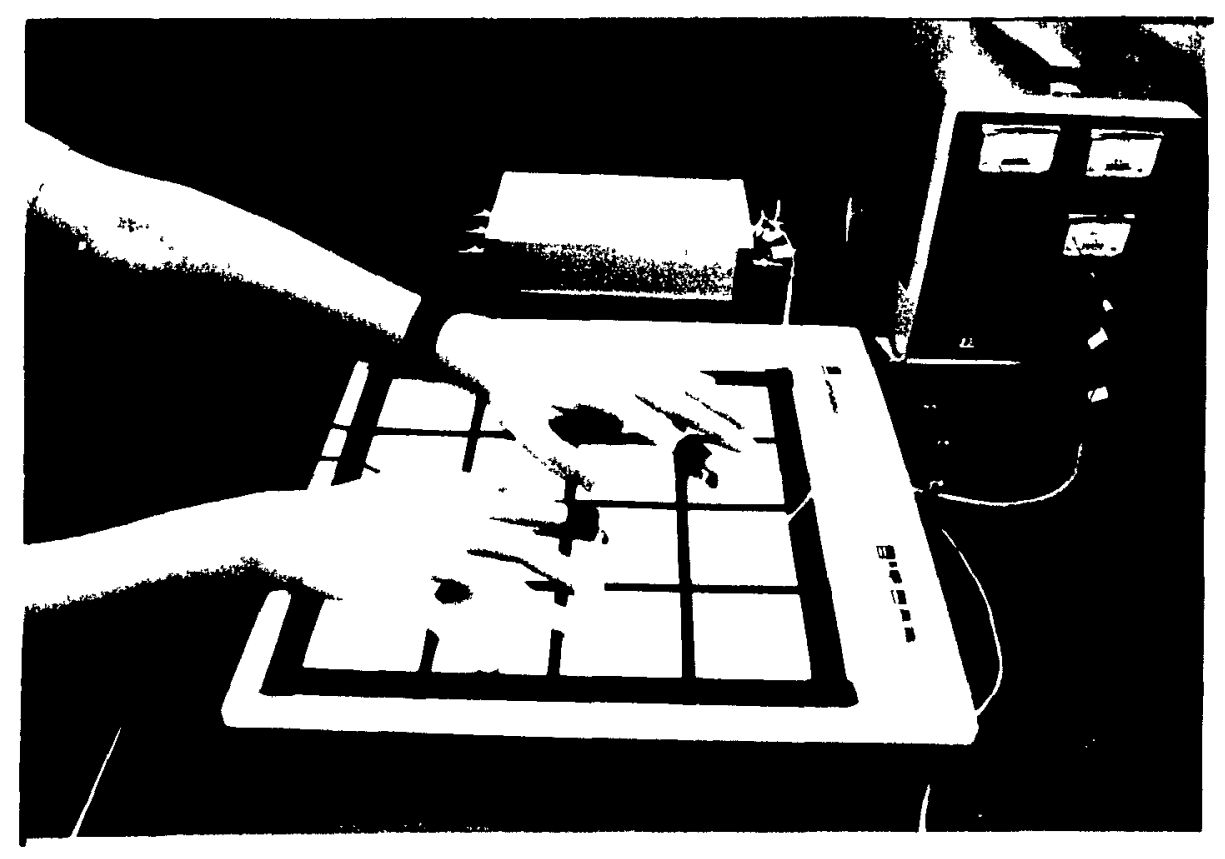

Fig. 2-5 The Bit Pad One with square grids for spatial orientation

Electric tape $(0.5 \mathrm{~cm}$ wide) was put on top of the tablet surface to create a square grid as shown in Fig. 2-5. The parallel lines were $7 \mathrm{~cm}$ apart. The tablet surface measured $28 \mathrm{~cm}$ square, so there were $4 \times 4$ square lines. The grid was used to help subjects navigate with the probes along the horizontal and the vertical directions, measure the length of edges being followed, and get the spatial orientation of the image.

The BPO senses simultaneously the location of two fingers probes as they pass over the tablet, and outputs X-Y coordinates and the nag signals (identifying the two probes). The BPO transmits the coordinates in the range 0-2200 with the origin located at the bottom left hand corner of the tablet. 


\subsubsection{Time-Multiplezer Circuit Board}

The control circuit (Time-Multiplexer Circuit) for simultaneously acquiring signals from the probes was designed and bullt for this research. It is mounted on a printed circuit board and shielded in a metal box. The detailed implementation of this circuit is described in Chapter 3. The synchronization of this circuit with the BPO is controlled by a signal coming from the BPO electronics circuit, called RPO. It serves as a control signal of the Time-Multiplexer circuit that reads alternately the signals from the two probes. The outputs of this circuit are the signals from the two probes and the flag signals. These signals are then sent to the BPO for forming the $X-Y$ coordinates of each probe and its flag.

\subsubsection{Personal Computer PC-AT (80286)}

A personal computer PC-AT is used to receive the coordinate pairs and the flag from the BPO through the asynchronous RS232 serial port. After the image to be visualized is recalled from the computer memory, the pixels of the recalled image are mapped one-to-one onto the cells of the computer graphics tablet by dividing the coordinate pairs by a scale factor The factor is used to lower the resolution of the lablet or the image When the blind user activates a cell on the tablet by touching it with either probe. the gray level of the corresponding pixel will be converted to a particular frequency parameter denoted by \#\#. In addition, the flag signals used to identify the two probes are converted to a channel number denoted by CC. 
From the channel number $\mathrm{CC}$ and the frequency parameter \#\#, the PC-AT forms a data word CC\#\#, which is later transmitted to the digital-signalprocessing board (TMS320C25 DSP Chimera board) for the generation and the outputting of the auditory stimuli. The detalled software implementation of this procedure is explained later in Chapter 4.

\subsubsection{TMS320C25 DSP Chimera Board}

The auditory stimuli were generated by using a computer add-on board, called the TMS320C25 DSP Chimera board, incorporating two Digitalto-Analog (D/A) interfaces which provide the stereo outputs in our study. This board is installed within the PC-AT. It receives the stream of data CC\#\# sent from the 80286 microprocessor of the PC-AT, and accordingly generates and sends the tones to the appropriate loud speaker. The software implementation of the auditory signals is described later in Chapter 5. 
Chapter 3

Data Acquisition

The Bit Pad One (BPO) has only one input channel. Hence, in order to use it with 2 finger probes, a Time-Multiplexer is needed. In this chapter, the design, implementation and typical results of this Time-Multuplexer are explained.

\subsection{Design Considerations}

\subsubsection{Data Transmission}

Later, in Chapter 5, some detalls concerning the critical duration of an auditory stumulus will be fully discussed. However, according to past 
studies done by J.M. Doughty and W.R. Garner [34], a minimum duration of approximately 30 milliseconds is needed for a listener to be able to accurately identify a tone. In our case, the auditory stimulus varies from 166 to $500 \mathrm{~Hz}$. Hence, its duration is set at 30.8 milliseconds so that a baud rate of 4800 bps can be used for serial transmission of data from the BPO to the PC-AT computer. In serial binary transmission, the maximum sampling rate [35] at $4800 \mathrm{bps}$ is $65 \mathrm{~Hz}$ (or a period of $15.4 \mathrm{~ms}$ ). This implies that a new sample is taken every $15.4 \mathrm{~ms}$. However, because of the alternation between the left and the right probes, each probe only reads a new value every 30.8 ms as shown in Fig 3-1.

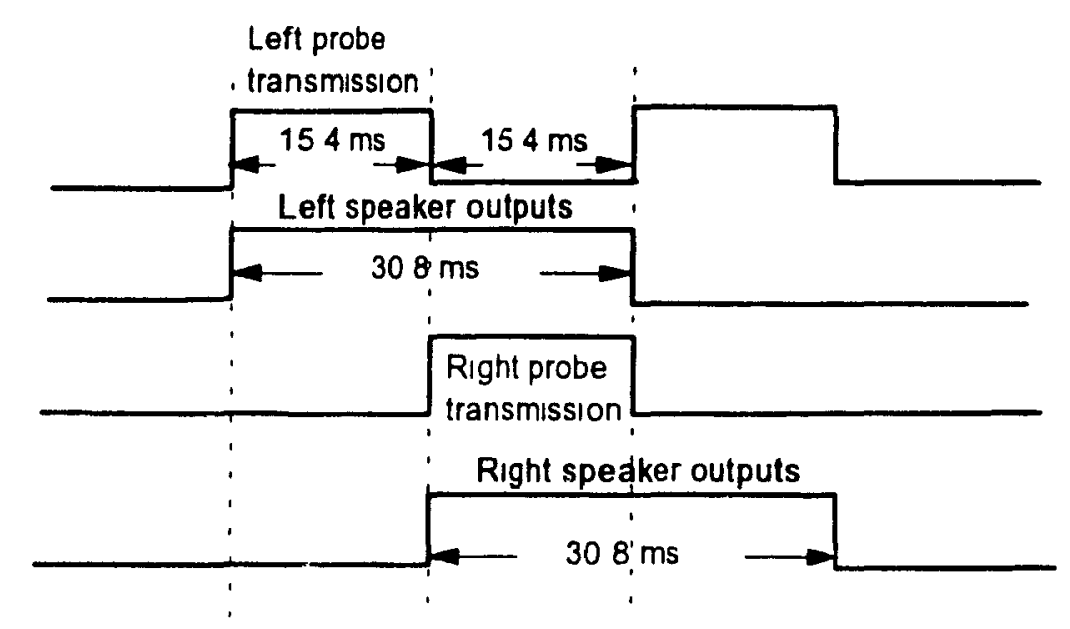

Fig. 3-1 The sampling tume of the left and the right probes.

In present research, we use a transmission format of 7 data bits, 2 stop bits, and "even" parity. The stop bits and the parity are imposed by the manufacturer. A C-language program is written for the PC-AT to receive the binary data through the asynchronous RS232 serial port. Its implementation is explained in Chapter 4. 
In order to send out one entire stream of data at a time from the BPO. one condition must be satisfied. Fig. 3-2 shows the three waveforms of the BPO. The first pulse of MSk occurs at the same time as the X trigger signal, and the second pulse occurs at the same time as the $Y$ trigger signal. When $\mathrm{X}$ and $\mathrm{Y}$ trigger pulses occur, the BPO generates the $\mathrm{X}-\mathrm{Y}$ coordinate. Hence. it is important that the control signal $R P O$, described in Chapter 2, be synchronized and triggered at the beginning of the $\mathrm{X}-\mathrm{Y}$ trigger pulses.

The interval between each $X-Y$ trigger pulse depends upon the sampling rate of the BPO. In other words, it depends on the Baud rate selected by the user. If this condition is not respected, the coordinates in the stream data will not be synchronized. It can give the receiver the $X$ coordinate of one particular time and the $\mathrm{Y}$ coordinate at some other time. This phenomenon becomes one of the criteria in the design and implementation of a Time-Multiplexer Circuit Board for two inputs. This circuit is fully described in this chapter.

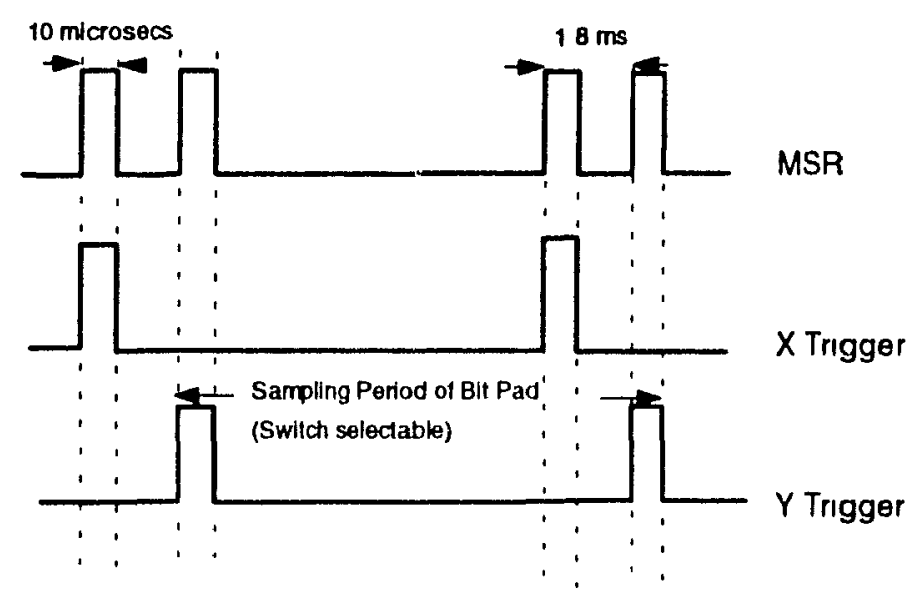

Fig. 3-2 The timing diagram of the control signals of the Bit Pad One. 

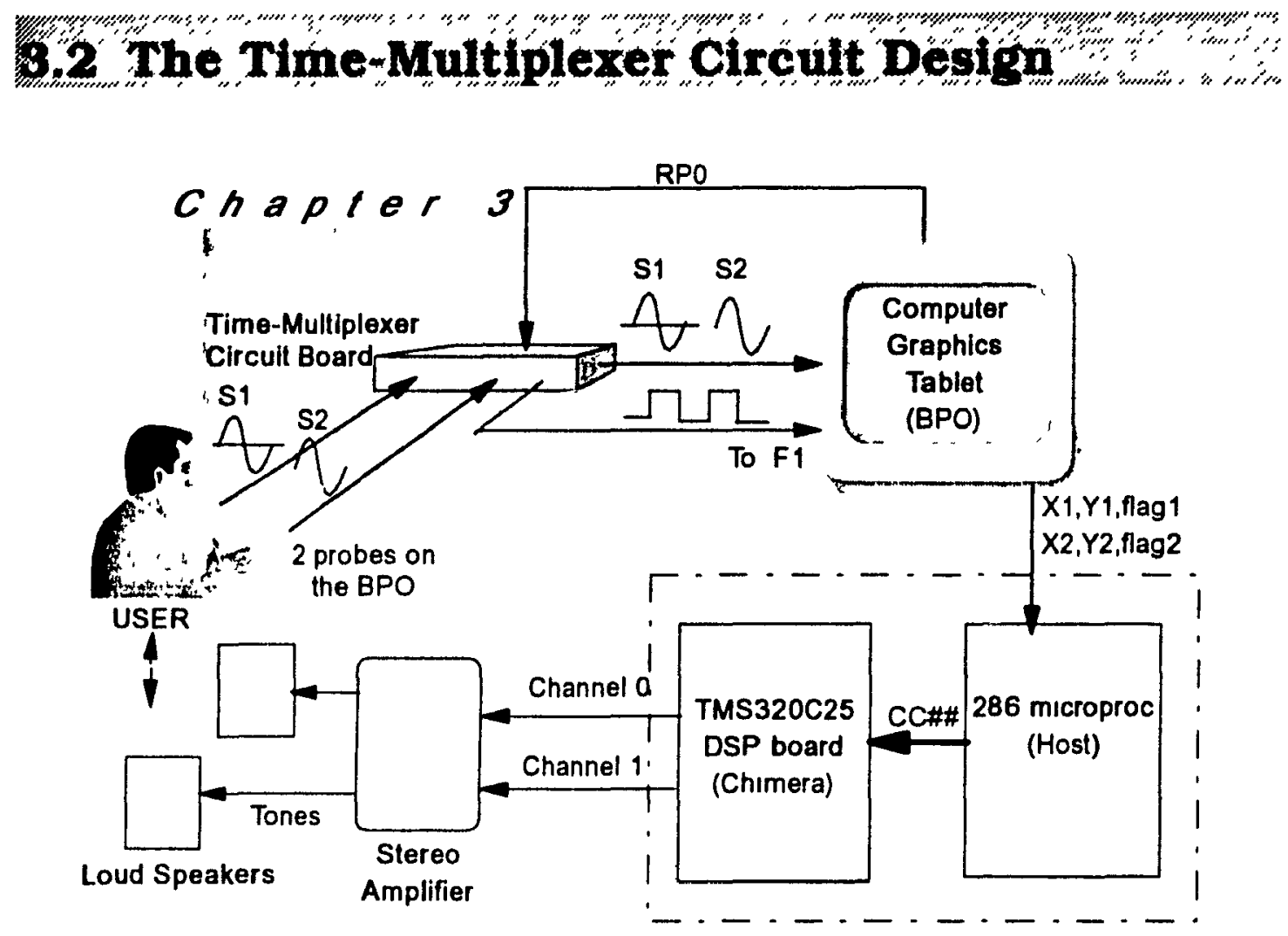

IBM PC-AT Computer

Fig. 3-3 The system implementation of the image-perception aid for our studies

As shown in the shaded area of Fig, 3-3, the Time-Multiplexer circuit is used as the interface between the two finger probes and the BPO. It has to transmit the signals and their associated identifier from the probes to the BPO. The signal from each probe is identified by a flag: A binary flag, "68" (see Appendix A) is associated to the RIGHT probe, and "76" is associated to the LEFT probe. 
To read data alternately from two probes, a square wave signal is used to control two switches. One switch is closed when the control signal is HIGH and another one is closed when the signal is LOW. Thus, when the control signal is HIGH, the switch transmits signal from the LEFT probe to the BPO. When the control signal is LOW, the switch transmits signal from the RIGHT probe. However, in some particular circumstances, the user may scan the image with only one probe. Hence, the BPO receives the data from only one probe.

By associating a flag to each incoming signal at each probe reading cycle, the source can be determined by the receiver. The flags must be configured according to the following cases:

- When the two probes are on the BPO surface, the flags for the signals must be different. Thus, the output of the BPO sent to the PC-AT must be in the format:

$$
\begin{aligned}
& X_{1}, Y_{1}, \text { flag1 } \\
& X_{2}, Y_{2}, \text { flag2 }
\end{aligned}
$$

where the subscript "1" specifies the probe on the right hand, and the subscript "2" specifies the probe on the left hand.

- If only one probe is down on the BPO surface, the flag associated to that probe must be present constantly (for 100\% duty cycle). Thus, the output of the BPO sent to the personal computer PC-AT must be in the format:

$$
X_{1}, Y_{1} \text {, flagl (for the right probe down only) }
$$

Or $\mathrm{X}_{2}, \mathrm{Y}_{2}$, flag2 (for the left probe down only) 
However, it is expected that the use of two probes simultaneously allows the user to perceive the image in a shorter time. Thus, there are two circuits to be implemented. One is to control the switching between the two probes, and the other one is to identify the incoming data from each probe.

\subsection{The Circuit Implementation}

The tasks of the Time-Multiplexer circuit are to output two signals: one control signal for the switches to read the signals of the probes alternately, and one flag signal for the BPO to recognize the source of the input data. The hardware implementations of these signals are described separately in the following subsections.

\subsubsection{Time-Multiplexer Process Implementation}

To obtain a $50 \%$ duty cycle signal from the BPO, one can think about modifying its EPROM program. Unfortunately, no documentation was available for the modification Thus, one way to obtain such a signal is to modify another signal which is stable, periodic, and related to the timing of the X-Y triggering signals. A stable signal is essential because most of the signals in the BPO circuitry are unstable. They change their frequencies when a probe is down on the tablet surface. 
Before reaching the hardware implementation itself, one can think about using a clock (a square wave) as the control signal for the switches. The external clock and the BPO internal clock can not be utilized as the control signal for the switches because they are not synchronized with the triggering signals generated by the 8035 mcroprocessor in the BPO for sampling the $\mathrm{X}-\mathrm{Y}$ coordinate. The result of this desynchronization is that wrong information can be sent to the PC-AT. The wrong information might be, for instance, that the BPO processes and sends out the $X$ coordinates of one probe and the $\mathrm{Y}$ coordinates of another as a data stream such as " $\mathrm{X}_{1}$, $\mathrm{Y}_{2}$, flagl" and "X, $\mathrm{Y}_{1}$, flag2".

By understanding the way in which the 8035 microprocessor of the $B P O$ receives the data and generates the $X-Y$ coordinates, the signal RPO (gate \#15) is extracted from the Multiplexer 74LS138 (IC \#Z16). (See the BPO electronic schematic provided in the Technical Reference of the Bit Pad Onc [35]). The RPO signal has been chosen to be the synchronization signal of the circuit because it is related to the $X-Y$ triggering signal, and is stable, and periodic as shown in Fig. 3-4.

Depending upon the status of the two probes, RPO can assume (wo different waveforms. When two probes are on the BPO tablet surface, RP() contains a pair of pulses (i.e., X-Y triggering signals), separated by 2 milliseconds and appearng regularly every 225 millısecond as shown in Fin 3-4(a). However, when only one probe is on the tablet surface, RP() contanns a set of three pulses (a pair of $X-Y$ triggermg signals plus onte inclepenutent pulse) appearing regularly every 272 millisecond as shown in Fig $3-4($ b)). By 
using the form and the timing of these narrow pulses, the circuit shown in Fig. 3-5 is implemented to derive the signal to control the switches.

(a)

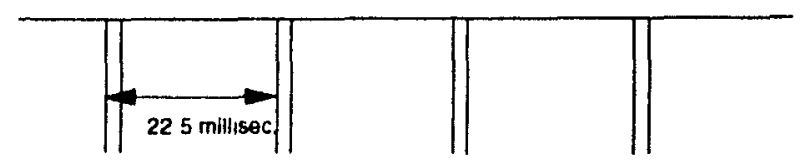

(b)

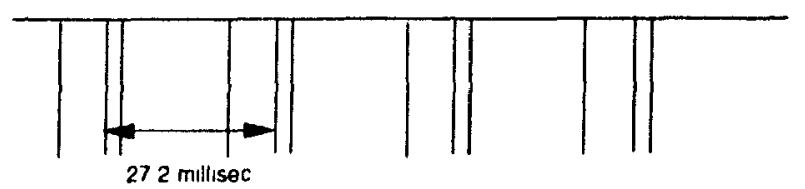

Fig. 3-4 The waveforms of RPO signal. (a) RPO when 2 probes are on the tablet. (b) RPO when only one probe is un the tablet.

According to the signal RPO shown in Fig. 3-4, the X-Y triggering signal pairs are periodic and separated by $22.5 \mathrm{~ms}$ for the case of two probes down, and $27.2 \mathrm{~ms}$ for the case of only one probe down. Each signal pair allows the BPO to read the $X-Y$ coordinates from a probe. Hence, a circuit, allowing the BPO to read the $X-Y$ coordinates from one probe then another, and so on, is needed. The schematic detail of this circuit is provided in Appendix B. However, the design of this circuit is explained in the format of block diagram shown in Fig. 3-5.

Since the RPO contains a pair of pulses, a monostable (74123) has been used to combine two pulses into one by adjusting the potentiometer connected to pin 15 of the monostable. The waveform mono4, the inverted output of the monostable, is further improved by feeding it as a clock to a toggled D Flip-flop. The output signal of D flip flop, dff, is triggered with the 
trailing edge of the mono4 to generate the desired square waveforms. Hence, dff can be used to control the switches. Its waveform is later inverted to turn

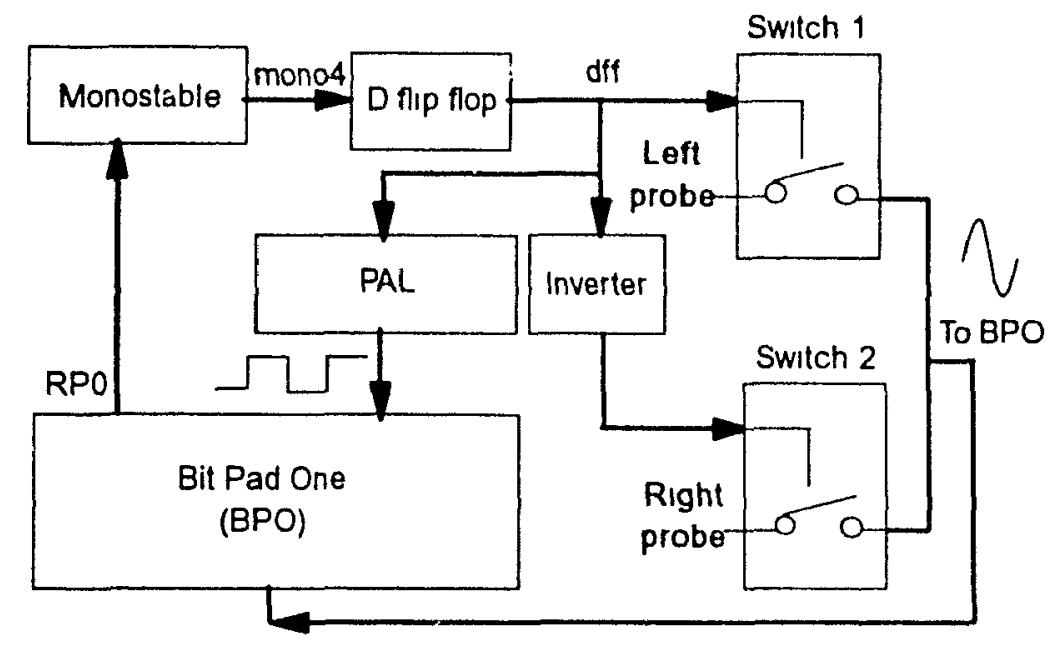

Fig. 3-5 The Time-Multıplexer circuit for two finger-probes

off the first switch IC while the second one is turned on by the non-inverted waveform. In this manner, the Time-Multiplexer circuit reads alternately the data from the RIGHT probe and from the LEFT probe in a synchronized manner.

The signals from the probes are very small relative to the observed noise level. Thus, they must be transmitted through a low noise TimeMultiplexer circuit. In this case, low impedance switches are used. The switches have input impedances which are lower than 50 Ohms in each integrated circuit DG200, there are two switches controlled by two different control signal gates. However, for improving the reliability, the two switches 
in each DG200 are connected together in parallel as shown in the Appendix $B$ and used as one switch.

\subsubsection{The Flag Implementation}

As previously discussed, the signal RPO changes its waveform to three pulses instead of two when only one probe is on the BPO tablet. Thus, it changes the $50 \%$ duty cycle of the signal dff (the outputs of D flip flop). In order to obtain a square signal of $50 \%$ duty cycle while only one probe is on the BPO tablet surface, a PAL (Programmable Array Logic) circuit is used to detect the $X-Y$ triggering signals and to output a proper square wave with $50 \%$ duty cycle.

The electronic schematic of the BPO shows the circuitry of the stylus connector [35]. This connector contains seven gates: one for the input data from the stylus, one for the common ground, one for the margin and Vcc, and four for the stylus flags. F0 (Connector gate \#3) is originally connected to Vcc. It constantly activates a "1" in the Flag byte (byte 0 ) of the Binary Format Data Stream (see Appendix A). Hence, from this point of view, an additıonal flag, such as Fl (connector gate \#1), can be generated in order to mark the input data of the second source. Once activated by the HIGH signal, Fl will generate "]" within the Flag byte (byte 0 ).

By associating the additional nag F1 to the two input data sources (the right and the left probes), the BPO can identify the data with its source. 
When F1 is not activated and FO is (always) activated (1.e., binary flag "68"), the coming $\mathrm{X}-\mathrm{Y}$ coordinate is considered to be from the RJGHT probe When FO and F1 are activated (i.e.. binary flag "76"), the coming coordinate is considered to be from the LEFT probe. The block diagram of the flag implementation is shown in Fig. 3-6. The functions of the circuit in Fig. 3-6 are: (a) to output a flag control signal "ctrl" as a square wave $150 \%$ duty cycle) when two probes are down on the BPO surface, (b) to output flag control signal "ctrl" as a constant HIGH signal (to deactivate Fl) when only the RIGHT probe is down, or (c) a constant LOW when only the LEFT probe is down (to activate the F1).

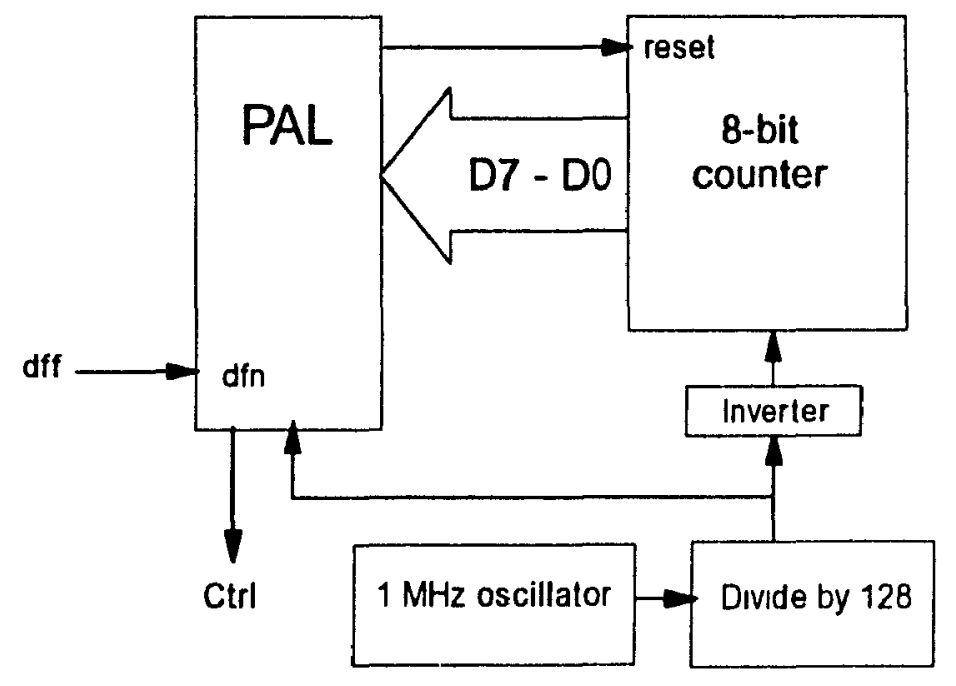

Fig. 3-6 The block diagram of circuit that implements flagl and flag2

In order to generate the signals respecting the above criteria, the output of the D Flip-flop, dff, has been taken into consideration. There are three different cases for the waveforms in the signal dff as shown in Fig. 3-7. 
1. When two probes are on the BPO, dff is HIGH only for 22.5 milliseconds. It is LOW for the next 22.5 milliseconds.

2. When only the RIGHT probe is on, dff is HIGH for 6.8 milliseconds. It is LOW for the remaining 20.6 milliseconds.

3. When only the LEFT probe is on, $d f f$ is HIGH for 20.6 milliseconds. It is LOW for the remaining 6.8 milliseconds.

(1)

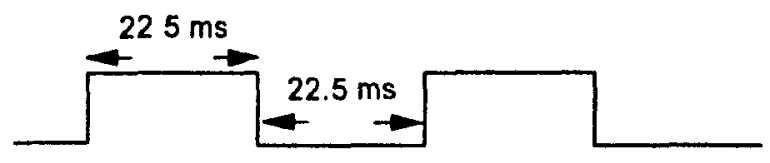

(2)

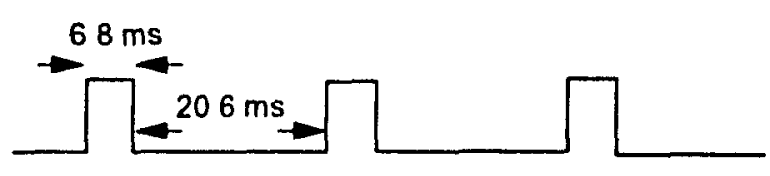

(3)



Fig. 3-7 The waveforms of signal dff in three cas's. (1) When 2 probes are on the BPO, (2) when only the RIGHT probe is on. (3) when only the LEFT probe is on.

With the above information, a PAL (PAL16RP6) is implemented to generate three desired flag signals for the three cases described above by detecting the rising and the falling edges of $d f f$. For Case 1, the PAL output, ctrl signal. is a square wave signal (50\% duty cycle) identical to the input dff. The ctrl signal is a constant HIGH signal for Case 2, and a constant LOW signal for Case 3 .

The PAL can generate these signals by using an 8-bit counter. This counter determines essentially the pulse width of the signal dff by counting 
the number of clock periods of an external clock of $7812.5 \mathrm{~Hz}$ (one period is 0.128 millisecond). The external clock is obtained from a $1 \mathrm{MHz}$ oscillator divided by 128 as shown in Fig. 3-6. Thus, the 8-bit counter needs 32.7 milliseconds to count from 0 to 255 (1.e.. 256 numbers). The PAL samples the dff signal at each clock period to detect the rising and the falling edges. When the PAL finds the edges, it reads the numbers from the counter and then resets it.

For Case 1, shown in Figs. 3-8 and 3-9, the dff signal is a square wave with a $50 \%$ duty cycle of 22.5 milliseconds. This means that the counter will count to 176 in this duration. There are 2 possible conditions: (a) If the previously sampled state of $d f f$ (called $d f n$ ) was $\mathrm{HIGH}$ and the present $d f f$ is LOW, it implies that a falling edge occurred. At this time, if the count is greater than 175 , then the PAL outputs a LOW signal and resets the counter. (b) In the case of a rising edge, the $d f n$ is LOW and $d f f$ is HIGH. so If the count is greater than 175, then the PAL outputs a HIGH signal.

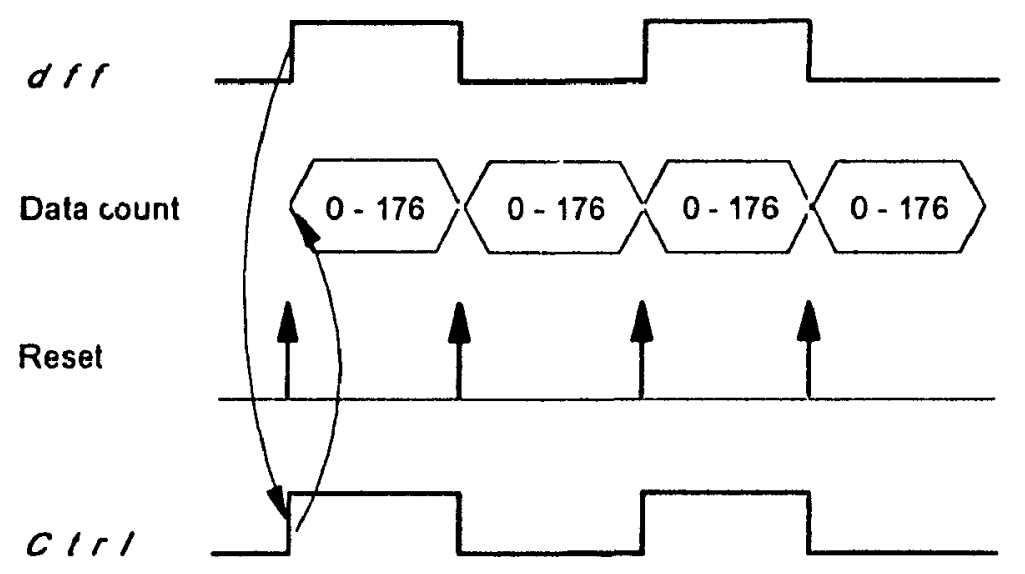

Fig. 3-8 The timing diagram of the signals generated by the PAL for Case 1 
For Case 2, shown in Fig. 3-10, dff signal is a rectangular wave (with $33 \%$ HIGH and $67 \%$ LOW duty cycle). The $33 \%$ HIGH of each duty cycle with $6.8 \mathrm{~ms}$ duration needs 55 counts, whereas the remaining $67 \%$ LOW with $20.6 \mathrm{~ms}$ of the duty cycle needs 160 counts. With the same principle described above, there are also two possible conditions: (a) At the rising edge ( $d f n$ is LOW, $d f f$ is $H I G H$ ), and the count is greater than 160, the PAL outputs a HIGH signal. (b) If the $d f n$ is HIGH, the $d f f$ is LOW, and the count is smaller than 55, then the PAL outputs a HIGH signal.

For case 3, shown in Fig. 3-11, dff signal is just the reverse state of the one in case 2 . Hence, the conditions in case 3 are just the reverse of those in case 2 . The PAL outputs the LOW signal and the counter is reset.

According to the three cases described above, there are six possible conditions. However, these conditions can be combined to form three distinct conditions summarized in Table $3-1$. The three distinct conditions are those that make the PAL generate a HIGH signal to activate the flag FO.

Table 3-1 Summary of the three distinct conditions

\begin{tabular}{ccccc}
\hline Conditions & $d f n$ & $d f f$ & Counts & PAL Outputs \\
\hline 1 & Low & High & $>175$ & High \\
2 & Low & High & $>16 n$ & High
\end{tabular}


High Low $\quad<55$

High

From thiee conditions listed in the Table 3-1, only two of them are used to program the PAL because Condition 1 can be incorporated into Condition 2. These two conditions are translated as the control signal "ctrl" in the PAL program listing with the PLD extension. The PAL program is later compiled by the ORCAD Programmable Logic Design (PLD) software package to generate the files with extension LST provided in Appendix C.

\subsection{Results}

The goals of the circuit described above is to generate the control signal for the switches and the flag signal for the BPO. Figs 3-9, 3-10 and 311 show the resulting timing diagram of the $X-Y$ coordinates related signal "rp0", the output of the monostable mono4, the control signal of the switches dff, and the flag control signal ctrl in three cases They represent the cases where two probes are on the BPO. only the RIGHT probe is on, and only the LEFT probe is on the BPO surface, respectuvely. All the tıming diagrams were measured with the digital Logic Analyzer PHILIPS PM3585 (200 Ml $/$ )

From Fig. 3-9, the time intervals are measured. For instance, $\mathrm{S}-\mathrm{X}=$ 22.5 milliseconds. All the displayed signals are 5 Volts in ampliturle. The dff signals designed to control the switches and $c t r l$ to identify the sources of 
data are identical. Thus, the output of the BPO is repetitively in the following format:

$$
X_{1}, Y_{1}, \text { flagl (for the right probe) }
$$

$\mathrm{X}_{2}, \mathrm{Y}_{2}$, flag2 (for the left probe)

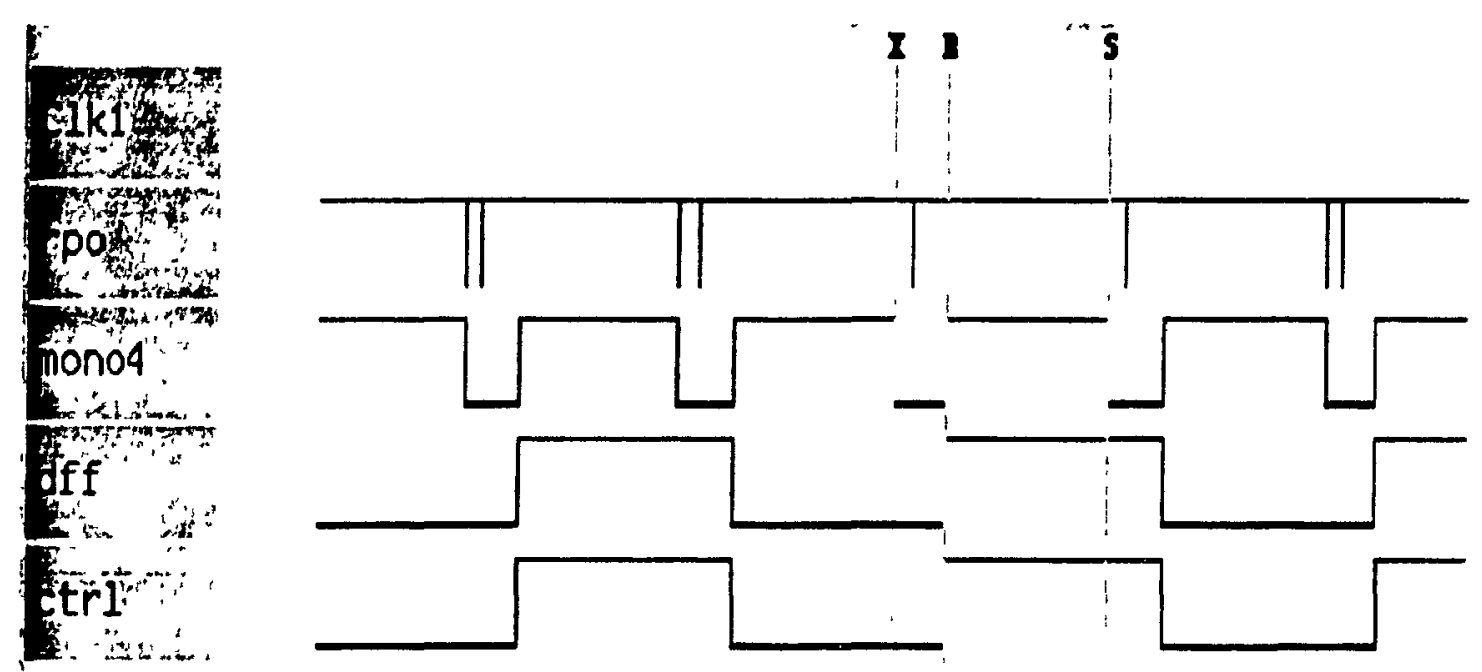

Fig. 3-9 The timing diagram when two probes are on the BPO surface 




Fig. 3-10 The timing diagram when only the RIGHT probe is on the BPO

Fig. 3-10 shows the main output signals of the circuit when only the RIGHT probe is on the BPO surface. In this case, the $d f f$ and ctrl signals are not the same. The dff signal is a rectangular wave with $33 \%$ duty cycle $(33 \%$ HIGH and 67\% LOW), whereas ctrl is always HIGH. Thus, the output of the $\mathrm{BPO}$, is repetitively in the following format:

$$
\mathrm{X}_{1}, \mathrm{Y}_{1} \text {, flagl (for the right probe down only) }
$$




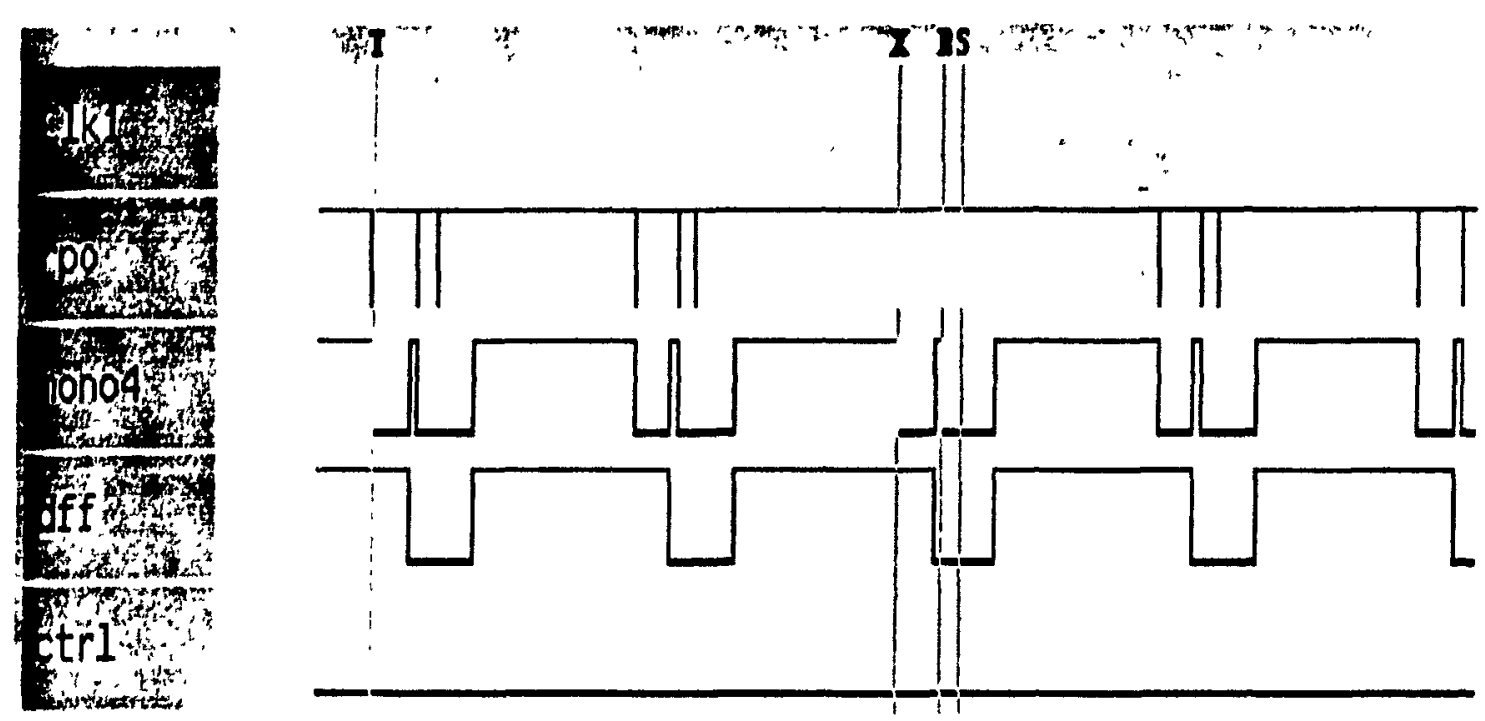

Fig. 3-11 The timing diagram when only the LEFT probe is on the BPO

Fig. 3-11 shows the main output signals when only the LEFT probe is on the BPO surface. In this case, the $d f f$ and $c t r l$ signals are not the same. The dff signal is a rectangular wave with $67 \%$ duty cycle $167 \% \mathrm{HIGH}$ and $33 \%$ LOW), whereas $c t r l$ is always LOW. The Jutput of the BPO, is repetitively in the following format:

$\mathrm{X}_{2}, \mathrm{Y}_{2}$, flag2 (for the left probe down only)

\subsection{Technical Remarks}

The Time-Multiplexer is designed and implemented on a two-layered printed circuit board (PCB) using the ORCAD PCB Software package. The components are mounted on only one side of the board. Such a Time- 
Multiplexer needs a synchronization signal from the BPO electronic circuit, called $R P O$, described previously. This signal is sensitive to external noise. In order to reduce noise, the Time-Multiplexer is shielded in a metal box.

The power supply of each integrated circuit (IC) is connected to a bypass capacitor of $0.068 \mu \mathrm{F}$. The bypass capacitor plays an important role in thi stability of the entire circuit. By connecting a bypass capacitor to each IC and to the on-board power supply (i.e., between Vcc and ground), the noise caused by the high frequency components mounted on the same board can be reduced.

In summary, the outputs of the BPO, are sent to the PC-AT in the binary format through the asynchronous RS-232 serial communication port. At the PC-AT computer side, the outputs are read as stream data of X-Y coordinates with a binary flag "68" for the RIGHT probe or "76" for the LEFT probe (corresponding to "flagl" or "flag2" respectively). Hence, the PC-AT has to be programmed in order to recognize the stream data and to use them to map onto an image cell within $30.8 \mathrm{~ms}$. The design and the implementation of such program for PC-AT (80286 microprocessor) are described in Chapter 4. 


\section{Chapter 4}

\section{DESIGN AND IMPLEMENTATION OF SYSTEM SOFTWARE}

In this chapter, the design and the implementation of software in Cprogramming language are described. The philosophy of the softwrre design seems to be a little bit complicated. However, the main goal of the design is to build a very user-friendly software. The software allows the PC-AT 80286 microprocessor to read the binary X-Y coordinates sent from the Bit Pad One (BPO), map it onto an image cell, read the gray level of that particular cell, and send out a data word to the TMS320C25 DSP Chimera board for outputting a tone to a specific channel, as indicated in the shaded area of Fig. 4-1. 




IBM PC-AT Computer

Fig. 4-1 The system implementation of the image-perception aid for our studies

\subsection{The Software Design}

As described in the previous chapters, the Time-Multuplexer circuit allows the BPO to read the inputs from both the RIGHT and the LEFT probes, accompanied by its source identification. The identification is done by using flags: "68" is assigned for the RIGHT probe and "76" for the LEFT probe. Hence, every $308 \mathrm{~ms}$, a data stream of $X-Y$ coordinates and a flag is received, in binary format, at the asynchronous serial communication port of the PC-AT. The asynchronous communication transmission is necessary in our case since the clocks, used by the PC-AT and the BPO, are not the same. 
Our programs are written in the C-programming language with different functions and subroutines. They are compiled and linked by the Guick $\mathrm{C}$ compller (version 2.0 ). In the following sections, only the essential subroutines are discussed. The explanations of the less important subroutines, such as menu selection, are provided in the program listings enclosed in the Image-Perception Aid User's Manual [36].

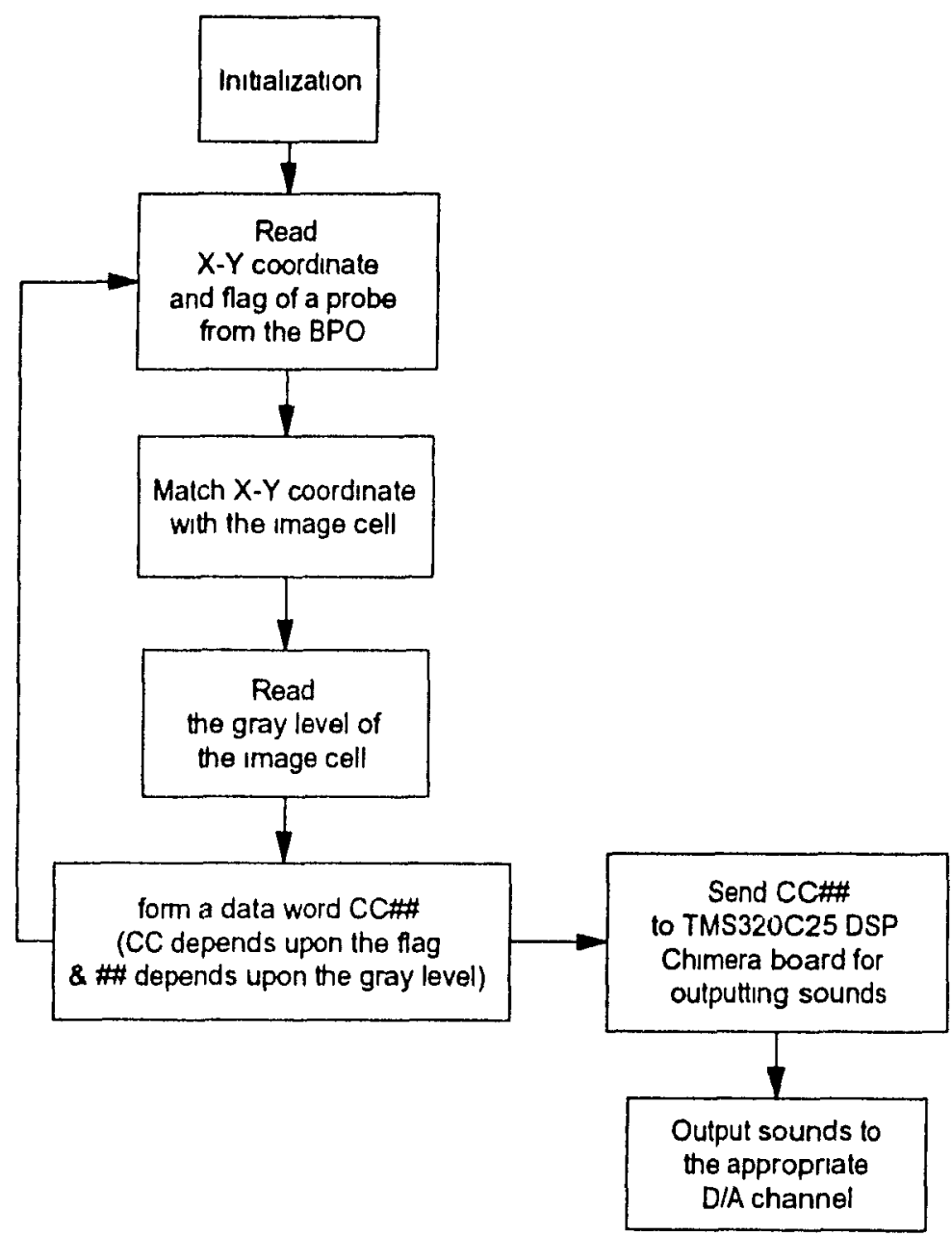

Fig. 4-2 Structure of the main function in VAS.C 


\subsubsection{System Software Overview}

The operation of the personal computer PC-AT is performed essentially by a main function located in the program VAS.C. The structure of this main function is shown in Fig 4-2. After inttialization, the main function first reads the $X-Y$ coordinates and the flag of a probe. Then it maps the coordinates onto the image cell of the BPO, and reads the gray level of that particular cell. The main function combines the gray level and flag into one data word "CC\#" where $\mathrm{CC}$ is the channel number derived from the flag of the probe, and the \# is the gray level read from the image cell. The single data word CC\#\# is then transmitted to the TMS320C25 DSP Chinera board for generating and outputting an auditory signal to the digital-to-analog (D/A) converters connected to each side of the loud speaker system.

\subsubsection{Software Descriptions}

The system software consists of the programs VAS.C, BPO.C and ASYLIB.C. Their hierarchy is shown in Fig. 4-3 The function of each program is described in the following paragraphs.

The program VAS.C contains essentally the function main and the complementary subroutines such as Load_Image( ), INITC25( ), CLRBUF( ). and SEND( ). The main function can be considered as the operation control of the PC-AT It is written to automatically download the TMS320C25 program into the Chimera board, download the input mage of user's chosce 
into memory, read the $X-Y$ coordinates from the serial communication port, map them onto the image cell, read the gray level of that image cell, and then send a data word to the Chimera board To perform these tasks, the main function calls the subroutines written in VAS.C, BPO.C and ASYLIB.C. The four subroutines located in VAS.C, called Load_Image( ), SEND( ), INITC25( ), and CLRBUF( ), are written to perform a specific task for the function main. Except for Load_Image( ), the subroutines are programmed in low-level style (i.e., program reads or writes directly to a specific Register) because SEND( ), INITC25( ) and CLRBUF( ) are used to communicate between the host 80286 microprocessor and the TMS320C25 DSP processor located on the Chimera board. To avoid exceeding the number of pages allowed to an M.Eng. thesis, the VAS.C program listing is provided in the Image-Perception Aid User's Manual [36].

The program BPO C, whose listing is provided in User's Manual [36], contains two subroutines LireCoordBPO(), and DemarreBPO() that are related to the BPO. LireCoordBPO( ) reads the coordinates and the flags from the serial port. DemarreBPO( ) initializes the serial communication port of the PC. AT

The program ASYLIB.C, whose listing is provided in the User's Manual [36], contains five subroutines of level 1 (i.e., closest to the 80286 microprocessor instruction sets). Among them, two subroutines participate directly in the serial 1/O process. They are called $A S Y I N I T()$ and $A S Y I N C H()$. ASYINIT( ) initializes the asynchronous serial communitation port. 


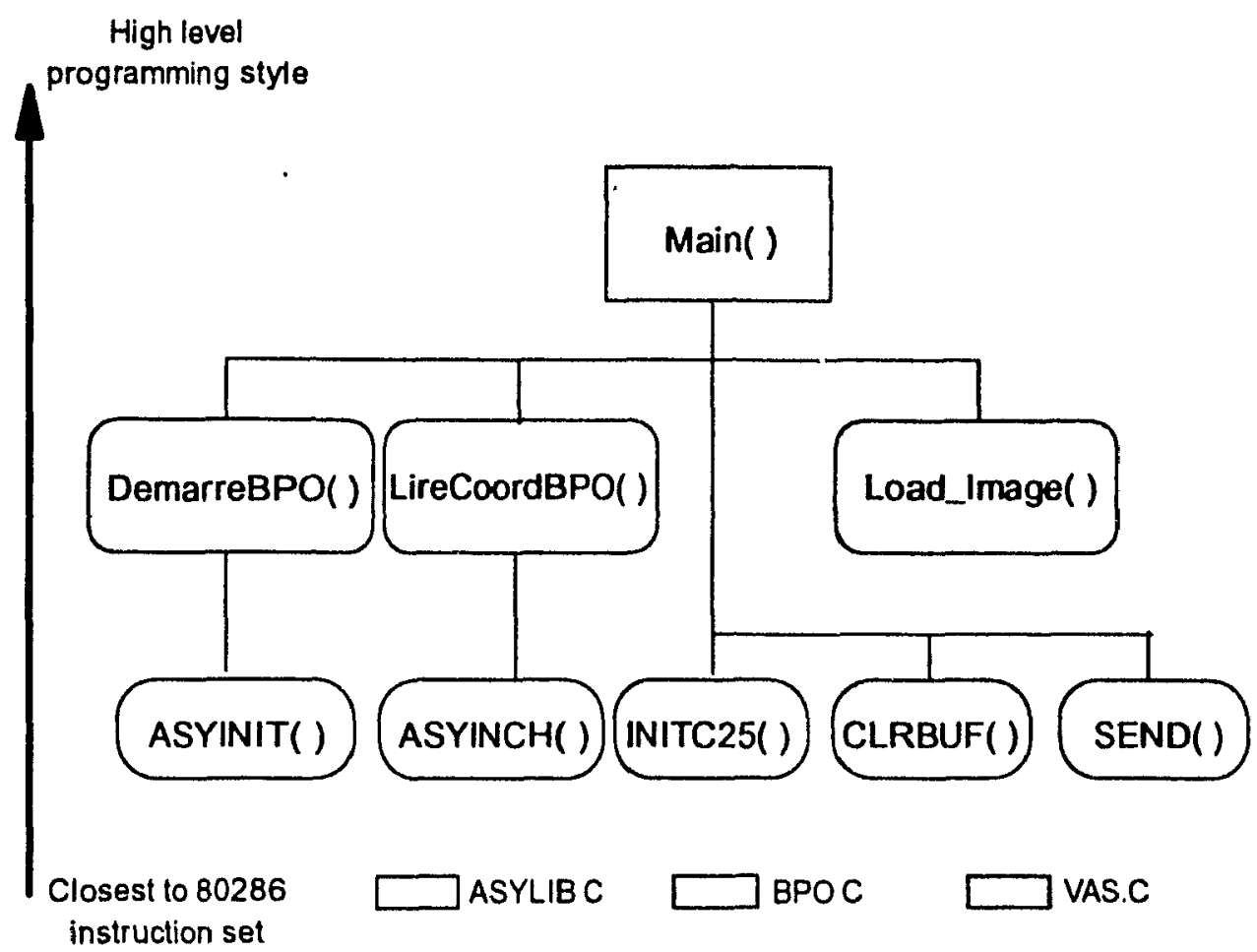

Fig. 4-3 The hierarchy of the subroutines

The remaining tasks are to implement these three programs. Obviously, the subroutines described above are not sufficient to make the system work. Other programming strategies have to be added for improving performance of the system and for making the system more user-fruendly. These details are to be explained in the next section.

\subsection{The Software Implementations}

In this section, the implementation of the three programs described in the previous section are explained along with the corresponding flowcharts. 
The implementations of the function main in VAS.C and its subroutines in the programs BPO.C and ASYLIB.C are discussed.

\subsubsection{Main Operation Control Program}

As described above, the function main of the program VAS.C is written to control the operation of the PC-AT. It also serves as the interface between the user and the system. In brief, after the desired image is specified by the user, the gray levels of the input image at a probe location are evaluated. By combining the evaluated gray levels and the value of pi esent flag (i.e.. D/A output channel number), the function main sends a data word to the TMS320C25 DSP Chimera board. It calls the subroutines written in the program BPO.C to accomplish these tasks. The flowchart in Fig. 4-4 describes the algorithm to implement the above procedures of function main.

\subsubsection{Initialization of The Chimera Board Environment}

The subroutine INITC25( ) is called at the beginning of the function main to set the D/A channel sampling rate at $20 \mathrm{KHz}$ on the $\mathrm{AD} 16$ Daughter board which is on the DSP Chimera board. This task has to be done in the host computer before sending data to the TMS320C25 processor. The algorithm of this subroutıne is explained in the flowchart shown in Fig. 4-5. 




Fig. 4-4 The flowchart of the function main in VAS C 




Fig. 4-5 The flowchart of subroutine INITC25()

For a better understanding about the setting of the parameters and the sampling frequency used in our study, please refer to the section Programming the Daughter Board in Chapter 5.

\subsubsection{Executing The Program in Chimera Board}

The compiled TMS320C25 DSP processor assembly instructions file, called tsp1.tag. is downloaded into the TMS320C25 processor internal RAM after the initialization, and is immediately started by the host system. If the downloading process fails, an error message is displayed to the user and the program is terminated. Otherwise, the flag for the Data Transfer Register, set by the Chmera Motherboard after loading tspl.tag file, is cleared by subroutine CLRBUF(). 


\subsubsection{Initialization of The Serial Communication Port}

The subroutine ASYINIT(, is used to initialize the serial communication port of the PC-AT and the channel status after being called by DemarreBPO() subroutine. It allows the user to set the appropriate communication parameters such as the communication port number, the baud rate, the parity, the stop bits and the data bits The parameters used in our case are mmmunication port 1,4800 baud rate (corresponding to the criteria discussed in (hapter 3), EVEN parity, 2 stop bits, and 7 data bits. The Fig. 4-6 describes the detail of the initialization procedure.

\subsubsection{Loading The Digitized Image}

For evaluation of the system. the images used were stored as files in a hard disk of the PC-AT computer. The function main calls the subroutine Load_Image( ) to load a digitized image into the PC-AT memory. The algorithm of this subroutine is described by the flowchart shown in Fig. 4-7. It first reads the name of the digitized image input by the user. If the Image cannot be found, an error message is displayed to the user and the program is terminated. Otherwise, the image file is read into the PC-AT memory and the image resolution (1.e., pixel size) is checked. If the resolution of the input image does not correspond to the resolution used by the loaded image in memory, the subroutine exits and an error message is displayed. Otherwise, the subroutine closes the image file and returns to the calling function main. 


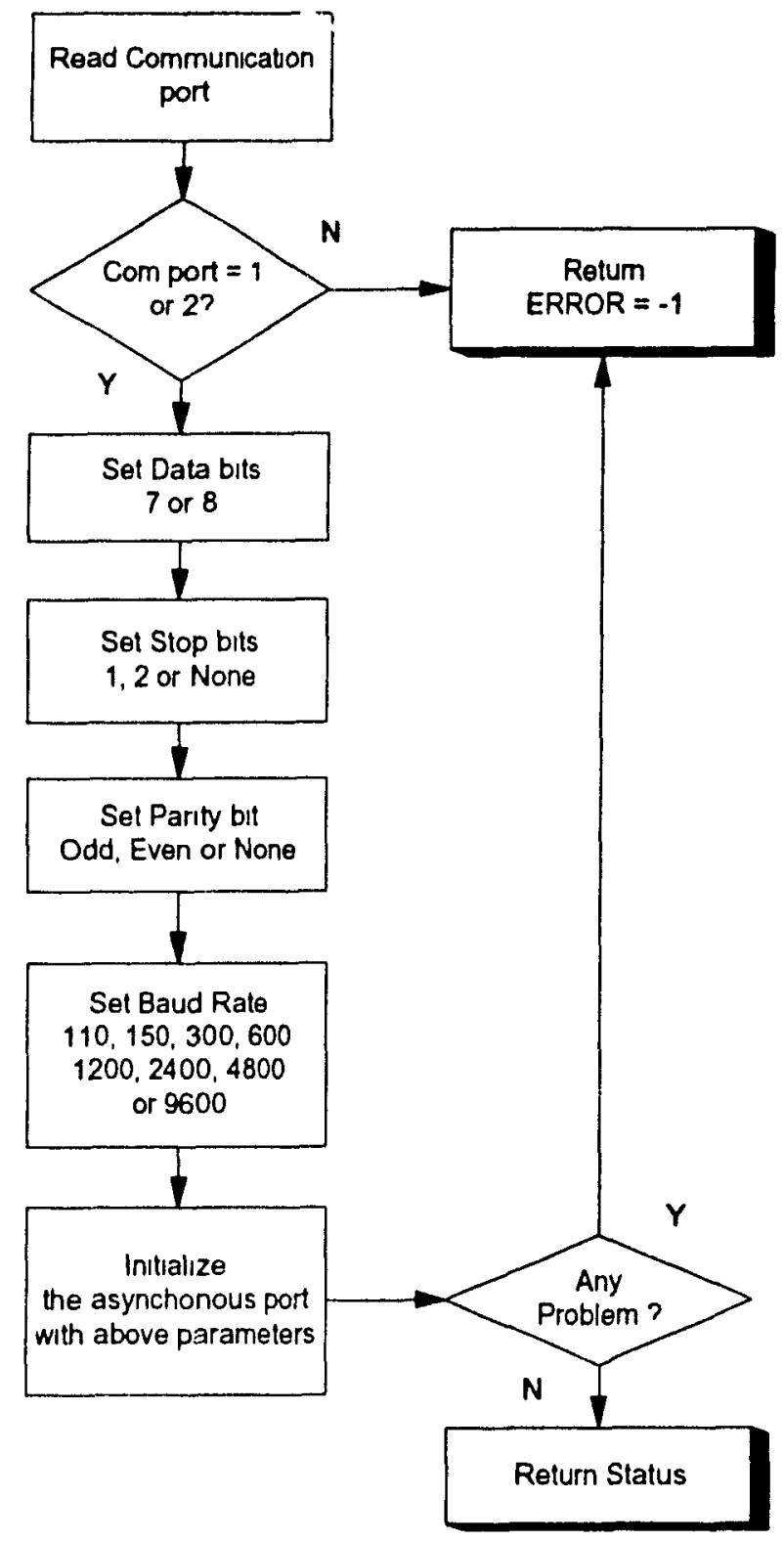

Fig. 4-6 The flowchart of subroutine ASYINIT) 




Fig. 4-7 The flowchart of subroutine Load_Image()

\subsubsection{Main Tasks}

When the above intualization is complete, the digitized image is ready to be mapped to the graphics tablet, and the Chimera Motherboard is ready to receive the data word from the host for outputting the audio signal to a specific D/A converter channel. A message is displayed that tells the uscr to press any key to start the system operation. When a key is pressed, the system also starts the timer to evaluate the elapsed time of the operation. 
Untll a key is pressed again to end the operation, the system performs the tasks described as below.

\subsubsection{Reading The Coordinates From The Serial Port}

The subroutine LireCoordBPO( ) in the program BPO.C is used to read, control and assemble the input characters to form X-Y coordinates and a channel flag LireCoordBPO() reads the data from the serıal port by calling ASYINCH' ) in ASYLIB.C. Because of the possible delays in the system, a number of read attempts are made to increase the possibility of success in data acquisition.

When the LireCoordBPO( ) is first called, it reads the present channel status as shown in Fig. 4-8. This status has been initialized by the DemarreBPO( ) to zero. The system defines the correct flag as "68" (called masque in the program) that represents the RIGHT probe. It also defines the output Digital-to-Analog (D/A) channel as channel 0 . After the flag and the output channel are defined, the value of present channel status is updated by invertıng the bit. In this manner, the system will read the other channel the next time the subroutine is called. The counter for number of trials is then set to be zero. The subroutine reads the flag byte from the communication port for a number of trials by calling ASYINCH( ) contained in ASYLIB.C. 




Fig. 4-8 The flowchart of subroutine LireCoordBPO() 
The subroutine ASYINCH() is used to read one transmitted character at a time from the selected asynchronous RS232 serial communication port. This subroutine is called by the programs VAS.C and BPO.C.

As shown by the flowchart in Fig. 4-9, the subroutine tries, for a selected number of times, to read the serial port to determine whether or not the character is in the buffer. If the character is not there, the subroutine tries to read again and the counter of trials is incremented. Five hundred trials are selected for our study. The number of trials can be increased or decreased depending upon how fast the user wants the subroutine to respond if there is an error signal. At the end of 500 trials, if the character is still not ready to be read, an error signal is returned. Otherwise, the character is read, and a zero is returned to the calling program to indicate the successful reading of a character.

If the flag character cannot be read from the serial port, then in turn LireCoordBPO( ) returns this error signal to the calling function main to indicate that the coordinates cannot be received at the present time. If the nag character can be read but it is not equal to "masque", LireCoordBPO( ) tries to read another input character agan because the character being read could only be useful for the X-Y coordinates. However, after 10 trials, if the flag character is still not equal to "masque", then an error signal is output to Indicate that reading from the present probe has failed. This case happens when one probe is not on the BPO surface. Otherwise, the flag character is equal to masque and the next four characters can be collectec' to form the 


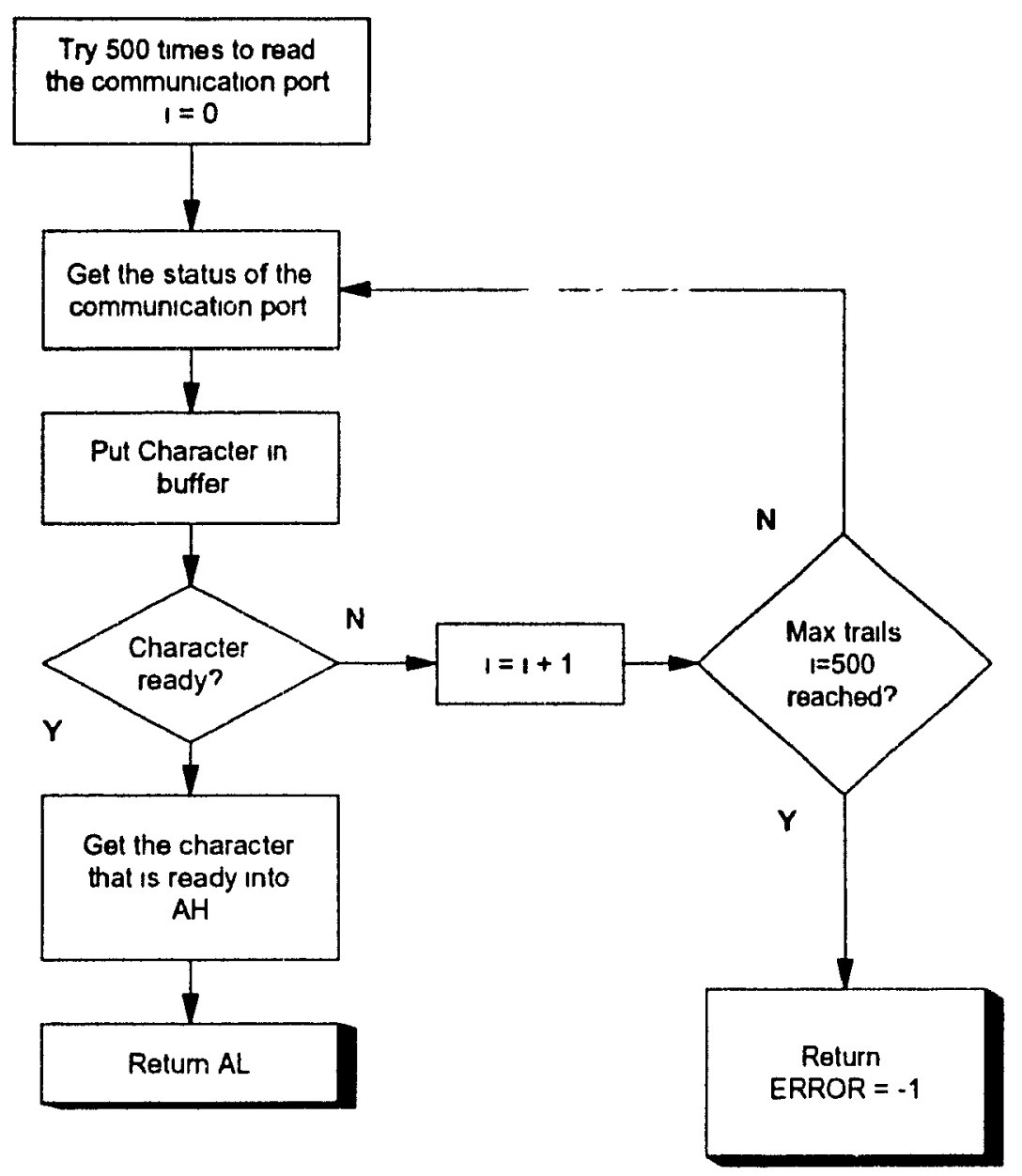

Fig. 4-9 The flowchart of subroutıne ASYINCH()

$\mathrm{X}-\mathrm{Y}$ coordinates. In the same way as previously described, these four characters are read and checked by the ASYINCH() The reading procedure of the characters to form $X-Y$ coordinates is explained in Appendix $A$ When all the desired characters are collected, a zero is returned to the callngh program, and LireCoordBPO( ) is ready to read data from the next probe.

In the following tume, the present channel status is "l". The system defines the correct flag as "68" whuch represents the RIGHT probe. The output Digilal-to-Analog (D/A) channel is defined to be channel 0 . The 
present channel status is then changed from " 1 " to become "0". In this way, the system will read the other probe next time, and so on.

\subsubsection{Mapping The Coordinates Into Image Cells}

When the reading of the characters from the serial port is successful, the actual $\mathrm{X}$ and $\mathrm{Y}$ coordinates are divided by a scale factor to reduce the inage resolution. The actual resolution of the $9 P O$ is $2200 \times 2200$ on a $28 \times 28$

$\mathrm{cm}^{2}$ surface. This resolution is too high for rescarch purposes. As a result, the $2200 \times 2200$ resolution is reduced to $40 \times 40$. Hence, one image cell corresponds to $78 \times 78$ coordinates on the BPO. In this way, an average gray level of each image cell can be evaluated.

In this study, 4-gray-level images are used. The gray levels of the image are defined as follows:

"0": the background of the image corresponds to no sound.

"1": the object in the mage has the "black" color which corresponds to the highest tone (i.e., frequency $=500 \mathrm{~Hz}$ ).

"2": the object in the image has the "dark grey" color which corresponds to the middle tone $(1 \mathrm{e}$., frequency $=250 \mathrm{~Hz}$ ).

"3"- the object in the mage has the "light grey" color which corresponds to the lowest of the three tones (1 e., frequency $=166 \mathrm{~Hz}$ ).

\subsubsection{Assembling The Data Word}


The system combines the gray level read from the image and the flag value sent from the BPU to become a data word (i e., CC\#\# described later) and sends it to the Chimera board by the subroutine SEND().

\subsubsection{Sending Data To TMS320C25 DSP Chimera Board}

SEND() is called by the function main every time the system wants to control the auditory stimuli output. This subroutine take: the gray levels of the image cells and multiplies them by 5 in this study to get the level of frequency divisor. This frequency divisor is later transferred to the lower byte of the Data Transfer Register, whose contents can be read by the TMS320C25 processor. If the gray level (i.e., "1". "2", or "3") is multiplied by 5 , the resulting frequency divisor, annotated \#\#, has the possible values of 5,10 or 15 , respectively. These resulting frequency divisors correspond to 500, 250 and $166 \mathrm{~Hz}$ output tones respectively for the Chimera board The smaller value for the frequency divisor results in a higher output tone In addition, the gray level " 0 " corresponds to frequency " 0 " (i e, no sound). The strategies are explained later in Chapter 5. If the user wants to increase the frequency of the output tones, the gray levels should be multuphed by a smaller scaling factor such as "4" or "3" instead of "5" used in this system

The present channel number is the number of the D/A channel to be used to output the frequency divisor mentioned above The channel number is stored in the hi her byte of the Data Transfer Register In this way, the data word to be ser to the Chmera board is CC\#\#, where CC, representing the D/A channel number, can be esther "00" or "01", and \#\# is two digil numbers representing any frequency divisor value from 00 to 99 This data 
word is sent to the TMS320C25 DSP Board using the Host Data Transfer Buffer Register. This Register in the Chimera processor I/O space is the counterpart to the read/write operation performed by the host computer at the lower and higher byte of the Data Transfer Register.. Hence, the SEND( ) subroutine sends out two 8-bits bytes from the host to the Chimera board. The first (lower) byte is the frequency divisor value \#, and the second (higher) byte is the D/A channel number CC.

\subsubsection{End of Operation}

As long as a key is not pressed by the user, the system reads the data one after another from the serial port. The data is essentially the characters representing the $X-Y$ coordinates and the flag of the RIGHT and LEFT probes However, when a second key is pressed, the elapsed time of the program operation is computed and displayed to the user. The sounds of both speakers are shut off and the T 320 C25 DSP processor is halted.

In brief, at this point, the host receives the rharacters from the serial port, forms the $\mathrm{X}-\mathrm{Y}$ coordmates, and assembles the channel number $\mathrm{CC}$ with the frequency divisor \#\# into a data word "CC\#". This data word is later sent to the TMS320C25 DSP. After decoding the channel number and the frequency chvisor, a tone is output at a specific channel specified by the channel number. All these procedures are fully explanned in the next chapter. 
Chapter 5 GENERATION OF AUDIO STIMULI

Sensory substitution is a way of compensation for a malfunctioning sensory system. In the case of the visual system, the auditory system can be a substitute if the visual information is -epresented as an audilory signal. In the past, many systems have attempted to utulize auditory stumuli to represent visual information One can recall the Sonc Gude and the Kurzweill Reading Machune as examples The Sonic Guide [37] is a secondary mobility and (used in conjunction with long cane or sighted guicle) that provides environment information such as car and tree in the street by outputting audio stimuli in different ways (e g, interisity, pitch and timbre), whereas the Kurzweill Reading Machine [8] transforms written text into speech. 
The stereo image perception aid described in this thesis provides auditory stimuli as a subject scans an image with two finger probes. In this experimental study, the images used contain 2 (1.e., binary), 3 or 4 gray levels. Thus, a particular stimulus is heard when the probe is located on a pixel with gray level "1". "2", or "3". No stimulus is heard if the probe is located on a pixel with gray level " 0 ". In images with several gray levels, the stimulus assocrated with each pixel must be distinct and easily recognizable. In this case, the duration of the auditory stimulus is a critical feature. Accurately identifying a note requires some minimal time. Experiments in psychoacoustics [34] have shown that after the onset of a tonal stimulus, at least 31 milliseconds must elapse before a $125 \mathrm{~Hz}$ signal is identifiable. Similar results have been reported by Turnbull [38]. A minimum duration of 37 milliseconds is needed for a $128 \mathrm{~Hz}$ signal. A shorter duration is needed for a $1024 \mathrm{~Hz}$ signal, and an even shorter duration for a $2048 \mathrm{~Hz}$ signal.

In addition to these constraints on the minimum duration, there is also a bound on the maximum duration of the stimulus. If the stimulus corresponding to a pixel in the image persists too long as the image is being scanned, then the stimulus makes the pixel sound like a streak. This phenomenon is due to the fact that the excessively long stimulus corresponding to the pixel will contunue even after the user has moved the probe away from that particular pixel. The user will then associate all pixels that are passed over untul the stımulus ends as having the same gray level. To meet these requrements discussed above, a stimulus of 30 millisecond duration is considered as adequate to allow the subject to recognize and to respond whule an image is being scanned. 
In order to respect the requirement of stimuli duration. a baud rate of $4800 \mathrm{bps}$ is selected to transfer data from the BPO to the host computer In binary format. This baud rate implies that the naximum sampling rate is 65 $\mathrm{Hz}$. Thus, each probe is read every 30.8 millisecond. This implies that the reading probe outputs an auditory stimulus for a 30.8 millisecond duration. This duration is considered as adequately recognizable by the subject while an image is scanned since 500, 250 and $166 \mathrm{~Hz}$ are used in our study to represent the gray levels "1", "2", and "3", respectively, as described in Chapter 4.

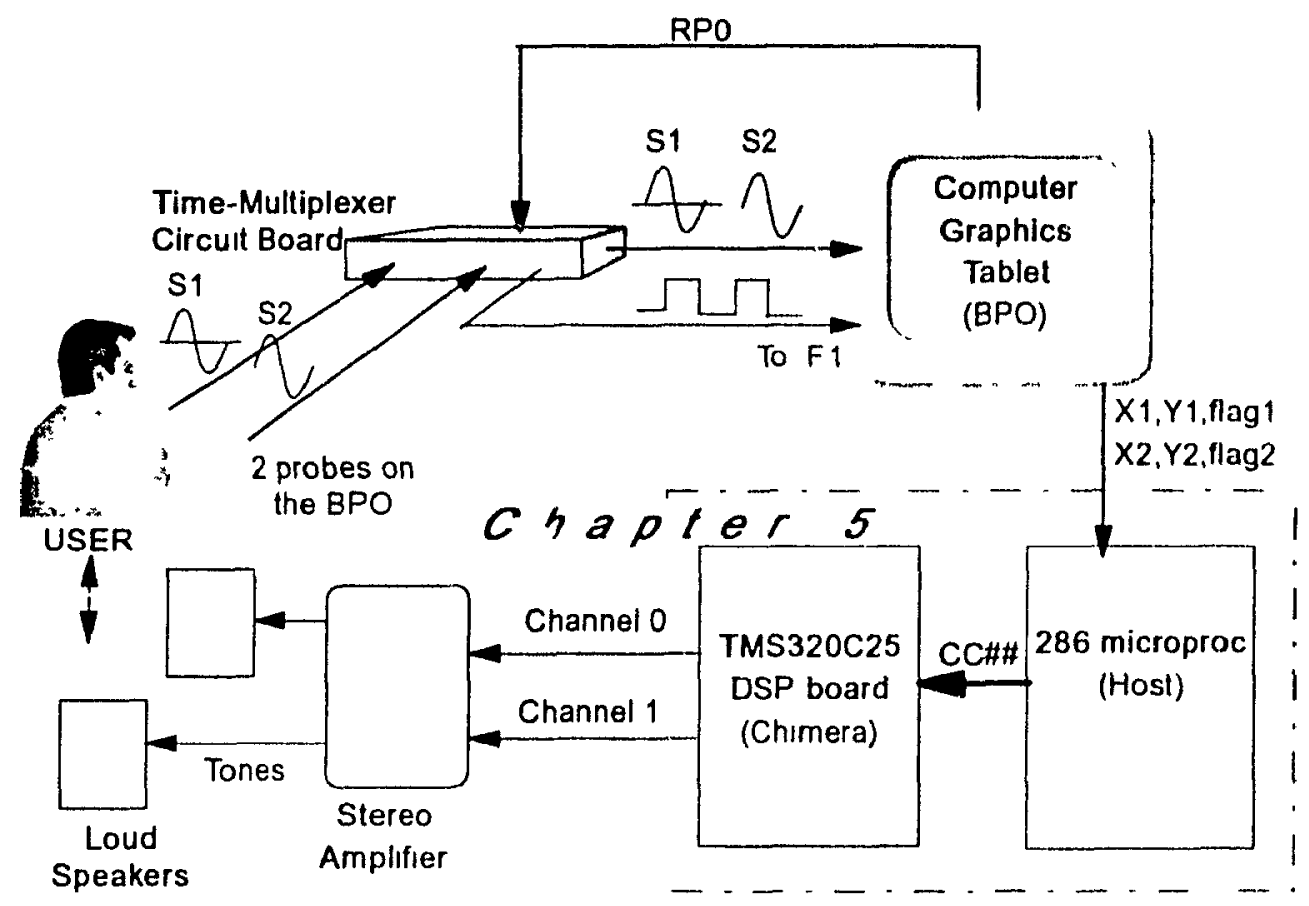

IBM PC-AT Computer

Fig. 5-1 The system implementation of the image-perception aid for our studies 
In Chapter 4, we have described the computer programs used by the host microprocessor (80286) to recelve the coordinates from the BPO, map them onto the image cell, and transmit a data word to the digital signal processor (DSP) board. The output of the host microprocessor is the data words CC\#\# sent to the TMS320C25 DSP Chimera board, as shown in the shaded area of Fig. 5-1. Now, the manner in which the DSP board is programmed to receive and generate the auditory stimuli is discussed here.

In our work, the important tasks of the DSP board are to generate and output the audio stimuli in real time. Thus, it allows the host microprocessor to obtain other coordinates from the BPO. The data word sent by the host has to be received, decoded, and output within a limited time With a fast DSP, such as the TMS320C25 by Texas Instrument Inc., the audio stimuli can easily be generated in real time. The DSP Board available in our laboratory, called the Chimera, has a TMS320C25 signal processor. With the Chimera board, many features can be added in future research It has not only sufficient computing power to output tones, but also to synthesize words. Furthermore, with its control register, two different tones can be simultaneously output to each digital-to-analog (D/A) channel. In our work, the Chmmera board is programmed to generate three different tones plus silence for representing four gray levels of the test images, and to output tones to the D/A channels.

The board has all the processor control features. In order to provide the Analog-to-Digital (A/D) or Digital-to-Analog (D/A) conversion, a Daughter 
Board $\mathrm{AD} 16$ has to be added to the Chimera Motherboard. The Information regarding these boards is given in the User's Manual $[39,40]$.

A TMS320C25 microprocessor assembly language program, called tsp1.asm, has been written to control the input and output of the DSP board. This program reads and decodes the data words sent by the host microprocessor, then generates and output tones to the specific digital-toanalog converter. The programming of each function used in this program will be fully discussed but some essential features on the Chimera Motherboard and $\mathrm{AD} 16$ Daughter board used in this research must first be described so that the design and organization of the program can be understood.

\subsection{Essential Features of The Chimera and AD16 Boards}

As indicated in Fig. 5-2, the essential elements on the Chimera board such as the TMS320C25 processor, the memory (RAM). the AD)16 Daughterboard. and the Data Interchange Register, enable the communication of the Chmmera board with the host microprocessor and the external devices. A brief description of each element is helphal to understand the programming of the Chimera board. 




Fig. 5-2 The communication of the Chimera Motherboard with the host computer and the external devices

\subsubsection{The TMS320C25 Processor}

The TMS320C25 is the processor of the Chimera Motherboard [39]. It contains a 32-bit ALU. Harvard-type architecture (separate program and data buses), and special digital signal processing instruction sets operating at $40 \mathrm{MH}$ clock speed the TMS320C25 is capable of executing 10 Mollion Instractions Per Second (MIPS) 


\subsubsection{The Memory (RAM)}

The TMS320C25 processor has an internal memory of 544 16-bil words on-chip data RAM. The processor can address a total of $64 \mathrm{~K}$ words of data memory. Thus, $63 \mathrm{~K}$ of external memory, located from $0400 \mathrm{~h}$ to OFFFFh, are added to the board for more storage capability.

The on-board memory is configured for both program and data memory simultaneously. The memory on the Chimera Motherboard is accessible by the host through a 16K-byte window in the host computer's memory. The segment address of the window is Dooo for the Chmera board Hence, only $16 \mathrm{~K}$ of memory on the Chimera board can be accessed at one time.

\subsubsection{The AD16 Analog Daughter Eoard}

The AD16 daughter board is a dual-channel analog unterface board for the Chimera Motherboard The two digital-to-analog (D)/A) channels of the Daughter board allow the proposed and to output the andios stimuld to the stereo audio amplifier and loud speakers Fig $5-3$ shows an overview of the communication of Daughter board with the host and the TMS:320(:25 processor. 


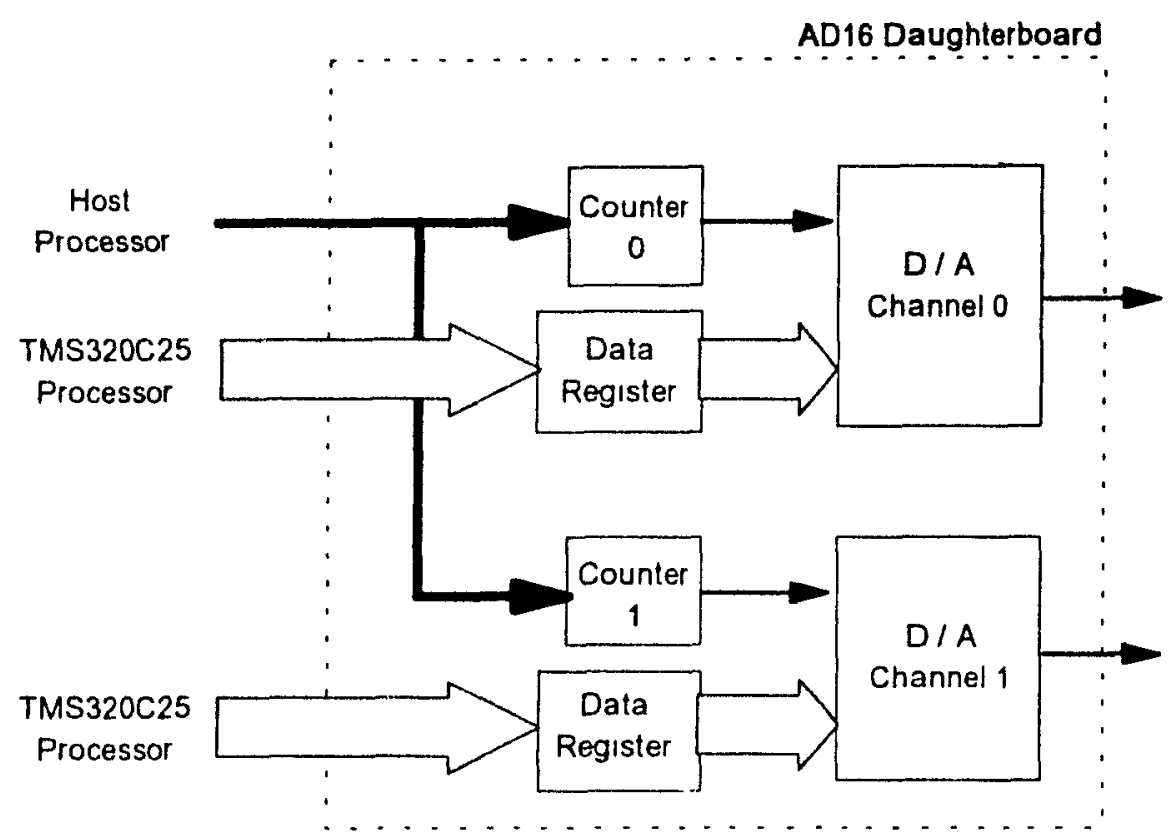

Fig. 5-3 The communication of the AD16 Daughter board with the host and TMS320C25 processor

As shown in Fig. 5-3, the host can access to the Daughter Board through two $1 / 0$ registers: Counter 0 and Counter 1 in order to set the samplung frequency of the D/A converters. Programming the counter for each channel consists of writing a control word to the control register followed by writung the count required to the appropriate counter.

\subsubsection{Data Interchange Registers}

A pair of 16-bit Data Interchange registers are used to pass data between the Chmera Motherboard and the host under programmed I/O control. This register is used to transmit the data word CC\#\# from the host processor in the TMS320C:25 processor. 


\subsection{Host - Chimera Board Communication}

The host processor (80286) can send data to the Chimera board by using the Data Interchange Register "C". Register C is the counterpart to the read/write operation performed by the host at $1 / O$ registers 0 and 1 when writing to the host, the Chmera to Host buffer full (THIBF) flag will be set When reading from register $\mathrm{C}$, the Host to Chmera bulfer full (1ITHF) nag will be cleared. In other words, when data is sent by the host, a buffer full flag is automatically set. In this manner, the TMS320C25 processor can just detect the status of the flag. and know when new data has arrived After reading the new data, the TMS320C25 processor automatıcally clears the fang

The Chimera processor uses IN and OUT instructions to $1 / 0$ register $\mathrm{C}$ while the host uses IN and OUT instructions to the host $1 / \mathrm{O}$ registers 0 and 1 . Both the host and the Chimera processor can operate in eilluer polled or interrupt mode.

\subsection{Programming The Daughter Board}

In order to use the D/A converters, their sambling frequency must first be set from the host processor. However, the host processor may not have enough time to directly transfer audio stmuli data to the $D / A$ 
converters in real time. Hence, the stimul data must be generated and sent through the TMS320C25 processor as shown in Fig. 5-4.

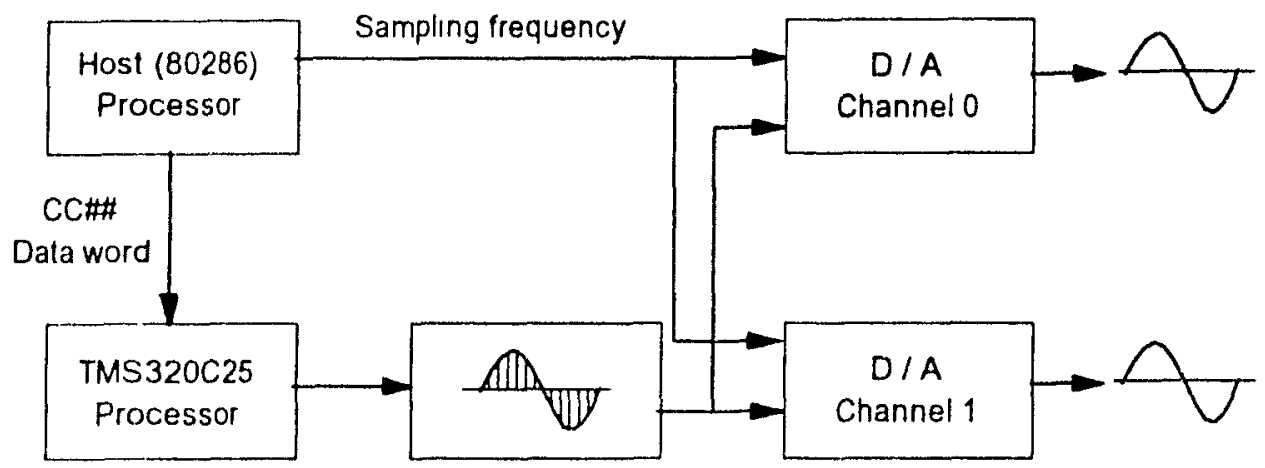

Fig. 5-4 Audıo stımulı data transfer

The control word required for the Counter 0 is $36 \mathrm{H}$, and for the Counter 1 is 7611 The count required can be computed by dividing the 10 $\mathrm{MHz}$ source clock by the sampling frequency The count is written to the 8bit device as the least significant byte first followed by the most signif ant byte. The counters can only be set by the host For instance, if it is required to set the sampling frequency to $10 \mathrm{KHz}$ for Channel $\mathrm{O}$ and using Counter $\mathrm{O}$, the host program must include the following lines: As $10 \mathrm{MHz} / 10 \mathrm{KHz}=$ $03 \mathrm{e} 8 \mathrm{H}$,

OUT 22Bh, 36h

OUT 228h, e8h

OUT $228 \mathrm{~h}, 03 \mathrm{~h} \quad$ where $228 \mathrm{~h}$ is the address of Counter 0. 


\subsection{The Software Design and Organization}

With the information on commumcation between the host and the TMS320C25, described in the previous sections, a TMS320('25 assembly language program called tspl.asm has been de'signed The listing of the program is provided in the Image-Perception Ald User's Manual |36| This program is downloaded nito the external memory of the Chmera board and runs in parallel with the host processor 80286 It allows the TMS:320("25 processor to control the data flow between the host, the Motherboard and the daughter board in order to output tones, depending upon the information received, through the two D/A converters.

\subsubsection{Audio Stimuli Outputting Method}

The audio stmmli can be generated as complex signals such as musical notes. However, for simplichty in this expermental study, a constant magnitude sine wave is used to generate tones. Thus, 40 values of a peroul of a sine wave are stored in a look-up table In real tume, the data values are output one-by-one to a specific D/A converter The infervat, AT, between two output values determmes the frequency of the ontput tones by the equation $\mathbf{f}=1 /(\Delta \mathrm{T} \times 47)$ By changing the $\Delta \mathrm{T}$, the omput frequenc $\mathrm{y}$ of the tones can be controlled Fig 5-5 shows an example of 2 tones with 40 ponth of dala. By varying the $\Delta T$ to a greater or smaller value, a tone of 25 ) $\mathrm{Hz}$ or $500 \mathrm{~Hz}$ is output. In the desıgn, each tone can he modifed only after outpulting every 
set of 40 values in order to avord the "click" caused by the sudden change from a non-zero value to zero, and after every $30.8 \mathrm{~ms}$ (i.e., the audio stimuli output duration).

(a)

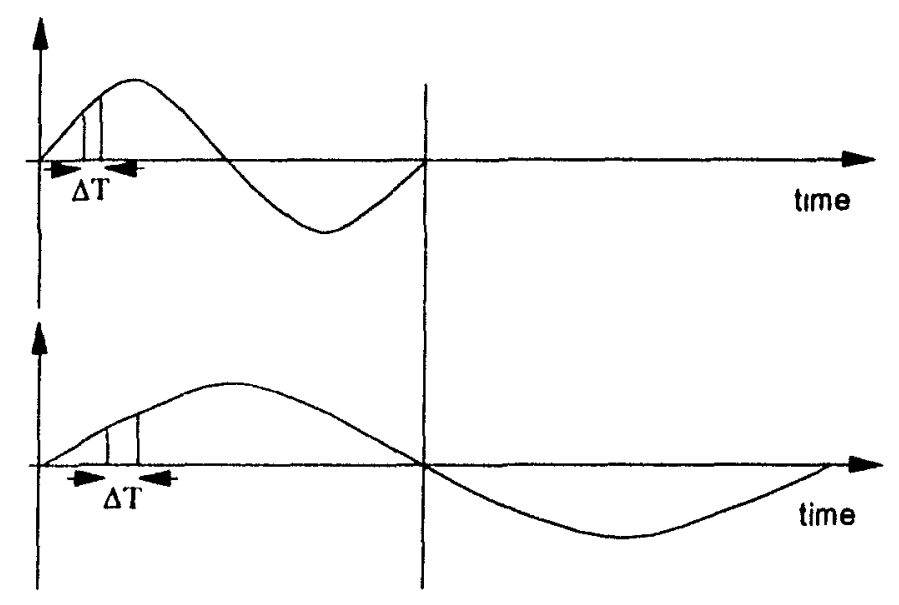

(b)

Fig. 5-5 The two output signals with 40 points of data. (a) Smaller $\Delta T$ gives, for instance, tone frequency $=500 \mathrm{~Hz}$. (b) $2 \times \Delta \mathrm{T}$ gives tone frequency $=250$ $\mathrm{Hz}$.

\subsubsection{Stereo Output}

In the case that two tones are designated to be output, depending upon the channel number CC\#\# spectied in the data word received from the host, two tones can be generated and smultanecusly output to the specific D/A converters. On the basis of the audio stmul outputting method described above, the TMS320C25 processor outputs a sine wave data to two $D / A$ channels using 2 separate control varables of $\Delta T$. For each channel, its $\Delta T$ can be modified based on the frequency divisor \#\#. 
The output of the tones has to be in real time. Each tone must be output completely before another data word arrives from the host processor

The program tsplasm is designed to write data to $\mathrm{D} / \mathrm{A}$ converter of channel 0 or 1 of the ADl6 daughter board The audio signal interval $\Delta \mathrm{T}$ is output under the control of the TIMER on the TMS320C25 processor. The timing constant is chosen to be "100" in order to generdte 1 intermut every $10 \mu \mathrm{s}$. The interval $\Delta \mathrm{T}$ is defined as $\Delta \mathrm{T}=\# \# \times 10 \mu \mathrm{s}$ where \#\# is the frequency divisor.

Each tume, the program waits to get two sets of data (i.e., one for channel 0 and one for channel 1) before decoding the input data. Thus, the TMS320C25 proc'sssor has to process the current data and output the desired tones at the correct channel before the TMS320C25 receives the next pair of data from the host.

\subsubsection{The Program Structure}

The program tsplasm is composed of three man parts onc mam program, and two subroutmes The two subroutines are called Init ffor Initialization) and Output (for outputting sounds). The functions of each part are described below. 


\subsubsection{The Sound Operation Control}

The flowchart of the main program is shown in Fig. 5-6. It first calls the subroutine Int to mutialize the processor and the variables used in the program After initialization, the interrupt is enabled in order to receive the input data from the host Then the program waits for the first data input, whoch is ready to be received when the 1/O flag is down in the Status Bit. So, the program reads the first mijut data word in the format $\mathrm{CC} \#$ sent from the host through the Data Exchange Register and writes th to a memory location named "Tempo" The program then waits for the second input data word to be read and written into "Templ" in the same way After recenving two input data words, the program starts decoding the mput data.

In the design, the decoding of the input data words (CC\#\#) yields the output channel number CC and the frequency divisor \#\# For instance, if the input data word is $O O \# \#$, wher 00 represents the channel number 0 and \#\# represents the fiequency divisor of any from 0 to 99 . then the channel 00 is, selected to output the audio signal frequency of $1 /(\# \# \times 40 \times 10 \mu \mathrm{s})$.

The strategy to program the decoding of input data words is to mask the data and then extract the channel number $\mathrm{CC}$ and the frequency divisor \#\# The second unput data word is decoded first if the decoded channel number $\mathrm{CC}$ is 0 , the frequency divisor \#\# is stored into variable SCALEO. It implies that the first mput data word stored in "TempO" belongs to channel 1. By masking the first mpul data, the frequency divisor \#\# of channel 1 can be decoded, and stored in variable SCALE1. 


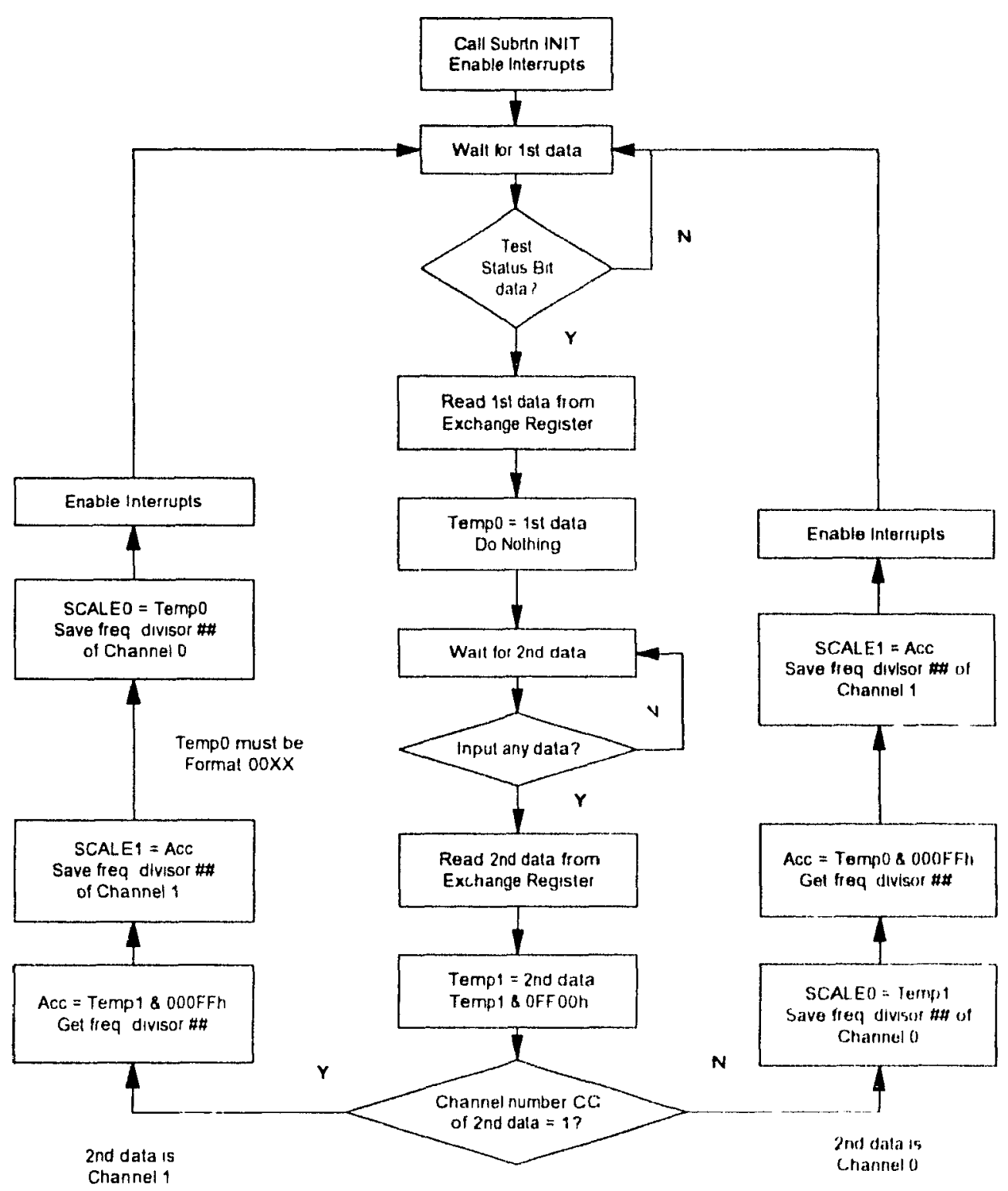

Fig. 5-6 "The flowchart of the Mam program in tsp1.asm

In the same way, if channel number $C C$ is 1 , it implies that the first input belongs to channel 0 . Thus, by masking this data word, the frequency divisor \#\# of channel 0 can be decoded. 
The tsp 1.asm program runs in the TMS320C25 processor : 'ntil a key press by the user causes the host to generate a "Halt" command which stops the operation of Chimera board as described in the VAS.C program in Chapter 4

\subsubsection{Initialization of The Mother and Daughter Boards}

The subroutine Int initializes the processor and the program as follows.

* Set the required data memory locations to zero.

* Specify the address for the D/A c'annel ports.

* Specify the Daughter Board control register for D/A conversion.

* Set the TIMER to 100 to send one interrupt every $10 \mu \mathrm{s}$

(As the TMS320C25 processor executes 100-ns per instruction, by setting the TIMER to 100 , one interrupt is generated every $10 \mu \mathrm{s}$ since $100 * 100 \mathrm{~ns} /$ instruction $=10 \mu \mathrm{s}$ )

The flowchart of this initralization subroutine is shown in Fig, 5-7. It shows all the procedures to set up the conditions before the TMS320C25 processor executes any task.

The variables NUMO and NUM1 are set to 39 since 40 auditory signal values are used to output tones. The variables ADDRO and ADDRI are used as a table pointer to the look-up table of the audio signal values for each channel The varables called SCALEO and SCALEl are set to 5 and 6. respectuely These varnables are used to test the Chmera board output by hearing immediately two different tones after the tsplasm program was 
downloaded into the TMS320C25 processor. The strategy for this is described in the next section where the subroutine OUTPUT is explained.

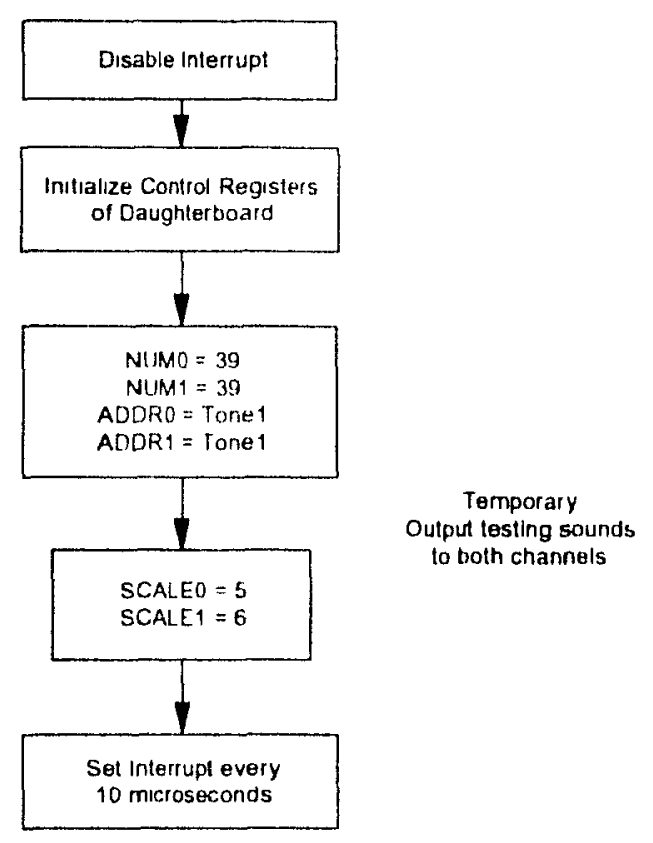

Fig. 5-7 The flowchart of the initualization subroutine Init

\subsubsection{Outputting Sounds}

The subroutme Output takes the 40 values of a simusomal sigmal stored in the table "Tonel" and converts them through the D/A chamels. The rate of the conversion depends on the freculency divisor \#\# assigned to each channel and is controlled by the TiMure interrupt The count of interrupts is stored in varables COUNTO and COUNTl for channel o and channel 1 respectively To output contmaomsly the andio sumuli, after a cycle of 40 values is output to $\mathrm{D} / \mathrm{A}$ chammel, the lable ponter ADIDRO or ADDRI goes back to the begunmug of the look-up talle, and starts outputtung rext cycle For mstance, if the mput frepuency divisor \#\# is 08 , 
every 8 interrupt occurrences, one value of the stored signal is output. By changing the frequency divisor \#\#, the stored signal can be output at various frequencies without storing data for all the frequencies in memory Here, the frequency divisor \# can be modified every $30.8 \mathrm{~ms}$.

The flowchart of this subroutine, shown in Fig. 5-8, explains the procedure for ocutputting the stimulus. The stimulus is generated by transferring all the values from the memory tahle "Tonel" at different rates to the channels tor conversion by using TIMER interrupts Every time an interrupt occurs, COUNTO is decremented. When COUNTO is 0 , a signal value of table "Tonel" is output to the D/A channel 0 After outputting 40 values, the pointer ADDRO is set to the beginning of the table "Tonel". In the same Inanner, a signal value of table "Tonel" is output to D/A channel 1 at a conversion rate specified in variahle COUNT1.

In brief, the manner of outputting one value at a time to each D/A channel allows the system to output two signals of different frequencies simultaneously from only one signal table Tone1. The output frequency at each D/A channel is.

$$
\text { freq }_{\mathrm{i}}=1 /(\# \# \times 40 \times 10 \mu \mathrm{s})=1 /\left(\text { COUNT }_{\mathrm{i}} \times 400 \mu \mathrm{s}\right), \quad \mathrm{i}=0,1
$$




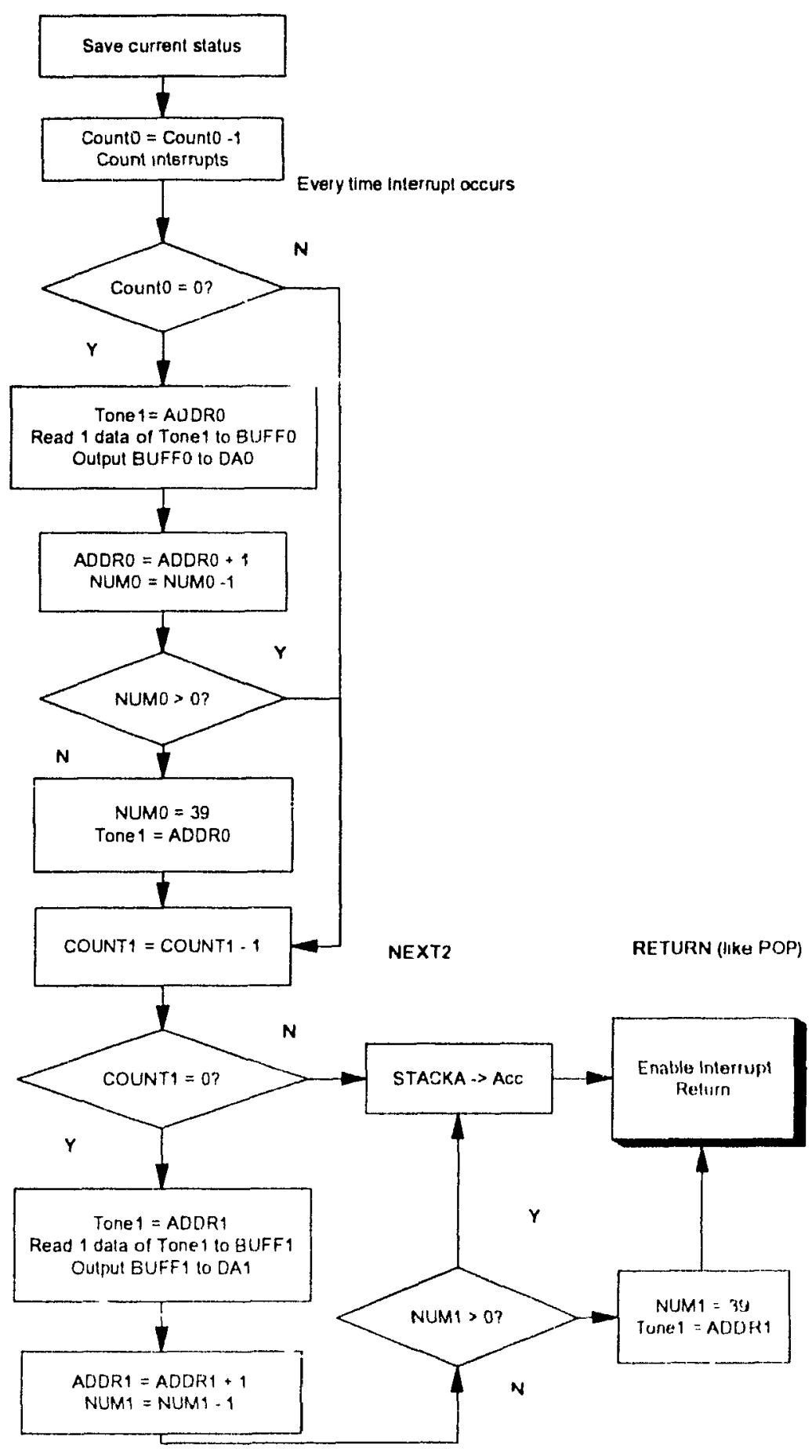

Fig. 5-8 The flowchart of the outputtung subroutine Outpul 


\section{Chapter 6}

\section{Evaluation and Discussion}

The method of evaluation to determine the effectiveness of a technical aid depends upon the type of aid. Generally, the method focuses upon ils specific abilities and performance.

The aids based on cortical stimulation were evaluated by focusing upon what type of electrical stimulation was needed to evoke phosphenes and how points in the cortex were mapped to the visual ficld $(41,42,43)$. P.E.K. Donaldson reported [30] on what type of patterns could be presented to the blind using cortical stimulation.

The reading ands, such as the Optacon or the Kurzveill Reading Machine, were evaluated by focusing upon the legibinty requirements of the: 
aids, and upon the reading rates subjects could achieve with them $[44,6,8,9]$.

The mobility aids, such as the Nottingham Obstacle Detector [45.46] and the Sonic Guide 147,37$]$, were evaluated to determine whether subjects can successfully navigate with them.

The procedures used to evaluate tactile stimulation devices that allow image perceptions were varied. In addition to the physiological studies that attempted to determine the best methods of stimulation $[17,48,49,50,51]$, there have been studies on how effective these aids were in allowing mobility [52,53], and the perception of block letters and object shapes $[16,33,54]$. One tactile stimulation aid was evaluated on its ability to help congenitally blind students conceptualize spatial relations [55].

In designing the method of evaluation for the present image perception aid. several types of images were considered for presentation to the subjects. It was decided not to use block letters, because images of this type are more meaningful for reading aids. It was decided not to use real images, because they would be too complex for subjects to perceive in this prehmmary study. Finally, it was decided to use geometrical shapes to evaluate the perceptual ability of subjects using this aid. The use of geometrical shapes, such as triangles or squares, would allow the subjects to be intually presented with simple shapes to perceive. As their ability improved after a few trials, they could be presented with more difficult 
shapes. After sufficient training. the subjects could presumably commence using the aid with complex shapes found in the real world.

In this project, a study was undertaken to determine how fast and accurately subjects can perceive different images, and how the time required for perception changes with increased experience.

\subsection{Methods}

The evaluation consisted of two parts. The first part was considered as a training period in which the subjects were explained how to use the aid. Six sets of 4 binary images were presented to the subjects for familiarization in sessions 1 to 6 . In later testing sessions, four images of three and four gray levels per session were presented.

The choice of using four images in each session was due to time and fatigue considerations. For some subjects, a thirty-minute experinental session led to poor results near the end of the session due to faligue Hence, in order to avoid the effects of fatigue, the subject was allowed to take a break of five to ten minutes at the end of each four-image session

The second part of the evaluation was considered as a testing period It consists of nine sessions (i.e., sessions 7 to 15) of three- and then fourgray-level images. During each session, four imagus of multi-gray level superimposed shapes were presented for perception. The results from this 
part of the evaluation were used to determine how accurate the subjects were at perception, and how the time needed for the perception changed with increased experience.

Sixteen subjects participated in the evaluation. Ten of them are sighted volunteers three undergraduate students, two economists, three engineers, one computer scientist, and one Canadian Armed Forces officer, aged from 20 to 35 . The remaining 6 subjects are blind-from-birth, aged from 22 to 52. The preparations for these two groups of subjects were completely different. The sighted subjects required more training concerning how the tactıle method can provide them with visual information. whereas the blind subjects needed more training concerning the geometrical shapes. To train the blind-from-birth subjects, ten geometrical shapes differing in size and type (i.e, outlined or filled) were cut from cardboard and stacked on a large piece of board to serve as samples. Thus, the blind-from-birth subjects could experiment with how the geometrical shapes appear. For the sighted subjects, they could learn how a tactile method could provide the visual information. When using the aid, the sighted subjects were blindfolded.

When a subject scans an outlined shape. the audio stimulus is provided when the finger probe is on the sutline only. On the other hand, when scanmung a filled shape, stimulus is provided if the finger probe is on any filled part of the image. 
Before the start of a session. the subject was su:aled in front of the Hit Pad tablet. The seating position of the subject is important. First. the subject was seated with his/her waist at the level of the lablet to avoid having fatigue after one or two sessions. Second, the subject should not be too close to the tablet in order to provide freedom of hand movement while scanmms on the tablet. Many subjects preferred a position where their arms were partially stretched to reach the tablet Two probes were altached under each index finger of the subjects by using the electric tape. Before commencing each training session, the subject would adjust the intensity of the auditory stimulus to a comfortable listening level.

During a session, the subject was presented with the images to be perceived $\mathrm{He}$ or she would take as much time as needed to accurately determine what was in each image. After scanning and perceiving an image. the subject told the system operator to stop the timer. Then, the blindfolded sighted subject was asked to sketch the image, describe the shapes percelved, and identify the gray level of each shape The bind-from-birth subjects described verbally what they percesved The ume required to determme the content of the image, as indicated by the computer, was also recorded.

After the subject had drawn (or described) what had been percelved. the subject was told the actual shapes and gray levels 11 the riage, and the time that he or she spent. If the subject felt tured in any circumstance, he or she could ask the system operator to stop the experiment and take a break. 
During the trainıng perind, subjects were allowed to re-scan images, in case of error, to become familiar with the system.

Throughout the experiment, subjects were encouraged to use several techniques that aided to acquire information in scanning. There are essentially three methods that can help perceive an mage rapidly:

1. At the beginning of each image presentation, the subject was encouraged to quickly scan with both probes, one on each hand, across the tablet from the top to the bottom, and from the left to the right of the tablet to hear the output sounds. These sounds can provide information about the contents of the image, such as the number of different gray levels (different sounds), and the type of the shapes (t.e., filled or outhned).

2. The subject was encouraged to follow a line or an edge by quickly moving the two finger probes back and forth over the line or edge, as opposed to trying to track it by keeping the finger probe above it.

3. By makıng use of the square grid lines on the tablet surface, the subject can feel with the finger probes (and other fingers) the vertical and the horizontal edges. The grid lines also served to determme the distances and the orientation of the scanning.

Most of the subjects used these three suggested methods together during their tranning and testung sessions to percerve images. The results, to be presented in the later sections, showed that the subjects can perceive 
much faster by using all three rather than only one or two of the suggested methods described above

\subsection{Computer Generation of Test Images}

A menu-driven computer program named Gen_Pic.C was wrillen in the $\mathrm{C}$ programming language to generate mult-gray level test mages The listing of Gen_Pic.C is provided in the Image-Perception Aid User's Manual [36]. Each image was stored in an array of $40 \times 40$ pixels Each element in the image array was intually set to 0 When it is desired to store a point at a particular location, the corresponding element is set to the gray level representation specified by the user.

The program offers the user two methods of generating images. The first method allows simple closed shapes such as polygons or circles to be generated if a polygon is desired, the user must mput the $(x, y)$ comrlinates of each vertex in the polygon. Each coordmate must fall in the range (0-40) To create the desired shape, each vertex un the mage is commected to the preceding one by stormg the gray level representation along a line between the two vertices The line is computed using the Bresenham lme drawng algorithm [56]. The same procedure is used to conned the last verlex to the first, resultung in a closed polygon The program also allows the generation of circles. In this case, the user must imput the desired location of the center of the circle, and the desired radius The program then calculates a set of $x$ 
and $y$ coordinates, and stores the desired gray level representation in image locations corresponding to the circumference of the circle.

The second method of creating images allows the user to create more complex images by using the computer graphics Lablet, the Bit Pad One. As a finger probe (used as a pen) is passed over the tablet surface, (x, y) coordinate pairs are generated and transmitted to the computer. These coordinates are in the range $0-2200$ By scalng with a factor of 55 , the transmitted coordnates can be mapped to the $40 \times 40$ image array. As the probe passes over a point on the tablet, the corresponding point in the image array is set to the desired gray level representation. This process continues untul the user presses a key on the computer keyboard.

The computer program also allows a user to load and store previously created images, and to create filled shapes.

\subsection{Initial Training}

\subsubsection{Images Used}

The mages that were presented during the first six sessions of the initial trainmg period are shown in Fig. 6-1. Each row in the figure shows the fmages presented in a particular session. The images used during the traming are only bunary (i.e.. 2 gray levels). They consist of triangles and squares of different sizes, form and location on the Bit Pad One (BPO). In 
order to facilitate image reference, a number is assigned to each inage in the figure instead of its name Thus, the images are numbered from 1 to 24 Furthermore, when ordermg the mages for presentation, we do not present the same mage twice in the same session, and alternate between filled and outlined figures.

\subsubsection{Results}

The details of the results from the initial traning are provided in Appendix D. When a subject incorrectly reproduced an image, the recorded time is noted with an asterisk $\left(^{*}\right)$ in the table. Table 6-1 shows the lowest. the highest and the average tume needed. measured in soconds. for the blindtolded sighted subjects to percerve the seven different inmgess in Fig. 6-1 for the first and the second trial Table 6-2 provides the same intormation from the results of the blind-from-birth subjects.

Fig. 6-2 shows the graph of the time required for the blindlolded sighted subjects to perceive a particular binary image in the first and second trial. Fig 6-3 shows the graph of the tume required for the blund-from-birth subjects to perceive the same mages in the forst and second trial The fime used by the subjects for a specific image for the first trial is represcinted by a thick bar. For the second tual, the ume is represented by a thm bar. The (op) and the bottom of the line represent the maxmum and the munmmm time required to percenve a particular image, respectuvely The mumus sign "-" attached to the line represents the average tume. Both graphs show that the 
Session 1
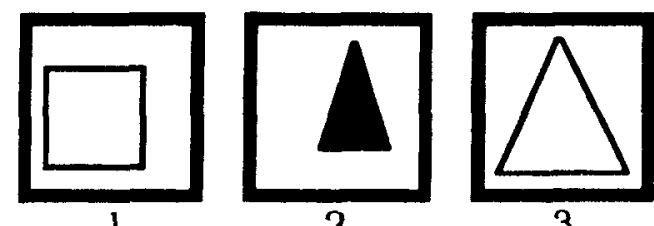

2 Session 2
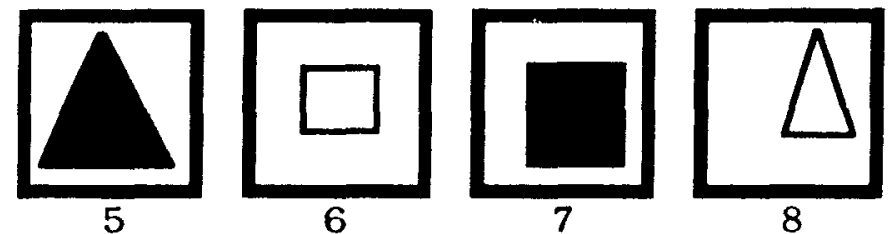

Session 3

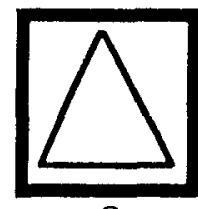

9
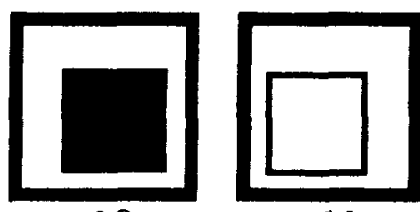

11

Session 4

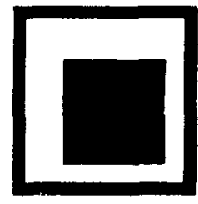

13
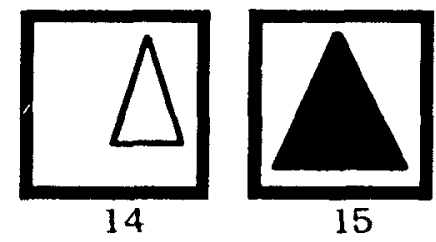

15

Session 5

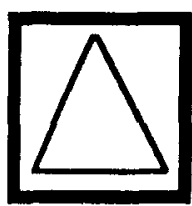

17

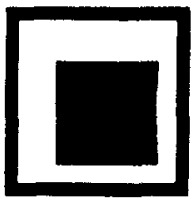

21

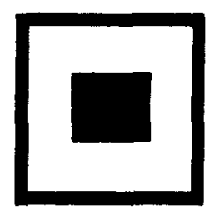

18

Session 6


Fig. 6-1 The binary amages used for the traning period. 
subjects took a shorter time to perceive an image that has already been presented in a previous session This could imply that the subjects have become familiar with the device and have learned to scan images in a more effective fashion.

Table 6-1 Time (in seconds) required for the ten blindfolded sighted subjects to perceive seven different images during training

\begin{tabular}{|c|c|c|c|c|c|c|}
\hline \multirow[t]{2}{*}{$\begin{array}{c}\text { Image } \\
\text { Number }\end{array}$} & \multicolumn{3}{|c|}{$\begin{array}{c}\text { 1st } \\
\text { Trial }\end{array}$} & \multicolumn{3}{|c|}{$\begin{array}{c}\text { 2nd } \\
\text { Trial } \\
\end{array}$} \\
\hline & Lowest & Highest & Average & Lowest & Highest & Average \\
\hline 1 & 39 & 92 & 70.3 & 39 & 78 & 568 \\
\hline 2 & 48 & $113^{*}$ & 76.6 & 37 & 81 & 538 \\
\hline 3 & 30 & 90 & 67.8 & 29 & 70 & 551 \\
\hline 4 & 30 & 103 & 632 & 27 & 86 & 588 \\
\hline 5 & 52 & 137 & 79.4 & 32 & 74 & 494 \\
\hline 6 & 33 & 122 & 693 & 20 & 77 & 510 \\
\hline 8 & 30 & 109 & 75.9 & 38 & 92 & 61.9 \\
\hline
\end{tabular}

${ }^{*}$ ) denotes that the subject did not perceive the inage correctly

Lowest. Highest and Average indicate respectively the mumum, the maximum, and the average time required to percesve images.

In addition, the average times required by the blind-from-birth subjects to perceive an image for the second trial are approxmat(ely 20) seconds shorter than the time required by the blundfoldeol shghted subjects. These data are graphed and shown on Fig 6-4. This may be due to the developed tactule ability of the blind-from-birth subjects after years of using bralle compared to the sighted subjects' long standing dependence upon their eyes. 
Table 6-2 Time (in seronds) required for the six blind-from-birth subjects to perceive seven different images during training.

\begin{tabular}{|c|c|c|c|c|c|c|}
\hline \multirow[t]{2}{*}{$\begin{array}{l}\text { Image } \\
\text { Number }\end{array}$} & \multicolumn{3}{|c|}{$\begin{array}{c}\text { 1st } \\
\text { Trial } \\
\end{array}$} & \multicolumn{3}{|c|}{$\begin{array}{l}\text { 2nd } \\
\text { Trial } \\
\end{array}$} \\
\hline & Lowest & Highest & Average & Lowest & Highest & Average \\
\hline 1 & 21 & 65 & 48.0 & 16 & 65 & 33.8 \\
\hline 2 & 23 & 52 & 36.2 & 13 & 40 & 31.8 \\
\hline 3 & 37 & 80 & 500 & 17 & 44 & 32.5 \\
\hline 4 & 17 & 65 & 38.0 & 17 & 58 & 35.0 \\
\hline 5 & 18 & 45 & 35.7 & 18 & 40 & 29.0 \\
\hline 6 & 30 & 65 & 47.7 & 11 & 45 & 31.0 \\
\hline 8 & 25 & 54 & 41.3 & 13 & 59 & 38.0 \\
\hline
\end{tabular}

Lowest, Highest and Average indicate respectively the minimum, the maximum, and the average time required to perceive innages.

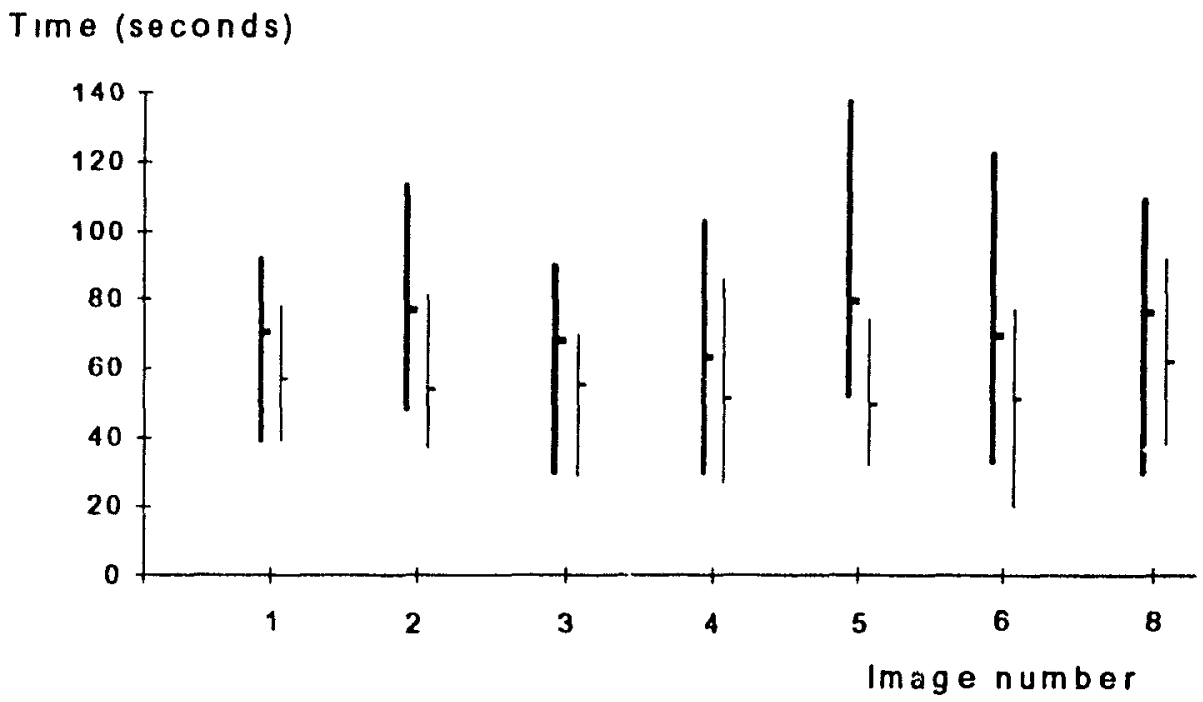

Fig. 6-2 The time requured by the blindfolded sighted subjects to percenve a particular binary image in the first trial (thick bar) and the second trial (thin bar). (-) shows the average time. 
Time (seconds)

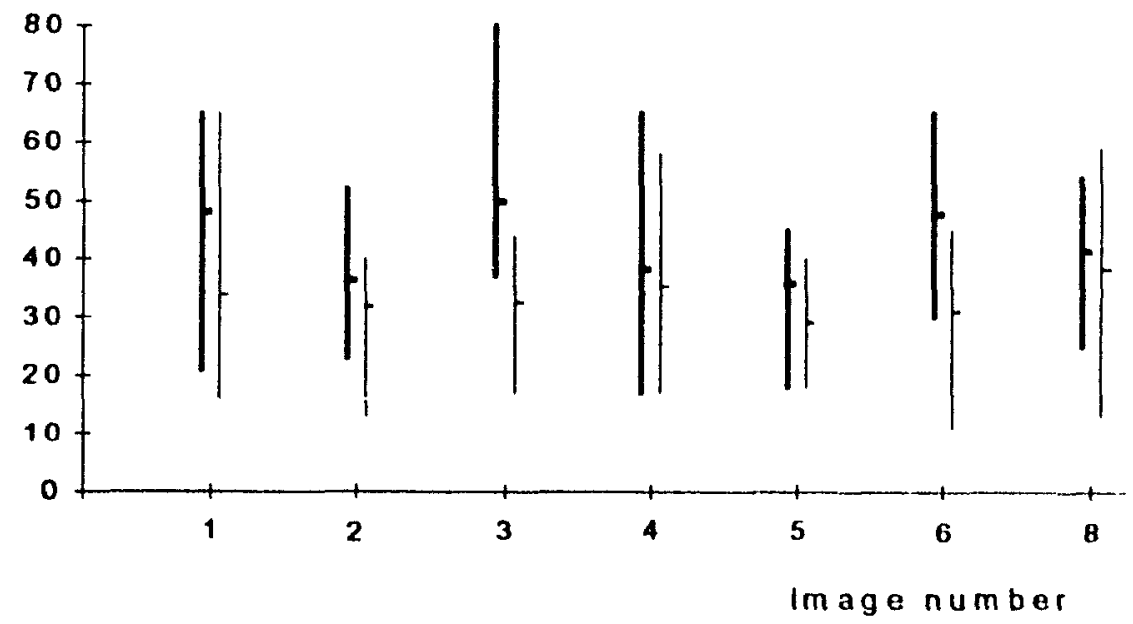

Fig. 6-3 The time required by the blind-from-birth subjects to perceive a particular binary image in the first trial (thick bar) and the second trial (thin bar). ( - ) shows the average tme.

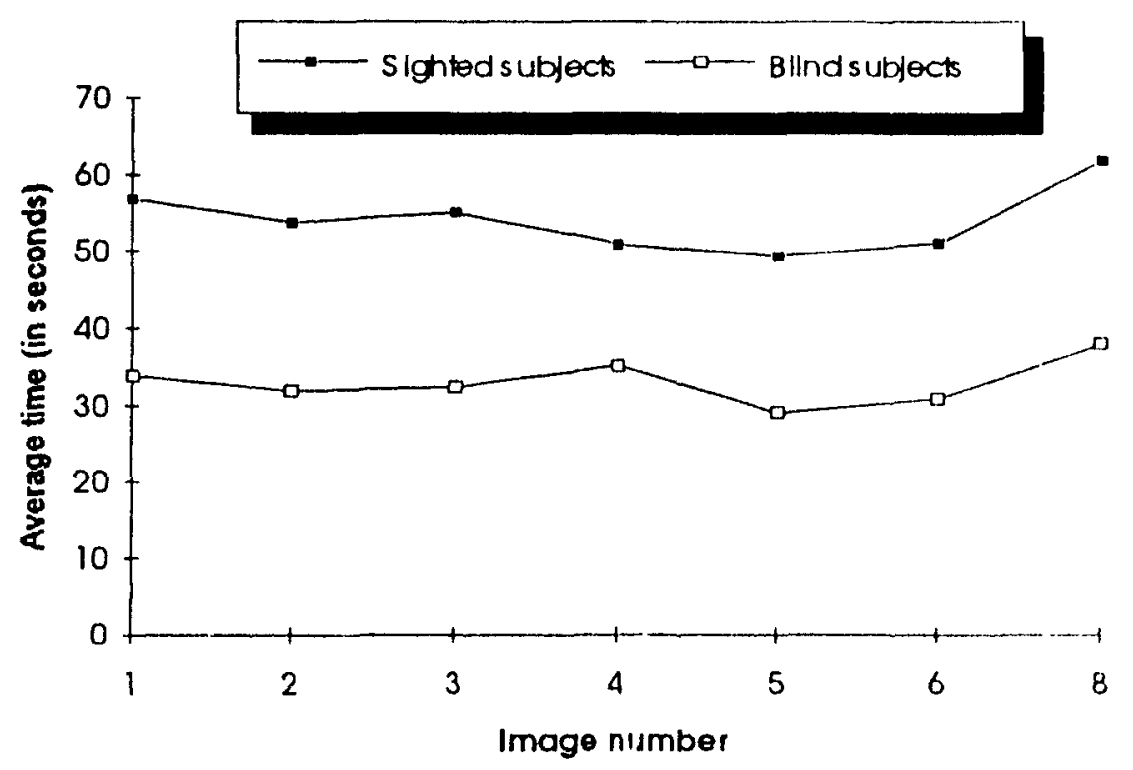

Fig. 6-4 The average time requared by the group of blundfolded sighted subfer is compared with the average tme required by the group of bhnd-frombirth subjects to perceive the binary mages at the second prescontation 
The goal of the initial training was to introduce the subjects to the use of the aid, but not to collect data for an in-depth analysis. Since this goal has been reached, a more elaborate testing paradigm was introduced and described in the following section.

\subsection{Testing of Subjects}

\subsubsection{Test Images}

Thirty-six images that were used for testing are shown in the Fig. 6-5 and Fig. 6-6. The first group, from session 7 to session 11 shown in Fig. 6-5. contains the images with 3-gray-levels and superimposed simple geometrical shapes. Each shape has a different gray level except for image number 25 of session 7, which has a small outlined square inside a large outlined triangle. Both shapes are binary. This image is designed especially for the beginning of session 7 to allow the subjects to have an experience with superimposed shapes before different gray levels. The subjects were accustomed to only one tone while scanning the binary images. However, the concept of different gray levels is not difficult to introduce since the gray levels are represented by different tones. The last group, from session 12 to session 15 shown in Fig. 6-6, contains the images with 4-gray-levels.

The images are arranged with the more difficult shapes occurring during the later sessions because it was desired to have the subjects as familiar as possible with the use of the device before having them perceive 
these irregular shapes. The images are also alternated between outlined and filled, then between simple and irregular shapes to avold grouping, such as shown in sessions 14 and 15 of Fig. 6-6.

\subsubsection{Test Results}

The details of the test results are provided in Appendix E. Table 6-3 displays the lowest, the highest and the average time, in seconds, needed for the blindfolded sighted subjects to perceive the images presented for the first and the second trial. Table 6-4 displays the results for the blind-from-birth subjects under the same conditions.

The data in Tables 6-3 and 6-4, are graphed in Figs. 6-7 to 6-10. Fig. 6-7 and Fig. 6-8 show the lowest, the highest and the average time, in seconds, required for the blindfolded sighted and the blind-from-birth subjects to perceive each 3-gray-level image. The time used by the subjects for a specific image is represented by a thick bar. The top and the bottom of the line represent the maximum and the minimum time reguired to perceive a particular image, respectively. The minus sign "-" atlached to the line represents the average time. The same manner of presentation is used in Fig. 6-9 and Fig. 6-10 to graph the time required for the two groups of subjects to percelve each 4 -gray-level image. 
Session 7
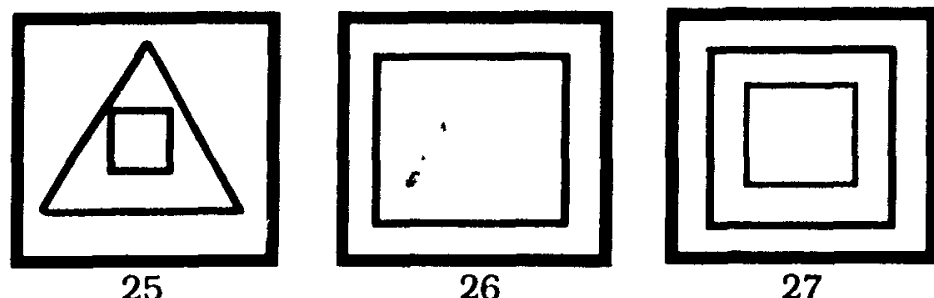

27

Session 8
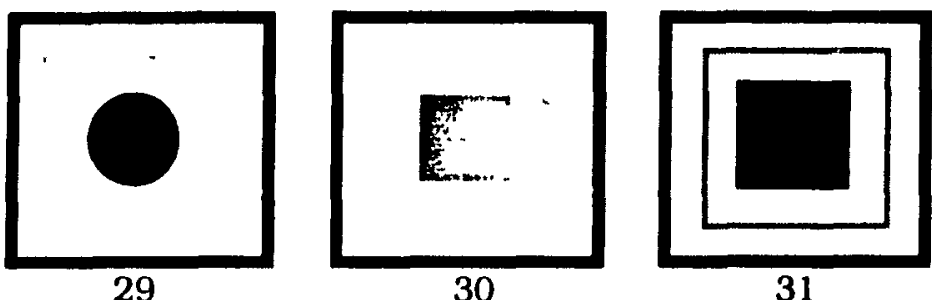

31

Session 9

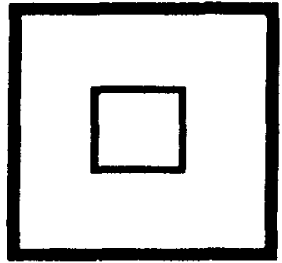

33

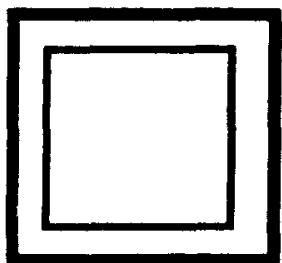

34



35

Session 10

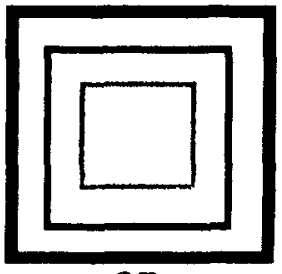

37

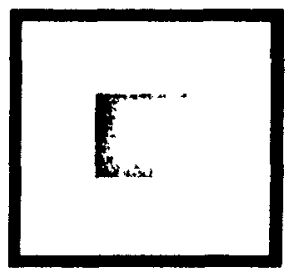

38

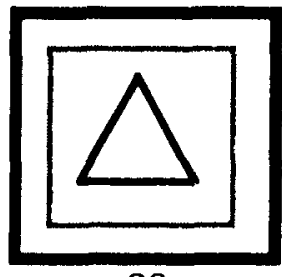

39

Session 11

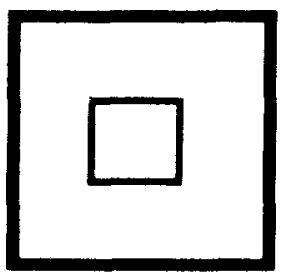

41

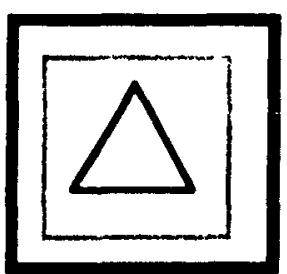

42

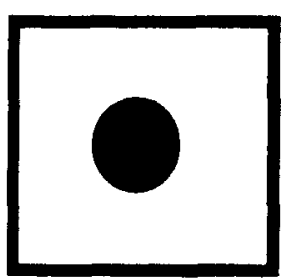

43
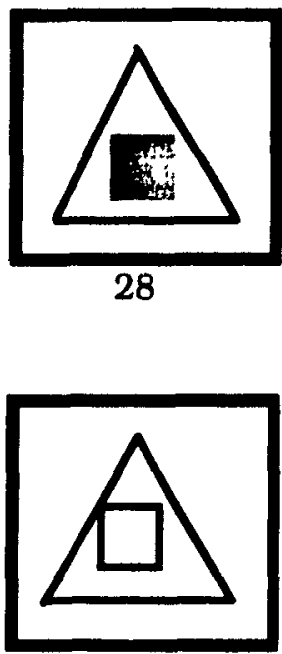

32

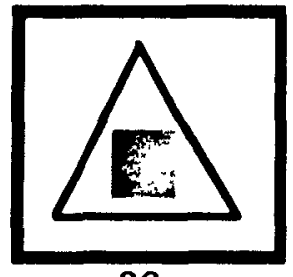

36

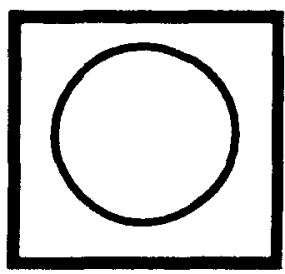

40

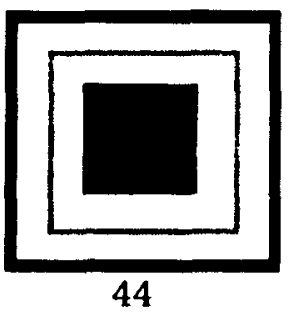

Fig. 6-5 The 3-gray-level images used for the testing 
Session 12

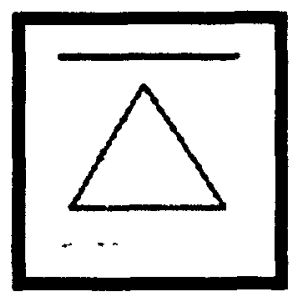

45
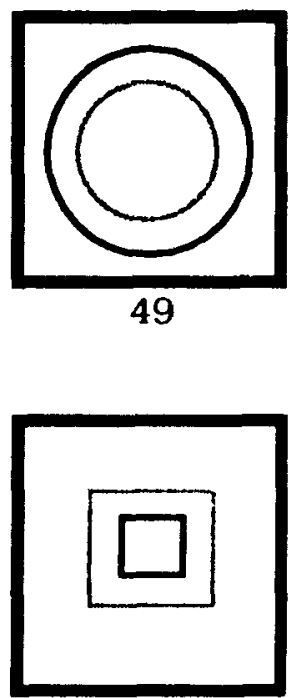

53

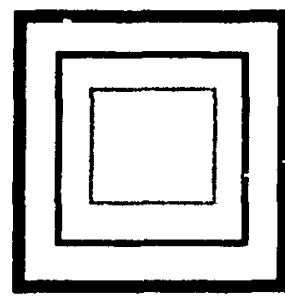

57

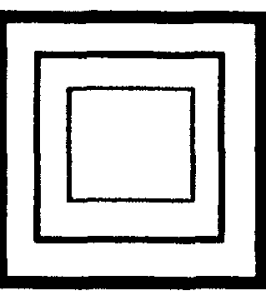

46

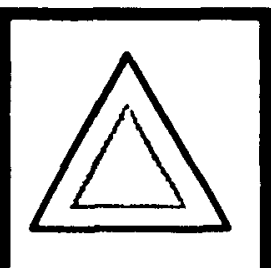

50

Session 14

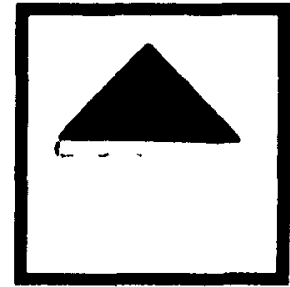

54

Session 15

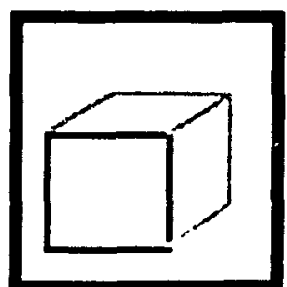

58

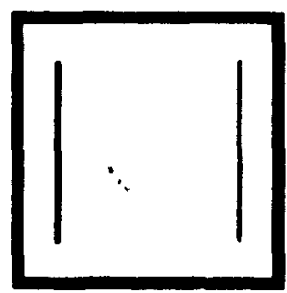

47

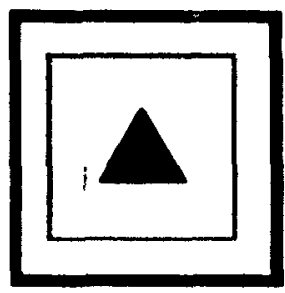

51

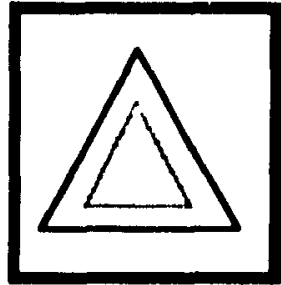

55

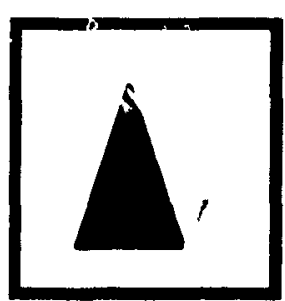

59

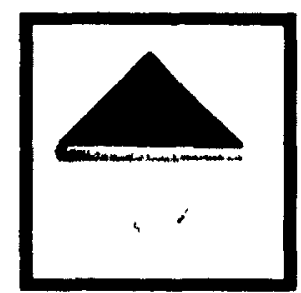

48

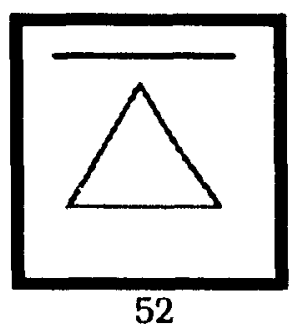

52

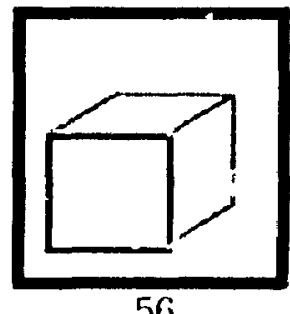

56

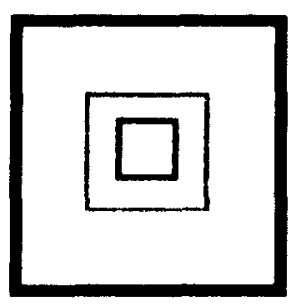

60

Fig. 6-6 The 4-gray-level images used for the testing 
Table 6-3 Time (in seconds) required for the ten blindfolded sighted subjects to perceive the 3- and 4-gray-level images.

\begin{tabular}{|c|c|c|c|c|c|c|}
\hline \multirow[t]{2}{*}{$\begin{array}{l}\text { Image } \\
\text { Number }\end{array}$} & \multicolumn{3}{|c|}{$\begin{array}{c}\text { 1st } \\
\text { Trial } \\
\end{array}$} & \multicolumn{3}{|c|}{$\begin{array}{l}\text { 2nd } \\
\text { Trial } \\
\end{array}$} \\
\hline & Lowest & Highest & Average & Lowest & Highest & Average \\
\hline 25 & 72 & 157 & 100.1 & 58 & 99 & 81.7 \\
\hline 26 & 46 & 116 & 80.7 & 55 & 87 & 73.8 \\
\hline 27 & 50 & 91 & 68.3 & 42 & 81 & 55.8 \\
\hline 28 & 62 & 111 & 86.5 & 60 & 83 & 69.8 \\
\hline 29 & 53 & 110 & 75.4 & 50 & 82 & 63.6 \\
\hline 30 & 70 & 146 & 98.2 & 27 & 87 & 68.2 \\
\hline 31 & 60 & 96 & 67.9 & 31 & 64 & 50.0 \\
\hline 33 & 53 & 108 & 80.6 & 24 & 95 & 66.0 \\
\hline 35 & 70 & 94 & 83.2 & 60 & 100 & 79.2 \\
\hline 39 & 60 & 96 & 74.6 & 33 & 76 & 57.7 \\
\hline 45 & 46 & 102 & 76.2 & 32 & 80 & 53.4 \\
\hline 46 & 87 & 141 & 111.1 & 58 & 98 & 76.4 \\
\hline 48 & 69 & 145 & 87.4 & 21 & 76 & 55.5 \\
\hline 50 & 66 & 115 & 92.6 & 44 & 90 & 64.7 \\
\hline 53 & 56 & 136 & 87.3 & 72 & 112 & 82.8 \\
\hline 56 & 87 & 156 & 116.6 & 39 & 112 & 79.8 \\
\hline
\end{tabular}

Louest, Highest and Average indicate respectively the minimum, the maximum, and the average time required to perceive images. 
Table 6-4 Time (in seconds) required for the six blind from-birth subjects to perceive the 3-and 4-gray-level images.

\begin{tabular}{|c|c|c|c|c|c|c|}
\hline \multirow[t]{2}{*}{$\begin{array}{c}\text { Image } \\
\text { Number }\end{array}$} & \multicolumn{3}{|c|}{$\begin{array}{c}\text { Ist } \\
\text { Trial } \\
\end{array}$} & \multicolumn{3}{|c|}{$\begin{array}{l}\text { 2nd } \\
\text { Trial }\end{array}$} \\
\hline & Lowest & Highest & Average & Lowest & Highest & Average \\
\hline 25 & 52 & 89 & 62.5 & 45 & 80 & 54.8 \\
\hline 26 & 45 & 76 & 57.0 & 43 & 66 & 52.8 \\
\hline 27 & 38 & 80 & 56.5 & 37 & 58 & 48.0 \\
\hline 28 & 45 & 100 & 63.3 & 41 & 68 & 61.0 \\
\hline 29 & 62 & 110 & 85.5 & 52 & 86 & 74.0 \\
\hline 30 & 53 & 93 & 74.5 & 53 & 90 & 700 \\
\hline 31 & 30 & 73 & 56.3 & 25 & 70 & 47.3 \\
\hline 33 & 41 & 109 & 84.2 & 35 & 93 & 69.5 \\
\hline 35 & 70 & 95 & 79.3 & 41 & 78 & 63.0 \\
\hline 39 & 34 & 81 & 64.8 & 28 & 74 & 560 \\
\hline 45 & 113 & 150 & 132.2 & 44 & 135 & 865 \\
\hline 46 & 84 & 99 & 87.0 & 74 & 90 & 81.2 \\
\hline 48 & 67 & 107 & 92.6 & 60 & 92 & 753 \\
\hline 50 & 81 & 122 & 102.5 & 69 & 96 & 797 \\
\hline 53 & 82 & 106 & 94.0 & 77 & 93 & 870 \\
\hline 56 & 158 & 230 & 193.5 & 130 & 194 & 1680 \\
\hline
\end{tabular}

Lowest. Highest and Average indicate respectuvely the munimum, the maximum, and the average time required to percerve images.

The graphs in Fig. 6-7 to Fig. 6-10 show that the subjects always perceived the images faster at the second presentation than at the first presentation. This is due to the experience obtained and the improved scanning ability with this technical and. 
$\operatorname{Time}(\operatorname{seconds})$

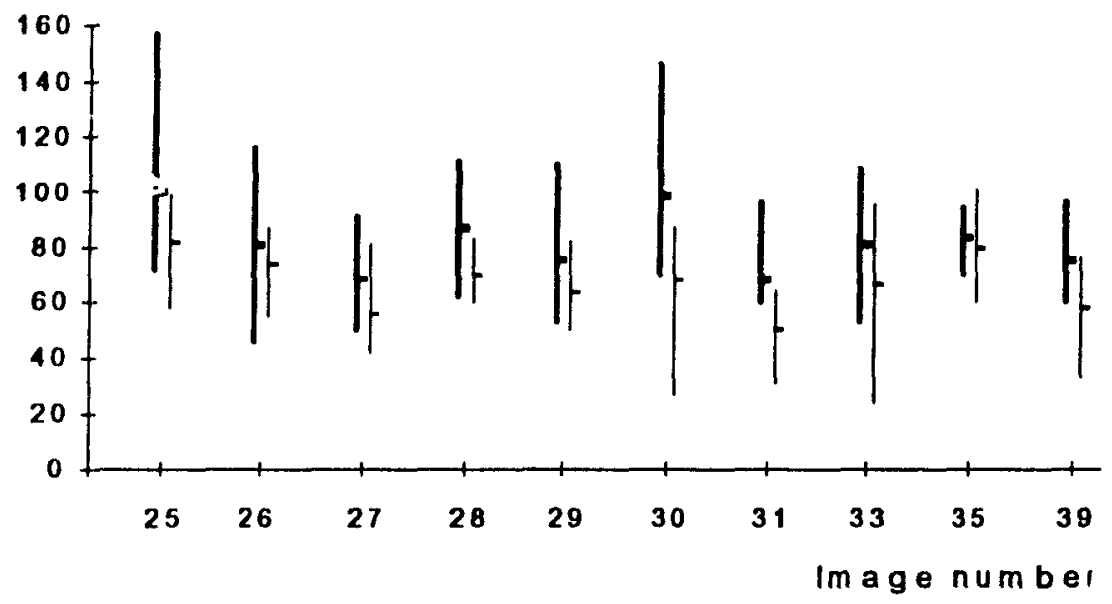

Fig. 6-7 The tume required by the blindfolded sighted subjects to perceive a particular 3-gray-level image in the first trial (thick bar) and the second trial (thin bar). (-) shows the average time.

Time (seconds)

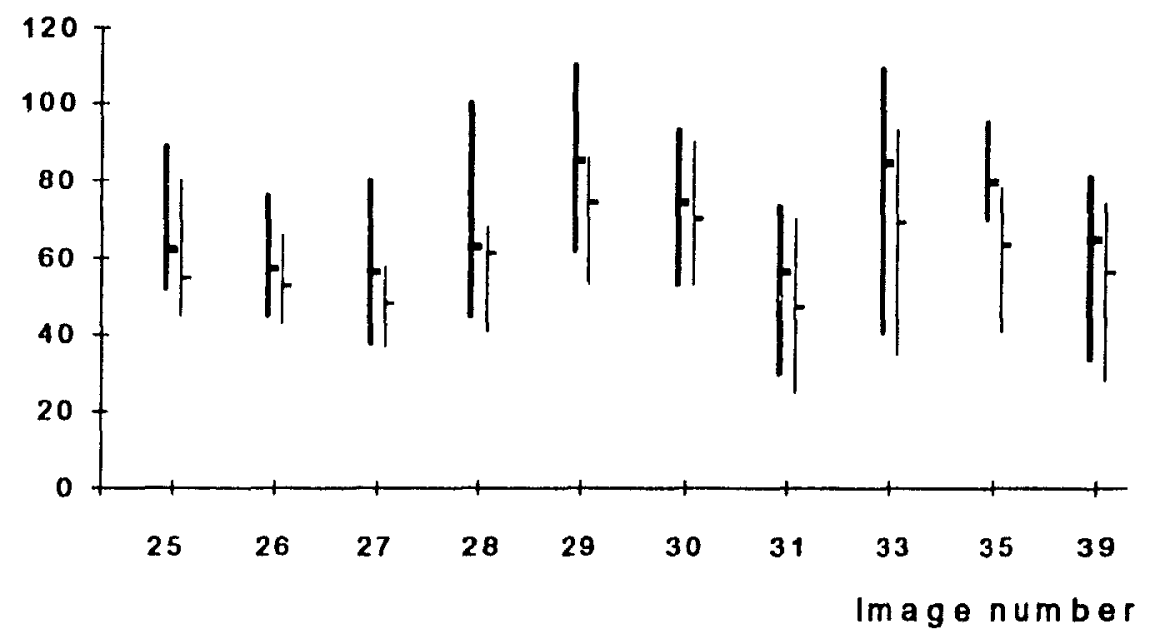

Fig. 6-8 The time required by the blind-from-birth subjects to perceive a particular 3-gray-level image in the first tnal (thick bar) and the second trial (thin bar). (-) shows the average time. 
Time (seconds)

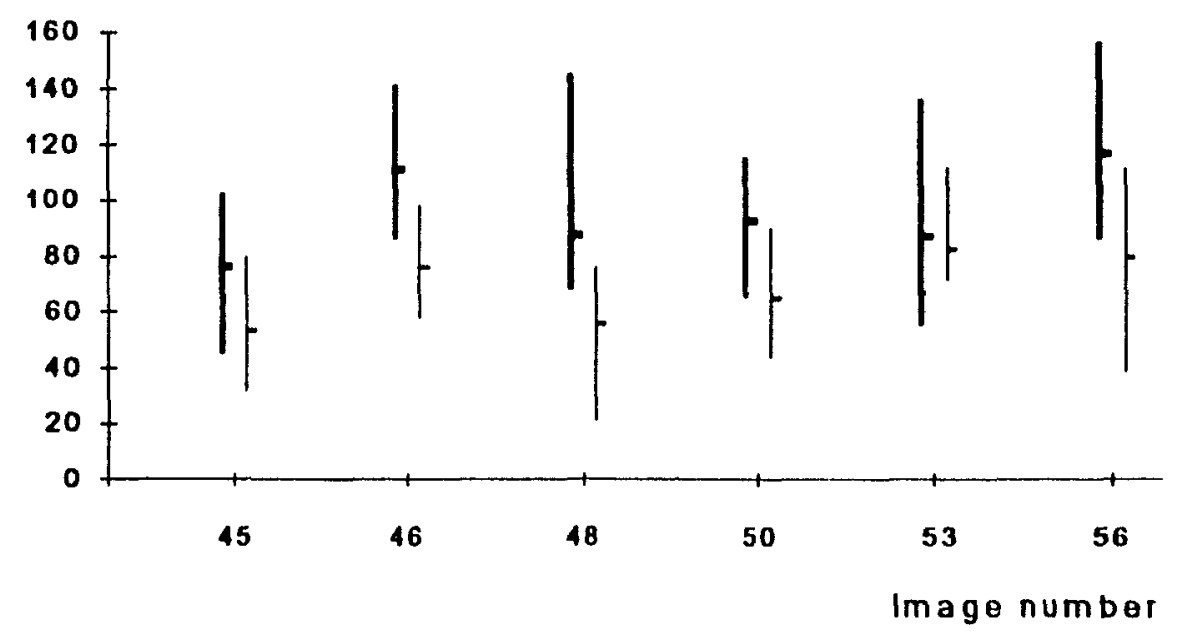

Fig. 6-9 The tume required by the blindfolded sighted subjects to percelve a particular 4-gray-level image in the first trial (thick bar) and the second trial (thin bar). (-) shows the average time.

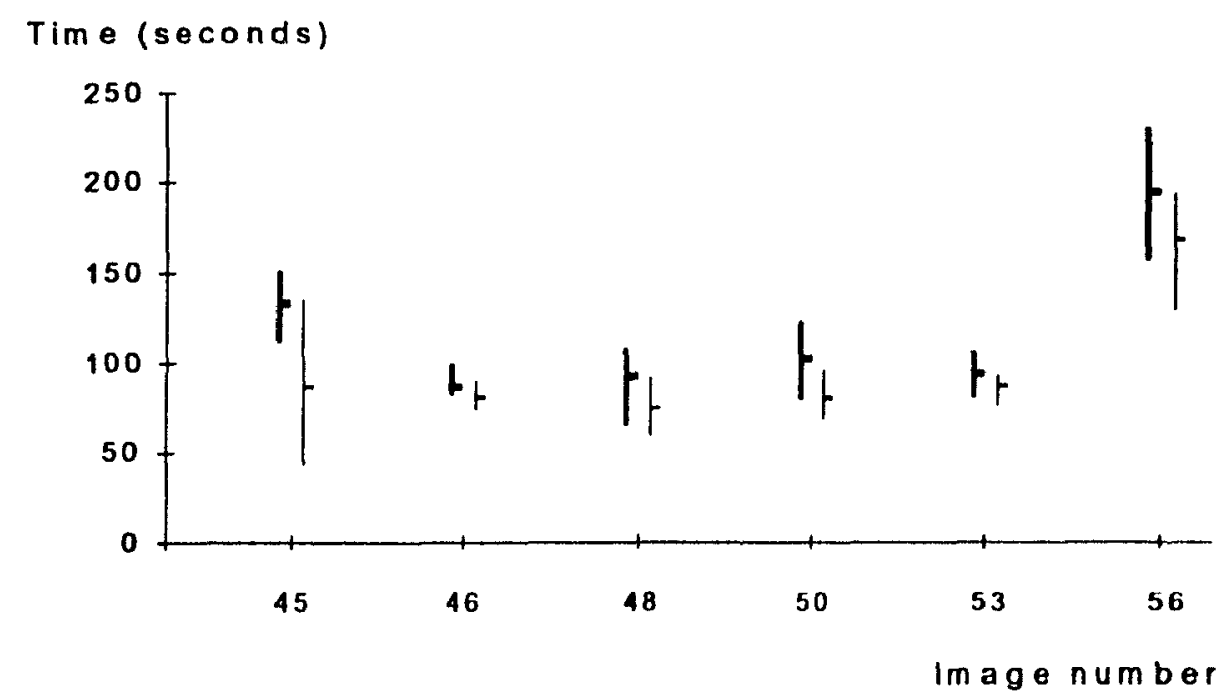

Fig. 6-10 The time required by the blind-from-birth subjects to perceive a particular 4-gray-level image in the first tral (thick bar) and the second tral (thin bar) (-) shows the average tume. 
For the 3-gray-level images, the average times of the blind-from-birth and blindfolded sighted subjects at the second presentation are graphed in Fig. 6-11 in order to compare the performance of these two groups of subjects. The graph tends to show that the blind-from-birth subjects in general have taken a shorter time to perceive the images than the blindfolded sighted subjects. In the case of the three images numbered 29 , 30 and 33, the blind-from-birth subjects have taken slightly more time than the blindfolded sighted subjects. This is due to the superimposed shapes of square and circle. To avoid potential errors, most of the blind-from-birth subjects have scanned the image more than once to verify the differences between both shapes.

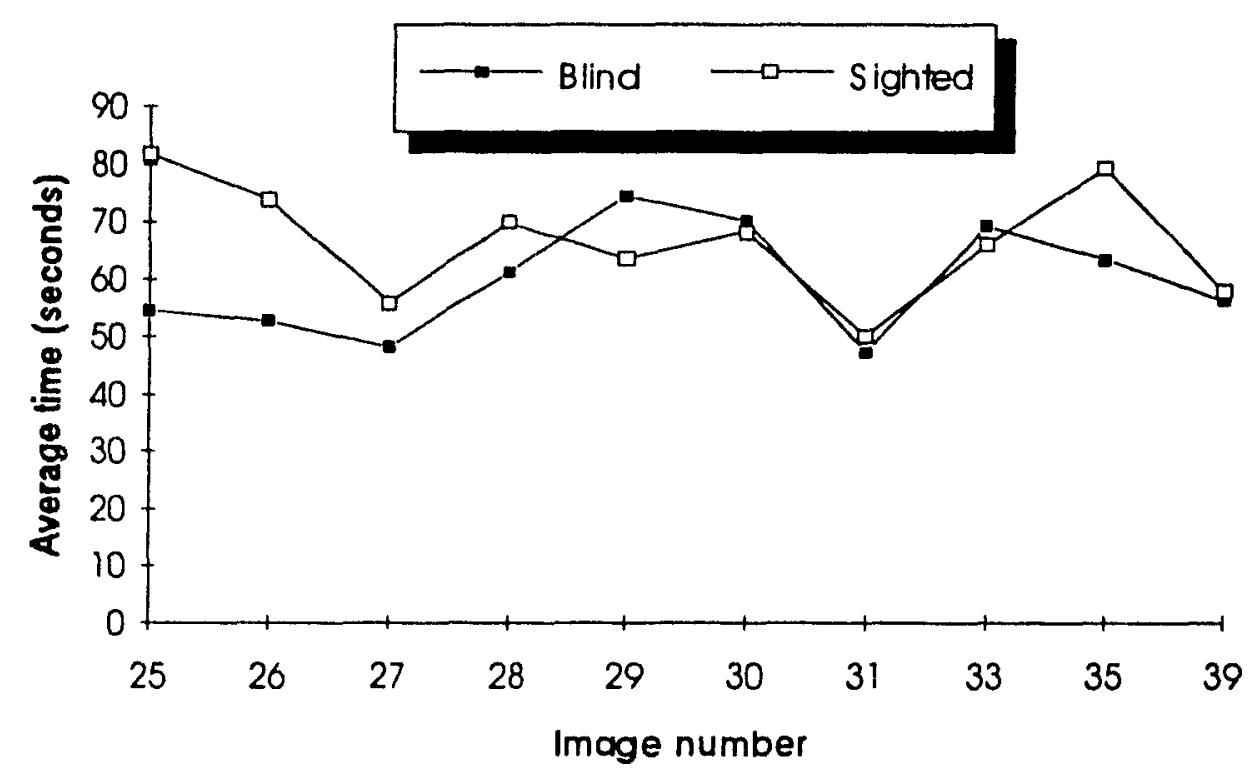

Fig. 6-11 The average time required for the blind-from-birth and the blindfolded sighted subjects to perceive the 3-gray-level images presented in the second trial. 
In the case of 4-gray-levels, the average times required for the blindfrom-birth and the blindfolded sighted subjects to percelve a particular image are also graphed in Fig. 6-12 to compare the performance between these two groups of subjects.

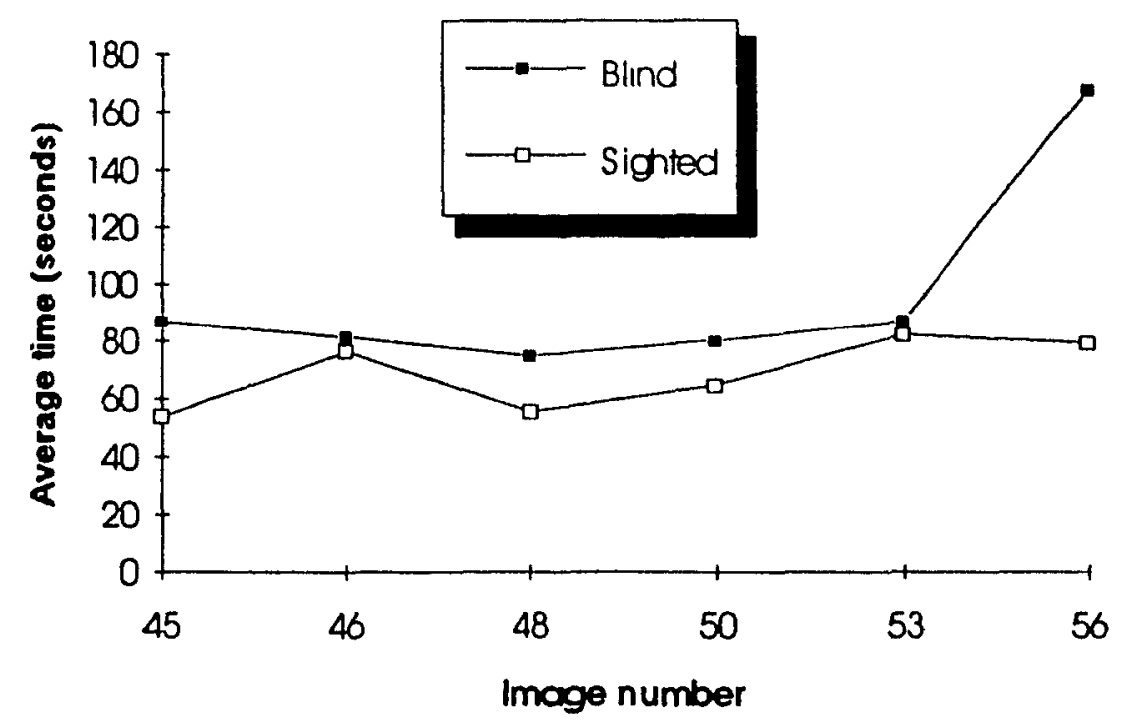

Fig. 6-12 The average time required for the blind-from-birth and the blindfolded sighted subjects to perceive the 4-gray-level images presented at the second trial.

The graph of Fig 6-12 shows the reverse trend The average limes required by the blind-from-birth subjects to perceive an image for the second trial are slightly longer than the average tme required by the blindfolded subjects. This may be due to the unusual images contaned in the later sessions. The blind-from-birth subjects tend to try to understand the scanned images before telling the system operator to stop the tumer because they are afraid of not being able to describe the scanned magge to the operator. Thus, sometmmes they scanned the same mage twice or even three times. For the case of image number 56, it is a partially filled cube. The blind-from-birth subjects took almost twice the time needed by the 
blindfolded sighted subjects. Since they are all blind-from-birth, they did not understand how a 3-dimensional cube was represented in a 2-dimensional plan. However, only after their correct descriptions of the perceived image, a real partially filled cube object (i.e., box) was presented to them for touching, Then, they were very happy to be able to visualize, for the first time in their life, a cube in the 2-dimensional plan.

At the later sessions of 4-gray-level images, both blind-from-birth and blindfolded sighted subjects aie considered to be familiarized with the technical aid. Four complex images were presented only once in the later sessions in order to evaluate the perceptual ability of subjects in each group. Table 6-5 shows the results of the lowest, the highest and the average time required for the blind-from-birth and blindfolded sighted subjects to perceive the 4-gray-level complex images presented only once durng the testing period These times are graphed in Fig. 6-13.

Table 6-5 Time (in seconds) required for the blind-from-birth and blindfolded sighted subjects to perceive the 4-gray-level images presented only once.

\begin{tabular}{|c|c|c|c|c|c|c|}
\hline \multirow{2}{*}{$\begin{array}{l}\text { Image } \\
\text { Number }\end{array}$} & \multicolumn{3}{|c|}{ Blind } & \multicolumn{3}{|c|}{ Sighted } \\
\hline & Lowest & Highest & Average & Lowest & Highest & Average \\
\hline 47 & 74 & 91 & 80.0 & 73 & 101 & 81.8 \\
\hline 49 & 81 & 112 & 88.5 & 81 & 103 & 94.3 \\
\hline 51 & 75 & 96 & 86.0 & 91 & 150 & 108.0 \\
\hline 59 & 103 & 145 & 126.3 & 94 & 169 & 135.8 \\
\hline
\end{tabular}

Lowest. Highest. and Average indicate respectively the minmum, the maximum. and the average tme required to percerve images. 
The graph in Fig. 6-13 shows that the blind-from-birth subjects took a slightly shorter time to perceive the complex 4-gray-level Images than the blindfolded sighted subjects. The time used by the blindfolded sighted subjects for a specific image is represented by a thick bar, and the time used by the blind-from-birth subjects is represented by a thin bar The top and the bottom of the line represent the maximum and the munimum time required to perceive a particular image, respectively This graph also states that after understanding the representation of a cube (i.e . the 3-dimensional object) in a 2-dimensional plan, the blind-from-birth subjects have taken shorter time to perceive another 3-dimensional object (i.e.. the pyramid) than the blindfolded sighted subjects did. The pyramid, image number 59. is presented only once in the last session in order to make sure that the blindfrom-birth subjects understand how a 3-dimensional object can be visualized in 2-dimensional plan.

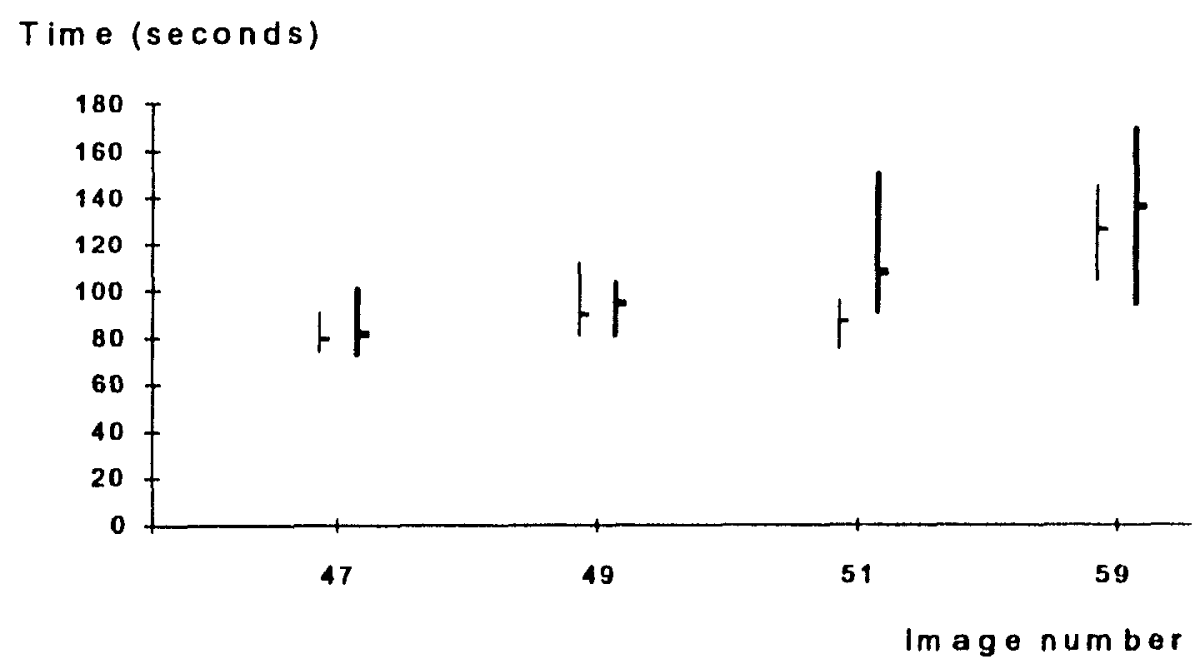

Fig. 6-13 The time required by the blind-from-birth (thin bar) and blindlolded sighted (thick bar) subjects to perceive a particular complex 4-graylevel image presented only once. $(-)$ shows the average time. 


\subsection{Discussion}

The number of subjects who successfully perceived the images, the time required to perceive each particular image, and the decrease in time required as experience increases, are the indications of how successful the aid is.

In this study, 60 images in total were presented to two groups of subjects' Ten blindfolded sighted subjects and six blind-from-birth subjects. Of the 24 bınary images containing squares or triangles that were presented in the training and learning period, only one subject did not perceive one of the shapes correctly in the first trial. Of the 36 images containing more difficult shapes, every subject perceived the images correctly. Thus, there was a high success rate of perception by the blind-from-birth and the blindfolded sighted subjects.

Table 6-1 and Table 6-2 provide an indication of how long the blindfrom-birth and blindfolded sighted subjects require to perceive simple binary images. Note that during the tranng. the blind-from-birth subjects required, on average, less time (approximately 20 secends less) than the blindfolded sighted subjects. This result can be seen from the graphs shown in Fig. 6-4. The reasons for the blind-from-birth subjects perceiving binary images faster than the blindfolded sighted subjects during the training period may be explanned by drawing a comparison with therr daily activities. After years of using braille and adapting to their environments, the blind-from-birth 
subjects may have developed better focus or attention on their tactile and auditory abilities whereas the sighted subjects are heavily dependent upon their eyes for receiving visual information. In brief. the two groups of subjects perceived the binary images in a reasonable time frame The blindfrom-birth subjects needed from 51 to 62 seconds to correctly identily the images in the second trial The blindfolded sighted subjects needed from 63 to 79 seconds to perform the same task.

'The improvement of subjects' skill as their experience with the ald increased can also be studied. In Fig. 6-2 and Fig 6-3, 11 is seen that when subjects perceived images the second tral, the time required was always less than the time required for the first trial durng the training period The data from the test section show similar trends in Fig. 6-7 to Fig 6-10 It is evident that later presentations generally a equire lower perception tumes

A study to determine whether subjects can easily perceive the superimposed outlined and filled shapes in multi-gray levels (i.e. 3dimensional object presented in 2-dimensional planl was also undertaken Referring to Figures 6-7 to 6-12, it is seen that both groups of subjec ts have taken on average from 50 to 87 seconds to correctly ulentufy a partucular 3 or 4-gray-level image Thus, they were able to percelve the mult filly level images without difhculty. Among these images, all bind-from-billu subjects could describe the image of a cube (i e, image \#58) from the scimmmg process whthout knowing that it is a "cube" represented m 2-dmmensmonal plan. They had never learned how a 3-dimensional cube can be presented in 2-dimensional plan However, when a second 3-dimensional ofjere 1. the 
pyramid, was presented for the first time at the end of the last session, the blind-from-birth subjects can perceive the image without difficulty. It is very encouraging to see the technical aid enabling blind-from-birth subjects to perceive a 3-dimensional object in 2-dimensional plan for the first time in their lives. 


\section{Chapter 7}

\section{Conclusion}

\subsection{Summary}

There exist many different types of technical aids for blind persons. These aids can be classified according to their purpose such as for reading, mobility, image perception, and others. Almost all previously reported technical aids for image perception use tactile stimulation. In this report, the design, implementation, and evaluation of a newly proposed imageperception aid are presented. This aid allows interactive access of the Image pixel by touch, and presents the pixel gray level as a characteristic sound.

The aid was implemented by using software and hardware. A computer graphics tablet (Bit Pad One) allows the user to scan an Image. A 
specially designed and implemented Time-Multiplexer Circuit Board allows the aid to read data simultaneously from the left and the right finger probes when both probes are on the BPO surface. Auditory stimulus is generated by an assembly program and simultaneously presented to the user through an audio stereo system. The $C$ programs run in the personal computer PC AT are used to receive the coordinates from the BPO, to map them onto the image cells, and to send a data word to a TMS320C25 processor to output the auditory signals.

The proposed technical aid was evaluated with two groups of subjects: Ten blindfolded sighted subjects, and six blind-from-birth subjects. A study was made to determine how accurately subjects could use the aid, and how the time they required to perceive binary, 3-, and 4-graylevel images with geometrical shapes changed with increased experience.

It has been found that blind-from-birth and ilindfolded sighted subjects can perceive geometrical shapes by using the aid. The results also showed that with successive presentations of images, the average time required for perception decreases. At the end of the testing. both groups of subjects were able to perceive binary, 3- or 4-gray-level images in less than 100 seconds, and both could perceive the complex 4-gray-level image (i.e., 3dimensional object presented in 2-dimensional plan) in less than 2 minutes, on average.

Furthermore, for the first time in their lives, the blind-from-birth subjects could correctly perceive, with the proposed technical aid, the 3- 
dimensional representation such as a cube or a pyramid in a 2-dimensional plan without difficulty. The results were encouraging and promising. Hence, the future research in this area should continue.

\subsection{Directions for Future Research}

According to the comments obtained from the blind subjects, several ideas for improving the research in this field are presented 1 ore The essential improvements focus upon the image analysis and the sound outputs.

Up to the preseri research level, the subjects can oblain the visual information by scanning all parts of the image with two probes attached to a finger of each hand. An improved mechanism should allow the user to perceive the image contents faster by using automatic computer image recognition. For instance, instead of scanning the entire line of a trangle. the user just needs to scan through the line with a probe and a word will be heard saying that the line is the "left edge" of the trangle. The present technical aid works with the TMS320C25 DSP Board, which outputs the stereo tones. These tones can be replaced by words or phrases in the improved aid. 


\section{References}

(1) S.B. Servais, "Visual aids," in Electronic Devices For Rehabilitation, ed. J. G. Webster, Chapman and Hall, London, pp. 31-78, 1985.

[2] B.J. Cox, "Transcription of braille textbooks by computer," J. Visual Imparment Blindness, vol 78, pp 244-247, 1984.

[3] J.A. Brabyn, "Assistive devices for blind and visually impaired," In Encyclopedia of Medical Devices and Instrumentation, ed. J. Webster. Wiley Interscience, vol. 1. pp 425-429, 1988.

[4] J.C. Bliss, "A relatively high resolution reading and for the blind," IEEE Trans. Man Machine Systems, MMS-10, pp 1-8, 1969.

[5] J C. Craig, "Some factors affecting tactule pattern recognition," Intern. $J$. Neuroscience, vol. 19, pp 47-58, 1983.

[6] P D. Gadbaw, P.T Dolan, and W R. De L'Aune, "Optacon skill acquisition by blunded veterans," J. Visual Impa rement Blindness, vol. 71, pp.23-28, 1977.

17] B. Markwick. "IBM Bralle mouse," Electronics Today, vol. 11, no. 6, p. 44. 1987.

[8] G.L. Goodrich, R B. Bennet, W.R. De L'Aune, H. Lauer, and L. Mowinskı, "Kurzweill reading machne: A partial evaluation of its optical character recogmition error rate," J. Visual Impairment Blindness, vol. 73, pp. 389-399. 1979.

[9] L.A Scadden, "Kurzweill readıng machıne: Evaluation of model one," J. Visual lmparment Blindness, vol 72, pp 415-418, 1978.

[10] J. Brabyn. "Some new sensory aids for the visually impaired," IEEE Engineering in Medicune and Biology Tenth Annual International Conference, pp. 1582. 1988 
[11] A. Jampolsky, J. Brabyn, and D. Gilden, "Touch-Pad computer accsess system." Veterans Administration Rehabilitation R\&D Progress Reports. pp 315-316, 1988.

(12) W. Loughborough. "Establishing parameters for a screen reader." International Conference of The Association For The Adwancement of Rchabilitation Technology. Montreal, pp. 208-209, 1988.

[13] J. Brabyn and W. Loughborough, "A digitizing touch-table/synthetic speech computer interface," 13th Ann. Int. Conf. IEEE EMBS, vol 13, pp 1833-1834. 1991.

[14] R.S. Schwerdtfeger, "Making the GUI talk." Byte, vol 16, pp 118-1128. December 1991.

[15] P. Bach-y-Rita, "Visıon substitution by tactile image projection," Nature, vol. 221, pp. 963-964, 1969

[16] P. Bach-y-Rita, C.C Collins, B White, F.A. Saunders. L Scadden, And R. Blomberg, "A tactile vision substitution system," Am. J. Optometry. vol. 46. pp. 109-111, 1969.

[17] C.C. Collins. "Tactule television-mechanical and electrical image projection," IEEE Trans. Man-Machune Systems, MMS-11, pp. 65-71, 1970

[18] K.L. Beauchamp, D.W. Matheson, and LA. Scadden, "Effects of stimulus change method on tactıle image recognition," Perceptual and Motor skills. vol. 33, pp. 1067-1070, 1971.

[19] P. Bach-y-Rita, "Tactile vision substitution: Past and future." Intern. J. Neuroscience, vol. 19, pp. 29-36, 1983.

[20] K. Kaczmareck, P. Bach-y-Rita, W.J. Tompkins, and J G. Webster, "A tactile vision-substitution system for the blind: Compuler controlled partial image sequencing," IEEE Trans. Biomedical Engineering. BME-32, vol 8, pp 602 608,1985

[21] S F.Frisken-Gibson, P Bach-y-Rita, W J Tompkins, and J G Webster, "A fiA solenoid. four-level fingertip search display for the blind," IEEE Trans. Biomedical Engmeering. BME-34, vol. 12, pp 963-965, 1987

[22] D.R. Maure. "Tactule graphucs display." Suxth Anmual Conference On Rehabiltation Engineering, San Diego, pp 315-317. 1983

123] D.L. Jaffe, "A tactule graphic display for the blind," IEEE Eughth Arinual Conference of The Enginnering in Medicine and Biology Socie(y. pp) 1821-1 R22. 1986. 
[24] N. Ohnishi, Y. Kawal, and N. Sugie, "A support system for the blind to recognize a diagram," IEEE Engineering in Medicine and Biology Eleventh Annual International Conference, pp. 1510-1511, 1989.

[25] N. Ohnishi, H Minagawa, and N. Sugie, "A trial development of a map database system for the blind," 13th Ann. Int. Conf. IEEE EMBS, pp. 1921$1922 ; 1991$.

[26] S.K. Guha and S. Anand, "Computer as a group teaching aid for persons who are blind," Journal of Rehabilitation Research and Development, vol. 29. No. 3. pp 57-63, 1992.

[27] H.C. Lee and S.R. Goodfellow, "Prelıminary desıgn and testıng of an auditory image-perception and for the blind," 12th Ann. Int. Conf. IEEE EMBS, pp. 22792280, 1990

[28] G.S. Bnndley. "Report to the conference on visual prothesis," in Visual Prothesis: The Interdisciplinary Dialogue, eds. T.D. Sterling. E.A. Bering, S.V. Pollack, and H.G Vaughan, Academic Press, New York, pp. 40-42, 1971.

[29] G.S Brindley, P E K Donaldson, M.A. Falconer, and D.N. Rushton. "The extent of the region of the occipital cortex that when stimulated gives phosphenes fixed in the visual field," Proceeding of The Physiological Soctety. pp. 57-59. 1972.

[30] P.E.K Donaldson. "Engineerıng visual protheses," Engineering in Medicine and Bıolog! Magazine, pp. 14-18. June 1983.

[31] P.E K. Donaldson, and E Sayer, A Technologically Implantable Hermetic Package. Part 2: An Implementation, vol. 19, pp. 408-413, 1981.

[32] L.S. Morrica, and R.V Slocum, "Pattern recognition on the forehead: An electronic scan system," J. Visual Impairment Blindness, vol. 71, pp.164-167. 1977

[33] BW White. "Perceptual findings with the vision substitution system," IEEE Trans Man-Machune Systems, MMS-11, pp. 54-58, 1970.

[34] J.M Doughty. and W.R. Garner. "Pitch characterisucs of short tones: I. Two kinds of pitch threshold," J. Expenmental Psychology. vol 37, pp. 351-365, 1947

[35] Summagraphucs Corporatıon, MM 1201 and MM 961 Data Tablets Technical Reference. Fairfield, 1984

[36] P Tantribeau. "Image-Perception and user's manual," Department of Electrical Engineering, McGill Unversity, Montreal. Quebec, Canada, 1992. 
[37] L. Kay, "A sensory aid to enhance spatial perception of the blind: Engmeering design and evaluation," Radio Electronic Eng. Devices Rehabiltaton. PP 37-41. 1974 .

[38] WW. Turnbull, "Pitch description as a function of tonal duration," J. Experimental Psychology, vol 34, pp 302-316, 1944

[39] Texas Instruments Incorporated. TMS320c25 User's Gude, July 1986

[40] Atlanta Signal Processors Incorporated. ADP Chmera Algorthm De'velopment Package for The Texas Instruments TMS32020 Famly of Digntal Signal Processing Microcomputers, Version 1 33. August 1988

[41] G.S. Bnndley, and W S Lewn, "The sensations produced by electrical stimulation of the visual cortex," J. Physiol, vol. 196, pp 23-37, 1968.

[42] W.H. Dobelle. "Current status of research on providing light of the blind by electrical stimulation of the brain," $J$ Visual Impairement Blindness, vol 71. pp 290-297, 1977.

[43] W H. Dobelle, M.G. Mladejovsky, and J P Grivin, "Artificial vision for the blund: Electrical stimulation of visual cortex offers hope for a functional prothesis." Science, vol. 183, pp. 440-444, 1974.

[44] J.C. Craig, "Vibrotactile pattern perception: Extraordinary Observers," Science. vol 196, pp. 450-452, 1977

[45] A.G Dodds, J D Amstrong. and C.A. Shingledecker. "The Nottingham obstacle detector Development and evaluation," J. Visual Imparement Blindne'ss, vol 75. pp 203-209. 1981

[46] A.D. Hayes, "The Nottunggham obstacle detector: A techncal description," J. Visual Impairment Blindness, vol. 75. p 206, 1981

[47] W. Jacobson, "Complementary travel aids for blund persons. The sonicgulde used with a dog gude," J. Visual Imparment Blundness, vol 73, pp 10-12, 1979.

[48] C.C. Collins, "Tactıle vision synthesis." in Visual Prothests: The Inlerdisciplinary Dialogue, eds TD Sterhng, EA Benng, SV Pollack, and H G Vaughan. Academic Press, New York, pp 267-279, 1971

[49] F A. Saunders, and C C Colluns, "Electrical stmulation of the sense of touch," Journal of Bıomedical Systems, vol 2, pp 27-37, 1971

[50] F.A. Saunders, and VF. Saunders, "Intradermal recording during electrocutaneous stimulation," Federation Proceeding, vol. 33, pp 3-6, 1974 
[51) A. Szeto, and F.A. Saunders, "Electrocutaneous stimulation for sensory communication in rehabilitation engineering," IEEE Trans. Biomedical Engincering. BME-29, pp. 300-308, 1982.

[52] C.C Collins, "A portable seeing aid prototype." J. Biomedical Systems, vol. 5 , pp. 3-10. 1971.

[53] W. Starkiewicz, W Kupnaowicz, and F. Petruczenko, "60-Channel electroftalm with photoresistors and forehead tactile elements." in Visual Prothesis: The Interdisciplınary Dialogue, eds. T.D. Sterling, E.A. Bering, S.V. Pollack, and H G Vaughan, Academic Press, New York, pp. 267-279, 1971.

[54] P. Bach-y-Rita, "A tactile vision substitution system based on sensory plasticity," in Visual othesis: The Interdisciplinary Dialogue, eds. T.D. Sterling. E A Benng, $\$$ V. Pollack, and H.G. Vaughan, Academic Press, New York, pp 281-290, 1971 .

[55] G Miletic, B Hughes, and P. Bach-y-Rita, "Vibrotactile stimulation: An educational program for spacial concept development." J. Visual Impairment Blindness, vol 82, pp. 366-370, 1988.

[56] J.D Foley and A Van Dam. Fundamentals of Interactive Computer Graphics, Addision-Wesley, Reading, 1982. 


\section{Appendix A}

\section{The Binary Data Format}

The binary data format transmits less than half the number of characters used in ASCII format. Our system adopts this binary format in order to speed up the transmission rate. The coordinates are transmitted in a binary coded format of five bytes as shown in Table A-1.

Table A-1 The Binary Data Format Representation of The Bit Pad One

\begin{tabular}{|c|c|c|c|c|c|c|c|c|}
\hline BYTE & BIT 7 & BIT 6 & BIT 5 & BIT 4 & BIT 3 & BIT 2 & BIT 1 & BIT 0 \\
\hline 0 & $\mathrm{P}$ & 1 & $\mathrm{~F} 3$ & $\mathrm{~F} 2$ & $\mathrm{~F} 1$ & $\mathrm{FO}$ & 0 & 0 \\
\hline 1 & $\mathrm{P}$ & 0 & $\mathrm{X} 5$ & $\mathrm{X} 4$ & $\mathrm{X3}$ & $\mathrm{X} 2$ & $\mathrm{X} 1$ & $\mathrm{X} 0$ \\
\hline 2 & $\mathrm{P}$ & 0 & $\mathrm{X} 11$ & $\mathrm{X} 10$ & $\mathrm{X} 9$ & $\mathrm{X} 8$ & $\mathrm{X} 7$ & $\mathrm{X} 6$ \\
\hline 3 & $\mathrm{P}$ & 0 & $\mathrm{Y} 5$ & $\mathrm{Y} 4$ & $\mathrm{Y} 3$ & $\mathrm{Y} 2$ & $\mathrm{Y1}$ & $\mathrm{Y0}$ \\
\hline 4 & $\mathrm{P}$ & 0 & $\mathrm{Y} 11$ & $\mathrm{Y} 10$ & $\mathrm{Y9}$ & $\mathrm{Y} 8$ & $\mathrm{Y} 7$ & $\mathrm{Y} 6$ \\
\hline
\end{tabular}

Two elements should be emphasized First, FO is constantly HIGH. which is built-in by the manufacturer. Bit 6 of all the coordinate data bytes (i.e., bytes $1,2,3$, and 4) are " 0 " except for the flag byte (i e, byle 0$)$, which has a "l" in that position. Thus, during the program execution, when a byte value greater than or equal to 68 (1 e., 1001000) is encountered, the present 
byte is a flag byte. Then, the next four bytes are going to be, in case of errorfree transmission, the coordinate bytes.

The second element should be noticed that only the last 6 bits of each byte carry the coordinate data. There are 12 bits per coordinate, which are required to represent numbers up to 2200 (i.e., The selected range). In order to put logether the bits to form the string $\mathrm{X} 11 \times 10 \times 9 \ldots . . \times 0$ for the $\mathrm{x}$ coordinates and similarly for the $y$ coordinate, the following conversion formulae are used:

$(x$-coordinate $)=$ byte $1+$ byte $2($ shifted to the left by 6 bits $)$ $(y$-coordinate $)=$ byte $3+$ byte 4 (shifted to the left by 6 bits $)$ $c$ 


\section{Appendix B}

The Time-Multiplexer Circuit Schematics 


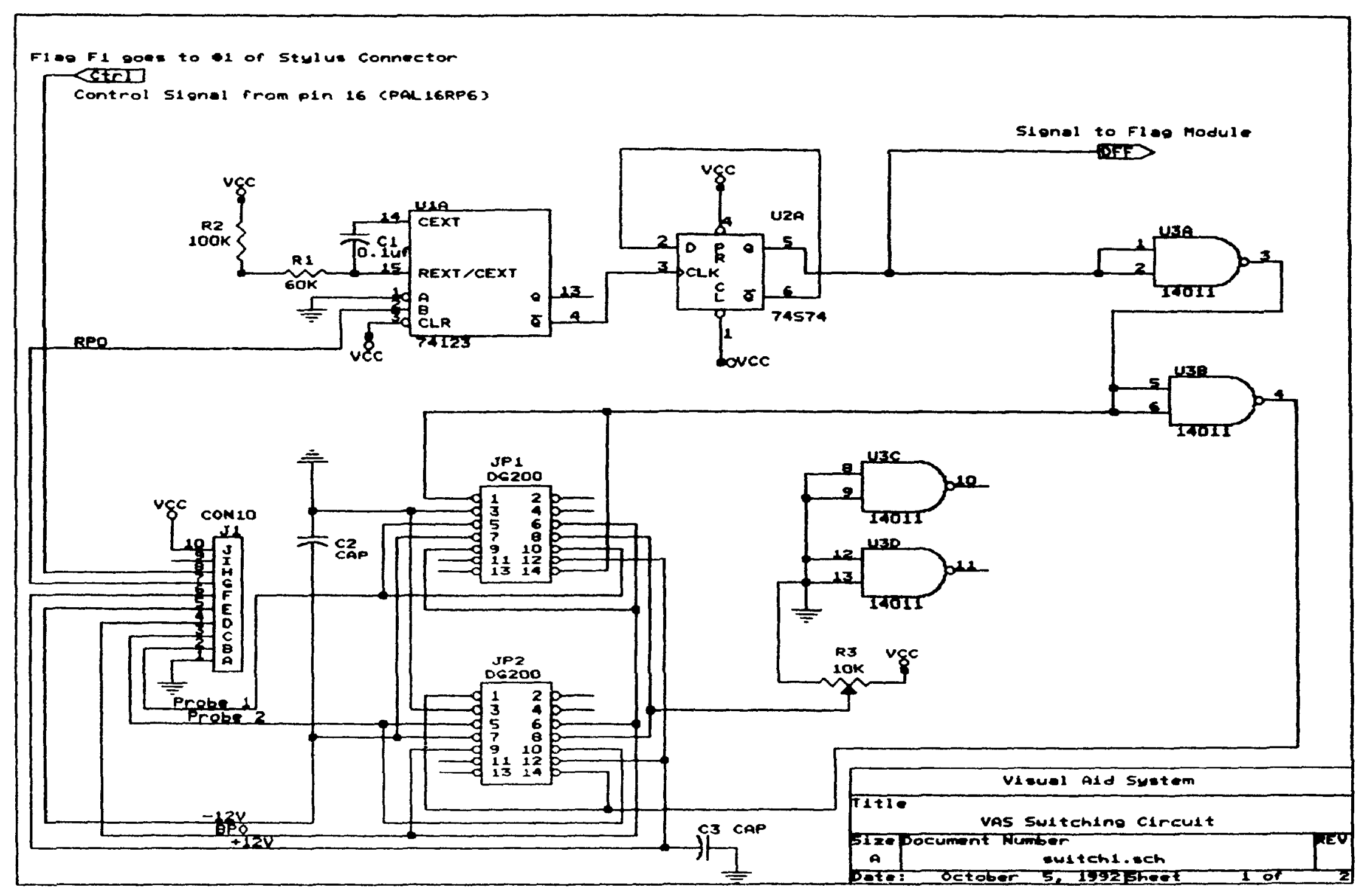




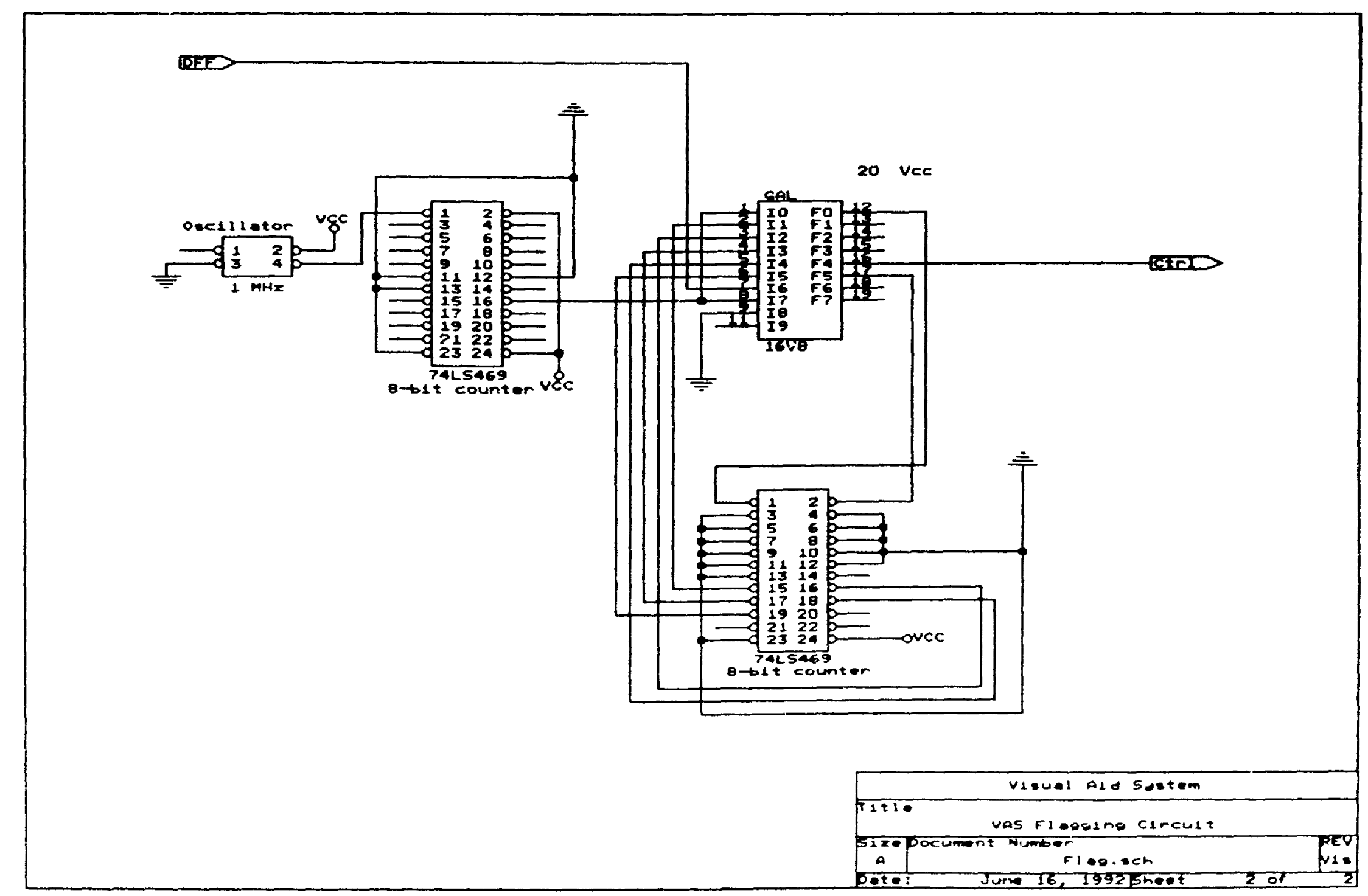




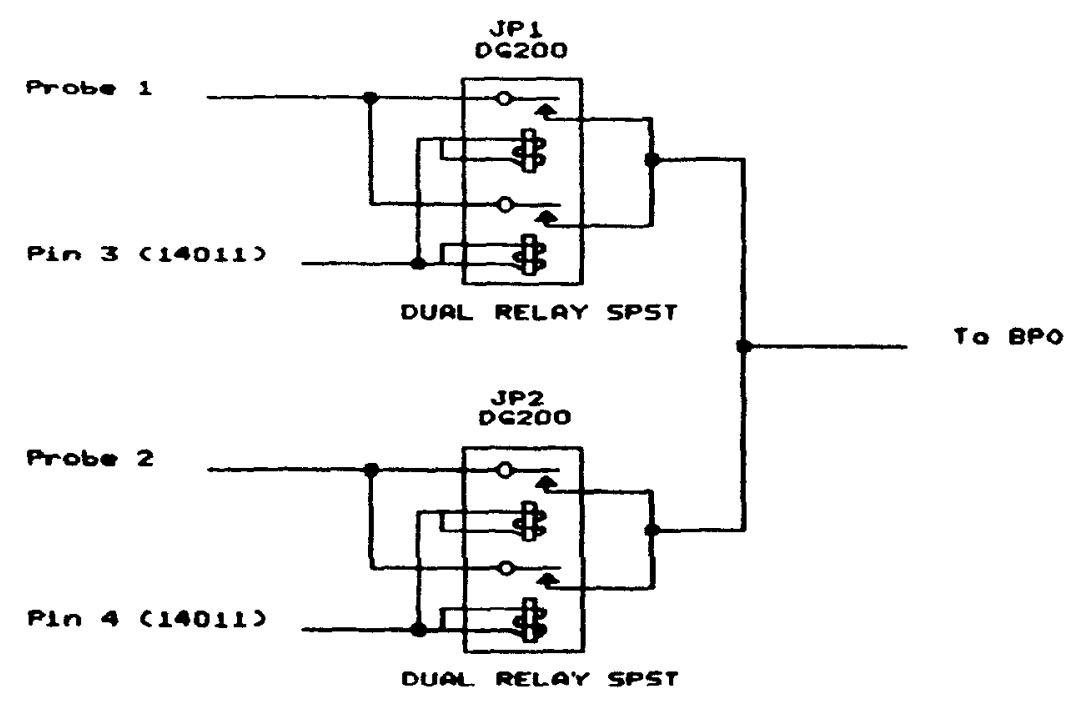

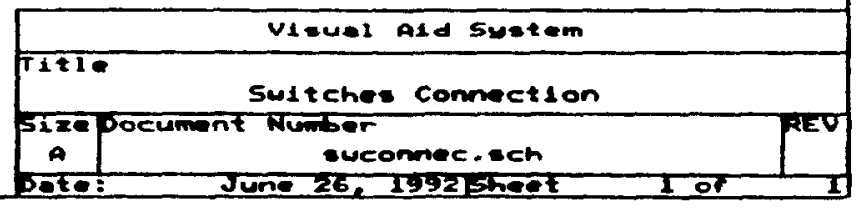




\section{Appendix C}

\section{The Programming of the PAL16RPG}

The PAL program in extension .FLD shown in Table $\mathrm{C}-1$ is complled by the ORCAD Programmable Logic Design (PLD) software package to generate the files with extension LST and JED. The LST extension file Indicates the pin numbers and other compiling information of the PAL for hardware or debugging use. The JED extension file contains the compiled codes ready to be download into the PAL integrated circuit for operation.

According to the program listing of the PAL16RP6 in .PLD extension file, the clear counter clc signal is output when an edge of the signal for the maximum count) is reached. Thus, the Ctrl signal is output only when its conditions are met. The PAL detects the present state of control signal ctrl, the edge of the $d f f$, the reset signal, and the previous state of the signal diff. When the conditions of these detected signals described above are met, ctrl outputs a desired flag slgnal for the BPO. 
Table C-1 The listing of PAL16RP6 codes in PLD extension file

\begin{tabular}{|c|c|}
\hline $\begin{array}{l}\text { |PAL16RP6 } \\
1 \\
1 \\
\text { | title: } \\
\text { | active-low } \\
\text { | dfn = dff } \\
\text { I invout = in } \\
\text { | edge = (dfn } \\
\text { | clc = edge } \\
\text { | ctrl = /ctr| \& } \\
\text { | } \\
\text { | }\end{array}$ & 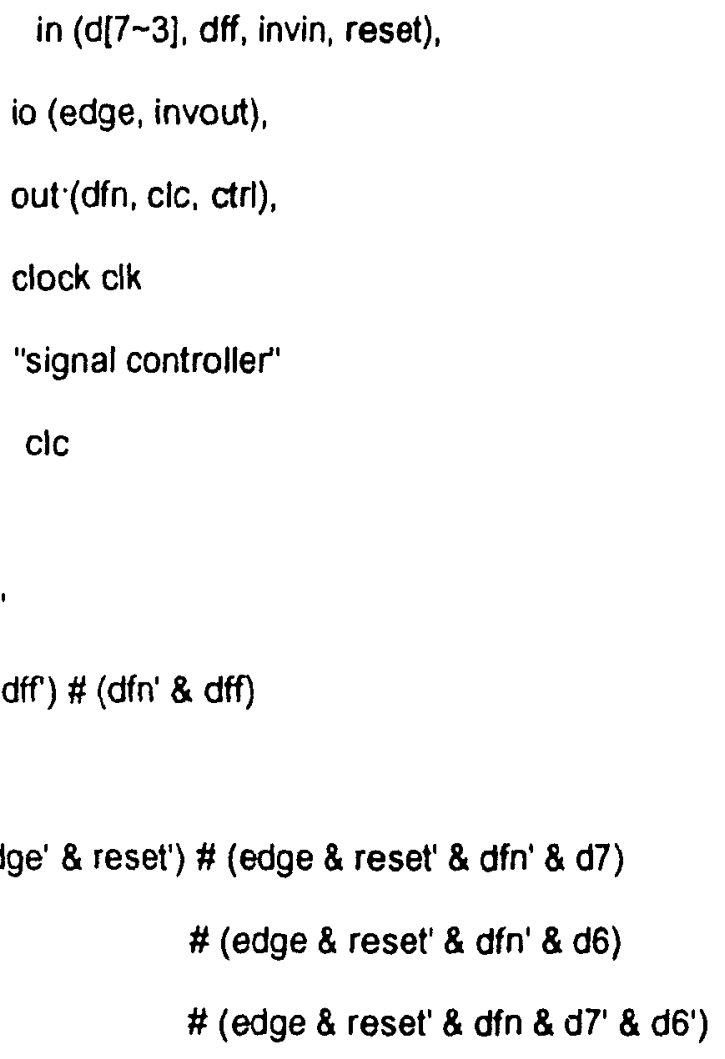 \\
\hline
\end{tabular}

After compiling the .PLD program, the .LST list is generated as shown below:

SIGNAL ASSIGNMENT

Pin Signal name Column

\section{Rows}

Beg Avail Used

1.

2.

3.

4.

5

6.

$\begin{array}{ll}\text { clk } & - \\ \text { d7 } & 0 \\ \text { d6 } & 4 \\ \text { d5 } & 8 \\ \text { d4 } & 12 \\ \text { d3 } & 16\end{array}$

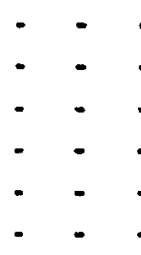

High

High

High

High

High

Activity

High

(Clock) 


$\begin{array}{rll}7 . & \text { dff } & 20 \\ 8 . & \text { invin } & 24 \\ 9 . & \text { reset } & 28 \\ 12 . & \text { invout } & 30 \\ 13 . & - & 26 \\ 14 . & - & 22 \\ 15 . & - & 18 \\ 16 . & \text { ctrl } & 14 \\ 17 . & \text { clc } & 11 \\ 18 . & \text { dfn } & 6 \\ 19 . & \text { edge } & 2\end{array}$

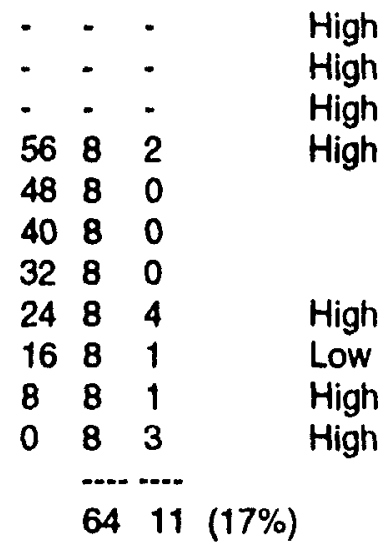

W320 Signal $\mathrm{d} 3$ is not used in the final equations.

W320 Signal d4 is not used in the final equations W320 Signal d5 is not used in the final equations.

1200 No fatal errors found in source code 1201 Three warnings. 


\section{Appendix D}

\section{The Evaluation Data of Binary Images}

The evaluation data of the binary images were obtained from two groups of subjects. Table D-1, contains the time (in seconds) that each blindfolded sighted subjects took to perceive a particular image during sessions 1 to 6 . In the same manner, Table D-2 shows the data of each blind-from-birth subjects. The images are identified by using the figure numbers provided in Fig. 6-1 of chapter 6.

Table D-1 The time used by the blindfolded sighted subjects to perceive a binary image in sessions 1 to 6 .

\begin{tabular}{|c|c|c|c|c|c|c|c|c|c|}
\hline session & subject & & & & & & & & \\
& & $\# 1$ & $\# 2$ & $\# 3$ & $\# 4$ & $\# 5$ & $\# 6$ & $\# 8$ & $\# 18$ \\
\hline 1 & 1 & 91 & 100 & 90 & 57 & & & & \\
& 2 & 92 & $113^{*}$ & 87 & 71 & & & & \\
& 3 & 74 & 53 & 30 & 42 & & & & \\
& 4 & 39 & 91 & 76 & 53 & & & & \\
& 5 & 59 & 48 & 38 & 30 & & & & \\
& 6 & 86 & 91 & 83 & 82 & & & & \\
& 7 & 50 & 60 & 85 & 103 & & & & \\
& 8 & 86 & 70 & 55 & 63 & & & & \\
& 9 & 62 & 68 & 89 & 91 & & & & \\
& 10 & 64 & 72 & 45 & 40 & & & & \\
& Ave & 70.3 & 76.6 & 67.8 & 63.2 & & & & \\
\hline
\end{tabular}

(continued on next page ...) 


\begin{tabular}{|c|c|c|c|c|c|c|c|c|c|}
\hline session & subject & $\$ 1$ & $\# 2$ & $\# 3$ & $\# 4$ & 45 & 16 & 48 & \#18 \\
\hline 2 & $\begin{array}{c}1 \\
2 \\
3 \\
4 \\
5 \\
6 \\
7 \\
8 \\
9 \\
10 \\
\text { Ave }\end{array}$ & & & & $\begin{array}{c}60 \\
68 \\
57 \\
67 \\
40 \\
53 \\
69 \\
62 \\
74 \\
38 \\
58.8\end{array}$ & $\begin{array}{c}64 \\
85 \\
137 \\
81 \\
52 \\
61 \\
78 \\
84 \\
80 \\
72 \\
79.4\end{array}$ & $\begin{array}{c}38 \\
33 \\
40 \\
53 \\
90 \\
122 \\
90 \\
42 \\
100 \\
85 \\
69.3\end{array}$ & $\begin{array}{c}90 \\
72 \\
30 \\
56 \\
64 \\
109 \\
92 \\
73 \\
100 \\
73 \\
75.9\end{array}$ & \\
\hline 3 & $\begin{array}{c}1 \\
2 \\
3 \\
4 \\
5 \\
6 \\
7 \\
8 \\
9 \\
10 \\
\text { Ave }\end{array}$ & $\begin{array}{c}65 \\
48 \\
54 \\
39 \\
56 \\
48 \\
63 \\
78 \\
60 \\
57 \\
56.8\end{array}$ & $\begin{array}{c}37 \\
81 \\
40 \\
43 \\
45 \\
50 \\
54 \\
62 \\
66 \\
60 \\
53.8 \\
\end{array}$ & $\begin{array}{c}55 \\
64 \\
50 \\
58 \\
29 \\
50 \\
61 \\
50 \\
70 \\
64 \\
55.1\end{array}$ & $\begin{array}{l}47 \\
50 \\
35 \\
41 \\
27 \\
47 \\
84 \\
58 \\
86 \\
35 \\
51\end{array}$ & & & & \\
\hline 4 & $\begin{array}{c}1 \\
2 \\
3 \\
4 \\
5 \\
6 \\
7 \\
8 \\
9 \\
10 \\
\text { Ave } \\
\end{array}$ & & & & $\begin{array}{l}77 \\
42 \\
85 \\
29 \\
35 \\
34 \\
59 \\
44 \\
62 \\
33 \\
50\end{array}$ & $\begin{array}{c}41 \\
57 \\
51 \\
44 \\
40 \\
38 \\
32 \\
74 \\
56 \\
61 \\
49.4 \\
\end{array}$ & $\begin{array}{l}68 \\
30 \\
51 \\
20 \\
75 \\
34 \\
51 \\
40 \\
64 \\
77 \\
51 \\
\end{array}$ & $\begin{array}{c}58 \\
64 \\
63 \\
38 \\
92 \\
62 \\
52 \\
66 \\
59 \\
65 \\
61.9 \\
\end{array}$ & \\
\hline 5 & $\begin{array}{c}1 \\
2 \\
3 \\
4 \\
5 \\
6 \\
7 \\
8 \\
9 \\
10 \\
\text { Ave }\end{array}$ & $\begin{array}{c}33 \\
28 \\
46 \\
40 \\
55 \\
22 \\
23 \\
73 \\
49 \\
47 \\
41.6\end{array}$ & \begin{tabular}{|c|}
36 \\
50 \\
104 \\
35 \\
65 \\
69 \\
48 \\
53 \\
55 \\
52 \\
56.7 \\
\end{tabular} & $\begin{array}{c}58 \\
66 \\
30 \\
45 \\
66 \\
35 \\
28 \\
43 \\
58 \\
60 \\
48.9\end{array}$ & & & & & $\begin{array}{c}27 \\
34 \\
87 \\
40 \\
48 \\
27 \\
55 \\
58 \\
60 \\
53 \\
48.9\end{array}$ \\
\hline
\end{tabular}




\begin{tabular}{|c|c|c|c|c|c|c|c|c|c|}
\hline session & subject & $* 1$ & $\# 2$ & $\# 3$ & $\# 4$ & $\# 5$ & $\# 6$ & $\# 8$ & $\# 18$ \\
\hline 6 & 1 & & 46 & & 29 & 36 & 22 & & \\
& 2 & & 43 & & 40 & 52 & 26 & & \\
& 3 & & 92 & & 100 & 32 & 93 & & \\
& 4 & & 37 & & 22 & 13 & 22 & & \\
& 5 & & 80 & & 48 & 55 & 75 & & \\
& 6 & & 71 & & 43 & 20 & 28 & & \\
& 7 & & 38 & & 27 & 27 & 40 & & \\
& 8 & & 61 & & 37 & 65 & 34 & & \\
& 9 & & 56 & & 55 & 52 & 56 & & \\
& 10 & & 60 & & 30 & 54 & 60 & & \\
& Ave & & 58.4 & & 43.1 & 40.6 & 45.6 & & \\
\hline
\end{tabular}

Table D-2 The time used by the blind-from-birth subjects to perceive a binary image in sessions 1 to 6 .

\begin{tabular}{|c|c|c|c|c|c|c|c|c|}
\hline session & subject & $\# 1$ & $\# 2$ & $* 3$ & $\# 4$ & 45 & 16 & $\#$ \\
\hline 1 & $\begin{array}{c}1 \\
2 \\
3 \\
4 \\
5 \\
6 \\
\text { Ave }\end{array}$ & $\begin{array}{l}21 \\
60 \\
54 \\
65 \\
48 \\
40 \\
48\end{array}$ & $\begin{array}{c}23 \\
41 \\
52 \\
36 \\
40 \\
25 \\
36.2\end{array}$ & $\begin{array}{l}50 \\
39 \\
43 \\
80 \\
51 \\
37 \\
50\end{array}$ & $\begin{array}{l}20 \\
62 \\
65 \\
37 \\
26 \\
17 \\
38\end{array}$ & & & \\
\hline 2 & $\begin{array}{c}1 \\
2 \\
3 \\
4 \\
5 \\
6 \\
\text { Ave }\end{array}$ & & & & $\begin{array}{l}35 \\
26 \\
58 \\
40 \\
34 \\
17 \\
35\end{array}$ & $\begin{array}{c}35 \\
45 \\
45 \\
36 \\
35 \\
18 \\
35.7\end{array}$ & $\begin{array}{c}53 \\
60 \\
65 \\
30 \\
48 \\
30 \\
47.7\end{array}$ & $\begin{array}{c}29 \\
54 \\
50 \\
48 \\
42 \\
25 \\
41.3\end{array}$ \\
\hline 3 & $\begin{array}{c}1 \\
2 \\
3 \\
4 \\
5 \\
6 \\
\text { Ave }\end{array}$ & $\begin{array}{c}31 \\
30 \\
65 \\
27 \\
34 \\
16 \\
33.8\end{array}$ & $\begin{array}{c}39 \\
32 \\
40 \\
35 \\
32 \\
13 \\
31.8\end{array}$ & $\begin{array}{c}30 \\
31 \\
44 \\
40 \\
33 \\
17 \\
32.5\end{array}$ & $\begin{array}{c}46 \\
24 \\
41 \\
17 \\
30 \\
14 \\
28.6\end{array}$ & & & \\
\hline
\end{tabular}

(continued on next page ...) 


\begin{tabular}{|c|c|c|c|c|c|c|c|c|}
\hline session & subject & & $*$ & $* 3$ & 44 & 45 & $* 6$ & $* 8$ \\
\hline 4 & 1 & & & & 37 & 40 & 30 & 40 \\
& 2 & & & & 33 & 24 & 45 & 52 \\
& 3 & & & & 24 & 29 & 27 & 26 \\
& 4 & & & & 26 & 34 & 41 & 59 \\
& 5 & & & & 28 & 30 & 32 & 40 \\
& 6 & & & & 14 & 18 & 11 & 13 \\
& Ave & & & & 27 & 29 & 31 & 38 \\
\hline 5 & 1 & 37 & 35 & 28 & 25 & & & \\
& 2 & 20 & 29 & 28 & 24 & & & \\
& 3 & 25 & 35 & 31 & 32 & & & \\
& 4 & 20 & 30 & 26 & 18 & & & \\
& 5 & 24 & 30 & 27 & 24 & & & \\
& 6 & 14 & 15 & 15 & 13 & & & \\
& Ave & 23.3 & 29 & 25.8 & 22.6 & & & \\
\hline 6 & 1 & & & & 27 & 50 & 28 & 25 \\
& 2 & & & & 30 & 15 & 40 & 42 \\
& 3 & & & & 20 & 20 & 23 & 21 \\
& 4 & & & & 21 & 21 & 40 & 50 \\
& 5 & & & & 23 & 27 & 29 & 33 \\
& 6 & & & & 14 & 24 & 10 & 18 \\
& Ave & & & & 22.5 & 26.1 & 28.3 & 31.5 \\
\hline & & & & & &
\end{tabular}




\section{Appendix E}

\section{The Evaluation Data of 3- and 4-Gray-Level Images}

The evaluation data of the 3- and 4-gray-level images are obtained from two groups of subjects. Table E-1 contains the tim a (in seconds) that each blindfolded sighted subjects took to perceive a particular 3-gray-level image during sessions 7 to 11 . In the same manner, Table E-2 shows the data of each blind-from-birth subjects. Table E-3 contains the time (in seconds) that each blindfolded sighted subjects took to perceive a particular 4-gray-levei image during sessions 12 to 15 . In the same manner, Table E-4 shows the data of each blind-from-birth subjects. The images are identified by using the figure numbers provided in Fig. 6-5 iand Fig. 6-6 in chapter 6.

(continued on next page ...) 
Table E-1 The time (in second) used by the ten blindfolded sighted subjects to percelve a 3-gray-level image in sessions 7 to 11 .

\begin{tabular}{|c|c|c|c|c|c|c|c|c|c|c|c|}
\hline Session & Subject & $\# 25$ & $\approx 26$ & $\because 27$ & $\$ 28$ & $\# 29$ & $\$ 30$ & $\# 31$ & \%33 & $\# 35$ & $\$ 39$ \\
\hline 7 & \begin{tabular}{|c|}
1 \\
2 \\
3 \\
4 \\
5 \\
6 \\
7 \\
8 \\
9 \\
10 \\
Ave
\end{tabular} & $\begin{array}{c}105 \\
92 \\
157 \\
120 \\
75 \\
72 \\
95 \\
91 \\
110 \\
84 \\
100.1\end{array}$ & $\begin{array}{c}59 \\
102 \\
68 \\
57 \\
92 \\
46 \\
102 \\
72 \\
116 \\
93 \\
80.7\end{array}$ & $\begin{array}{c}50 \\
54 \\
88 \\
50 \\
82 \\
91 \\
57 \\
63 \\
68 \\
80 \\
68.3\end{array}$ & $\begin{array}{c}75 \\
89 \\
100 \\
111 \\
110 \\
75 \\
62 \\
88 \\
68 \\
87 \\
86.5\end{array}$ & & & & & & \\
\hline 8 & \begin{tabular}{|c|}
1 \\
2 \\
3 \\
4 \\
5 \\
6 \\
7 \\
8 \\
9 \\
10 \\
Ave
\end{tabular} & $\begin{array}{c}99 \\
92 \\
58 \\
64 \\
70 \\
98 \\
87 \\
81 \\
92 \\
76 \\
81.7\end{array}$ & & & & $\begin{array}{c}75 \\
98 \\
81 \\
61 \\
110 \\
55 \\
53 \\
86 \\
60 \\
75 \\
75.4\end{array}$ & $\begin{array}{c}70 \\
103 \\
146 \\
123 \\
89 \\
68 \\
87 \\
120 \\
94 \\
82 \\
98.2\end{array}$ & $\begin{array}{c}60 \\
65 \\
96 \\
73 \\
61 \\
66 \\
61 \\
68 \\
66 \\
63 \\
67.9\end{array}$ & & & \\
\hline 9 & \begin{tabular}{|c}
1 \\
2 \\
3 \\
4 \\
5 \\
6 \\
7 \\
8 \\
9 \\
10 \\
Ave
\end{tabular} & & $\begin{array}{c}55 \\
87 \\
73 \\
80 \\
87 \\
55 \\
70 \\
62 \\
82 \\
87 \\
73.8\end{array}$ & & $\begin{array}{c}70 \\
79 \\
67 \\
83 \\
65 \\
75 \\
60 \\
62 \\
65 \\
72 \\
69.8\end{array}$ & & & & \begin{tabular}{|c|}
78 \\
101 \\
53 \\
65 \\
78 \\
108 \\
80 \\
78 \\
84 \\
81 \\
80.6
\end{tabular} & $\begin{array}{c}75 \\
93 \\
70 \\
85 \\
82 \\
94 \\
82 \\
87 \\
79 \\
85 \\
83.2\end{array}$ & \\
\hline
\end{tabular}

(continued on next page ...) 


\begin{tabular}{|c|c|c|c|c|c|c|c|c|c|c|c|}
\hline Session & Subject & $\because 25$ & 126 & $\because 27$ & *28 & $\$ 29$ & 130 & $\$ 31$ & $\$ 33$ & 135 & $\$ 39$ \\
\hline 10 & $\begin{array}{c}1 \\
2 \\
3 \\
4 \\
5 \\
6 \\
7 \\
8 \\
9 \\
10 \\
\text { Ave }\end{array}$ & & & $\begin{array}{c}55 \\
48 \\
55 \\
43 \\
42 \\
81 \\
53 \\
47 \\
62 \\
72 \\
55.8\end{array}$ & & & $\begin{array}{c}68 \\
84 \\
82 \\
27 \\
50 \\
68 \\
70 \\
72 \\
87 \\
74 \\
68.2\end{array}$ & & & $\begin{array}{c}72 \\
85 \\
60 \\
100 \\
90 \\
82 \\
75 \\
78 \\
79 \\
71 \\
79.2\end{array}$ & $\begin{array}{c}80 \\
76 \\
96 \\
75 \\
96 \\
53 \\
61 \\
81 \\
68 \\
60 \\
74.6\end{array}$ \\
\hline 11 & \begin{tabular}{|c|}
1 \\
2 \\
3 \\
4 \\
5 \\
6 \\
6 \\
7 \\
8 \\
9 \\
10 \\
Ave
\end{tabular} & & & & & $\begin{array}{c}77 \\
72 \\
61 \\
48 \\
82 \\
65 \\
50 \\
67 \\
54 \\
60 \\
63.6\end{array}$ & & $\begin{array}{l}57 \\
42 \\
55 \\
31 \\
31 \\
51 \\
56 \\
56 \\
64 \\
57 \\
50\end{array}$ & $\begin{array}{l}70 \\
81 \\
54 \\
24 \\
95 \\
48 \\
75 \\
62 \\
78 \\
73 \\
66\end{array}$ & & $\begin{array}{c}76 \\
73 \\
55 \\
47 \\
50 \\
33 \\
55 \\
66 \\
68 \\
54 \\
57.7\end{array}$ \\
\hline
\end{tabular}

Table E-2 The time (in second) used by the six blind-from-birth subjects to percelve a 3-gray-level-image in sessions 7 to 11 .

\begin{tabular}{|c|c|c|c|c|c|c|c|c|c|c|c|}
\hline Session & Subject & & & & & & & & & & \\
& & $\# 25$ & $\# 26$ & $\# 27$ & $\# 28$ & $\# 29$ & $\# 30$ & $\# 31$ & $\# 33$ & $\# 35$ & $\# 39$ \\
\hline 7 & 1 & 52 & 39 & 40 & 45 & & & & & & \\
& 2 & 54 & 76 & 65 & 50 & & & & & & \\
& 3 & 60 & 52 & 60 & 65 & & & & & & \\
& 4 & 89 & 73 & 80 & 100 & & & & & & \\
& 5 & 64 & 58 & 56 & 65 & & & & & & \\
& 6 & 56 & 45 & 38 & 55 & & & & & & \\
& Ave & 62.5 & 57 & 56.5 & 63.3 & & & & & & \\
\hline
\end{tabular}




\begin{tabular}{|c|c|c|c|c|c|c|c|c|c|c|c|}
\hline Session & Subject & $\$ 25$ & $\$ 26$ & \#27 & $\# 28$ & \#29 & $\# 30$ & $\$ 31$ & $\$ 33$ & \#35 & $\# 39$ \\
\hline 8 & $\begin{array}{c}1 \\
2 \\
3 \\
4 \\
5 \\
6 \\
\text { Ave }\end{array}$ & $\begin{array}{c}45 \\
48 \\
50 \\
80 \\
56 \\
50 \\
54.8\end{array}$ & & & & $\begin{array}{c}76 \\
86 \\
110 \\
92 \\
87 \\
62 \\
85.5\end{array}$ & $\begin{array}{c}55 \\
84 \\
93 \\
86 \\
76 \\
53 \\
74.5\end{array}$ & $\begin{array}{c}50 \\
68 \\
62 \\
73 \\
55 \\
30 \\
56.3\end{array}$ & & & \\
\hline 9 & $\begin{array}{c}1 \\
2 \\
3 \\
4 \\
5 \\
6 \\
\text { Ave }\end{array}$ & & $\begin{array}{c}45 \\
65 \\
44 \\
66 \\
54 \\
43 \\
52.8\end{array}$ & & $\begin{array}{l}41 \\
65 \\
68 \\
91 \\
60 \\
41 \\
61 \\
\end{array}$ & & & & $\begin{array}{c}96 \\
90 \\
109 \\
87 \\
82 \\
41 \\
84.2\end{array}$ & $\begin{array}{c}82 \\
70 \\
74 \\
95 \\
80 \\
75 \\
79.3\end{array}$ & \\
\hline 10 & $\begin{array}{c}1 \\
2 \\
3 \\
4 \\
5 \\
6 \\
\text { Ave }\end{array}$ & & & $\begin{array}{l}40 \\
56 \\
58 \\
50 \\
47 \\
37 \\
48\end{array}$ & & & $\begin{array}{l}53 \\
80 \\
90 \\
78 \\
69 \\
50 \\
70\end{array}$ & & & $\begin{array}{l}78 \\
68 \\
70 \\
60 \\
61 \\
41 \\
63\end{array}$ & $\begin{array}{c}81 \\
60 \\
73 \\
75 \\
66 \\
34 \\
64.8\end{array}$ \\
\hline 11 & $\begin{array}{c}1 \\
2 \\
3 \\
4 \\
5 \\
6 \\
\text { Ave }\end{array}$ & & & & & $\begin{array}{l}70 \\
84 \\
86 \\
80 \\
72 \\
52 \\
74\end{array}$ & & $\begin{array}{c}48 \\
70 \\
47 \\
46 \\
48 \\
25 \\
47.3\end{array}$ & $\begin{array}{c}93 \\
81 \\
72 \\
65 \\
71 \\
35 \\
69.5\end{array}$ & & $\begin{array}{l}74 \\
60 \\
51 \\
68 \\
55 \\
28 \\
56\end{array}$ \\
\hline
\end{tabular}

(contunued on next page ...) 
Table $\mathrm{E}-3$ The time (In second) used by the blindfolded sighted subjects to perceive a 4-gray-level image in sessions 12 to 15 .

\begin{tabular}{|c|c|c|c|c|c|c|c|c|c|c|c|}
\hline session & subject & $\$ 45$ & 46 & $\$ 47$ & $\$ 48$ & 449 & $\$ 50$ & 451 & $\$ 53$ & \#56 & $\$ 59$ \\
\hline 12 & $\begin{array}{c}1 \\
2 \\
3 \\
4 \\
5 \\
6 \\
7 \\
8 \\
9 \\
10 \\
\text { Ave }\end{array}$ & $\begin{array}{c}481 \\
52 \\
46 \\
102 \\
95 \\
88 \\
80 \\
79 \\
90 \\
82 \\
76.2\end{array}$ & \begin{tabular}{|c|}
102 \\
106 \\
141 \\
109 \\
87 \\
140 \\
100 \\
122 \\
110 \\
94 \\
111.1
\end{tabular} & $\begin{array}{c}95 \\
84 \\
60 \\
84 \\
101 \\
85 \\
75 \\
73 \\
78 \\
83 \\
81.8\end{array}$ & $\begin{array}{c}79 \\
145 \\
74 \\
67 \\
120 \\
69 \\
80 \\
77 \\
79 \\
84 \\
87.4\end{array}$ & & & & & & \\
\hline 13 & $\begin{array}{c}1 \\
2 \\
3 \\
4 \\
5 \\
6 \\
7 \\
8 \\
9 \\
10 \\
\text { Ave }\end{array}$ & \begin{tabular}{|c|}
37 \\
32 \\
51 \\
45 \\
52 \\
55 \\
60 \\
54 \\
80 \\
68 \\
53.4
\end{tabular} & & & & $\begin{array}{c}103 \\
81 \\
87 \\
87 \\
96 \\
94 \\
96 \\
102 \\
98 \\
99 \\
94.3\end{array}$ & \begin{tabular}{|c|}
96 \\
84 \\
66 \\
105 \\
115 \\
106 \\
91 \\
74 \\
99 \\
90 \\
92.6 \\
\end{tabular} & $\begin{array}{c}103 \\
145 \\
91 \\
106 \\
105 \\
150 \\
97 \\
93 \\
98 \\
95 \\
108.3\end{array}$ & & & \\
\hline 14 & $\begin{array}{c}1 \\
2 \\
3 \\
4 \\
5 \\
6 \\
7 \\
8 \\
9 \\
10 \\
\text { Ave }\end{array}$ & & & & $\begin{array}{c}58 \\
23 \\
59 \\
21 \\
72 \\
46 \\
67 \\
58 \\
76 \\
75 \\
55.5\end{array}$ & & $\begin{array}{c}90 \\
45 \\
64 \\
48 \\
56 \\
44 \\
71 \\
68 \\
82 \\
79 \\
64.7 \\
\end{array}$ & & $\begin{array}{c}94 \\
106 \\
136 \\
63 \\
80 \\
56 \\
88 \\
82 \\
88 \\
80 \\
87.3\end{array}$ & \begin{tabular}{|c|}
92 \\
102 \\
125 \\
156 \\
87 \\
101 \\
135 \\
105 \\
140 \\
123 \\
116.6
\end{tabular} & \\
\hline
\end{tabular}

(continued on next page ...) 


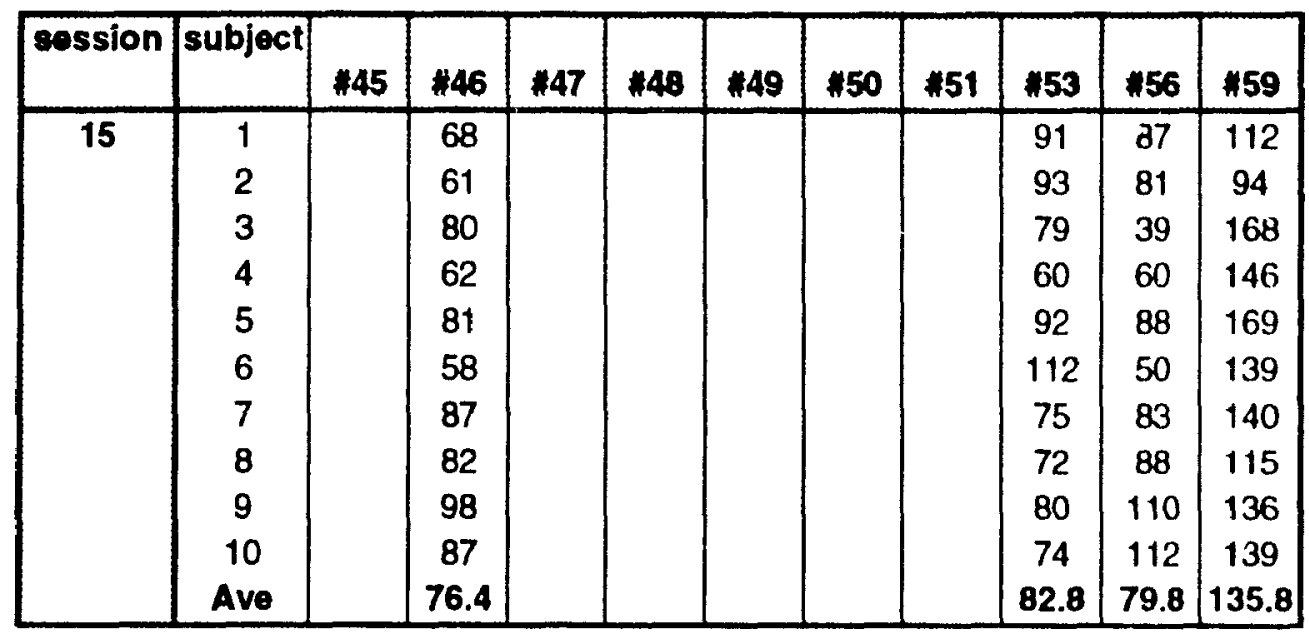

Table E-4 The time (in second) used by the six blind-from-birth subjects to perceive a 4-gray-level image in sessions 12 to 15 .

\begin{tabular}{|c|c|c|c|c|c|c|c|c|c|c|c|}
\hline session & subject & *45 & $\# 46$ & $\# 47$ & $\$ 48$ & 149 & $\because 50$ & *51 & 453 & 456 & 459 \\
\hline 12 & $\begin{array}{c}1 \\
2 \\
3 \\
4 \\
5 \\
6 \\
\text { Ave }\end{array}$ & $\begin{array}{c}142 \\
121 \\
150 \\
113 \\
127 \\
140 \\
132.2\end{array}$ & $\begin{array}{l}99 \\
78 \\
91 \\
84 \\
86 \\
84 \\
87\end{array}$ & $\begin{array}{l}91 \\
82 \\
75 \\
74 \\
81 \\
77 \\
80\end{array}$ & $\begin{array}{c}107 \\
93 \\
90 \\
67 \\
94 \\
105 \\
92.6\end{array}$ & & & & & & \\
\hline 13 & $\begin{array}{c}1 \\
2 \\
3 \\
4 \\
5 \\
6 \\
\text { Ave }\end{array}$ & \begin{tabular}{|c|}
135 \\
83 \\
82 \\
44 \\
85 \\
90 \\
86.5 \\
\end{tabular} & & & & $\begin{array}{c}112 \\
80 \\
92 \\
84 \\
82 \\
81 \\
88.5\end{array}$ & $\begin{array}{c}122 \\
108 \\
81 \\
94 \\
100 \\
110 \\
102.5 \\
\end{array}$ & $\begin{array}{l}96 \\
75 \\
90 \\
81 \\
83 \\
91 \\
86\end{array}$ & & & \\
\hline 14 & $\begin{array}{c}1 \\
2 \\
3 \\
4 \\
5 \\
6 \\
\text { Ave }\end{array}$ & & & & $\begin{array}{c}92 \\
82 \\
60 \\
65 \\
77 \\
76 \\
75.3\end{array}$ & & \begin{tabular}{|c|}
5 \\
87 \\
78 \\
72 \\
76 \\
69 \\
79.7
\end{tabular} & & $\begin{array}{c}106 \\
96 \\
102 \\
85 \\
92 \\
82 \\
94\end{array}$ & \begin{tabular}{|c|}
208 \\
191 \\
186 \\
230 \\
188 \\
158 \\
193.5
\end{tabular} & \\
\hline
\end{tabular}

(continued on next page ...) 


\begin{tabular}{|c|c|c|c|c|c|c|c|c|c|c|c|}
\hline session & subject & 145 & 146 & 447 & 148 & 749 & 50 & 451 & 53 & 56 & 159 \\
\hline 15 & $\begin{array}{c}1 \\
2 \\
3 \\
4 \\
5 \\
6 \\
\text { Ave }\end{array}$ & & $\begin{array}{c}87 \\
90 \\
82 \\
75 \\
79 \\
74 \\
81.2\end{array}$ & & & & & & $\begin{array}{l}93 \\
92 \\
93 \\
82 \\
85 \\
77 \\
87\end{array}$ & $\begin{array}{l}164 \\
182 \\
170 \\
194 \\
169 \\
130 \\
168\end{array}$ & $\begin{array}{c}145 \\
143 \\
122 \\
103 \\
128 \\
117 \\
126.3\end{array}$ \\
\hline
\end{tabular}

